Illinois State University

ISU ReD: Research and eData

Theses and Dissertations

8-12-2021

\title{
Inclusive Math and Science Spaces Through Professional \\ Development: A Qualitative Study Focusing on Educator Views of Multilingual Learners and Educator Identity
}

Helen Dick Brandon

Illinois State University, helendbrandon02@gmail.com

Follow this and additional works at: https://ir.library.illinoisstate.edu/etd

\section{Recommended Citation}

Brandon, Helen Dick, "Inclusive Math and Science Spaces Through Professional Development: A Qualitative Study Focusing on Educator Views of Multilingual Learners and Educator Identity" (2021). Theses and Dissertations. 1483.

https://ir.library.illinoisstate.edu/etd/1483

This Dissertation is brought to you for free and open access by ISU ReD: Research and eData. It has been accepted for inclusion in Theses and Dissertations by an authorized administrator of ISU ReD: Research and eData. For more information, please contact ISUReD@ilstu.edu. 
INCLUSIVE MATH AND SCIENCE SPACES THROUGH PROFESSIONAL DEVELOPMENT:

A QUALITATIVE STUDY FOCUSING ON EDUCATOR VIEWS OF MULTILINGUAL

LEARNERS AND EDUCATOR IDENTITY

\section{HELEN BRANDON}

\section{Pages}

This action research qualitative study focused on the role that targeted professional development has on shifting the ways in which middle school math and science educators view their culturally and linguistically diverse (CLD) students; in addition, this study focused on the role that professional development plays on shifting teacher identity. Through this study, four middle level math and science educators took part in a four month professional development opportunity that included interviews, questionnaires, video lessons, and focus groups. Through this experience, the educators shifted their views of CLD students to be more asset-based. When looking at the shifts in their perceptions of identity, all of the educators shifted to be more comfortable talking about the role that identity plays in the educational system as well as shifted their understandings of the ways in which our identities affect the way we teach and the way that we, as well as our students, learn.

KEYWORDS: professional development, bilingual, multilingual learners, culturally and linguistically diverse learners, ELL, EL, ESL, identity, STEM, middle level education, middle school, math education, science education, STEM education 
INCLUSIVE MATH AND SCIENCE SPACES THROUGH PROFESSIONAL DEVELOPMENT:

A QUALITATIVE STUDY FOCUSING ON EDUCATOR VIEWS OF MULTILINGUAL

LEARNERS AND EDUCATOR IDENTITY

HELEN BRANDON

A Dissertation Submitted in Partial

Fulfillment of the Requirements

for the Degree of

DOCTOR OF EDUCATION

School of Teaching and Learning

ILLINOIS STATE UNIVERSITY

2021 
(C) 2021 Helen Brandon 
INCLUSIVE MATH AND SCIENCE SPACES THROUGH PROFESSIONAL DEVELOPMENT: A QUALITATIVE STUDY FOCUSING ON EDUCATOR VIEWS OF MULTILINGUAL LEARNERS AND EDUCATOR IDENTITY

HELEN BRANDON

COMMITTEE MEMBERS:

Ellis Hurd, Chair

Allison Antink-Meyer

Beth Hatt

Pauline Williams 


\section{ACKNOWLEDGMENTS}

Thank you to my dissertation chair, Dr. Ellis Hurd. You helped me in so many ways to accomplish my goals, flush out my ideas, and you pushed me to think at a higher level to accomplish this work. You are so very passionate about what you do, and that is contagious.

Thank you for the hours of conversation, being willing to deal with my countless emails, and for pushing me. I cannot imagine finishing this dissertation without your support.

Thank you to the rest of my committee, Dr. Allison Antink-Meyer, Dr. Pauline Williams, and Dr. Beth Hatt. You have all shown me what it means to be a scholar and have pushed me to advocate for all populations of students. You have shown me that we must think outside of the box to help students build on their amazing experiences to reach their goals. Your suggestions and comments pushed me and strengthened me as both as a scholar and educator.

To Dr. Beth Hatt and Dr. Juliet Lynd, you have no idea the profound effect that the Fulbright experience had on me and my vision of education. I would not be half the educator that I am had it not been for you taking a chance on our whole group that summer. Thank you.

To my parents and siblings who pushed me to grow for my family, for my students, and for myself. You always taught me the value of my education and fighting for what I believe in. Your constant support and the way you live your lives inspire me each and every day. I love you.

To my dear friends, Kim Taber and JoLynn Plato, you listened to me, put up with me sending you tons of texts with my graphs and figures, and pushed me to follow my passion. You are amazing educators and advocates. You were and always will be two of my biggest cheerleaders, and I am so very thankful for you both. 
I dedicate this work to my family and my students. To Heath, Phil, Jack, Jamie, and Ruby, you shared your wife and momma with school and work with love and support. You are my rocks, and I love you so very much. You push me to be better, and I am a better person because of you.

To my students and their families, you inspire me in ways I could never express in words. You deserve the absolute best, and our communities are better because of your amazing gifts and presence. Thank you for inspiring me each and every day.

H.B. 


\section{CONTENTS}

Page

ACKNOWLEDGMENTS

CONTENTS

TABLES Di

FIGURES

CHAPTER I: INTRODUCTION 1

Significance of the Study 3

Research Questions $\quad 5$

Limitations of the Study $\quad 5$

Definition of Terms $\quad 5$

CHAPTER II: LITERATURE REVIEW 28

$\begin{array}{ll}\text { Research Questions } & 8\end{array}$

Areas of Professional Development 9

STEM Education with CLD Learners $\quad 15$

$\begin{array}{ll}\text { Math Curriculum and Strategies } & 17\end{array}$

Science Curriculum and Strategies $\quad 25$

Different Education Models when working with CLD learners 30

$\begin{array}{ll}\text { Identity } & 33\end{array}$

Social Equity Frameworks $\quad 37$

Funds of Knowledge, Funds of Identity, and Smartness 46

Teacher Identity $\quad 56$

Professional Development $\quad 59$ 
$\begin{array}{ll}\text { Co-Teaching } & 62\end{array}$

$\begin{array}{ll}\text { Theoretical Framework } & 69\end{array}$

$\begin{array}{ll}\text { CHAPTER III: METHODOLOGY } & 74\end{array}$

$\begin{array}{ll}\text { Research Questions } & 74\end{array}$

$\begin{array}{ll}\text { Structure } & 79\end{array}$

$\begin{array}{ll}\text { Participants } & 82\end{array}$

$\begin{array}{ll}\text { Data Sources } & 85\end{array}$

Researcher Positionality $\quad 89$

$\begin{array}{lr}\text { Data Collection } & 89\end{array}$

$\begin{array}{ll}\text { Data Analysis } & 90\end{array}$

$\begin{array}{ll}\text { Ethical Considerations } & 92\end{array}$

Assumptions, Delimitations, and Limitations 93

CHAPTER IV: RESULTS AND FINDINGS 94

$\begin{array}{ll}\text { Overview } & 94\end{array}$

$\begin{array}{ll}\text { Participants } & 95\end{array}$

$\begin{array}{ll}\text { Data Collection } & 98\end{array}$

$\begin{array}{ll}\text { Data Analysis } & 98\end{array}$

Module Analysis $\quad 99$

$\begin{array}{ll}\text { Pre and Post-Interviews } & 111\end{array}$

Development of Codes and Themes 125

$\begin{array}{ll}\text { Findings } & 139\end{array}$

$\begin{array}{ll}\text { CHAPTER V: IMPLICATIONS } & 148\end{array}$

$\begin{array}{ll}\text { Summary } & 148\end{array}$ 


\section{TABLES}

Table

Page

2.1 Strands of Mathematical Proficiency as Outlined by The Council of the Great City

Schools

2.2 Importance of Talk (Chapin et al., 2013)

2.3 Mathematical Language Routines

$2.4 \quad$ Talk Moves

2.5 Dimensions of Multicultural Education (Bank, n.d)

2.6 Themes of Culturally Responsive Teaching (Aceves \& Orosco, 2014, p. 9-12)

2.7 Educator Competencies (Muñiz \& America, 2019)

2.8 Funds of Knowledge vs Funds of Identity (Subero et al., 2017, p. 253)

2.9 Cultural Wealth (Yosso, 2005)

2.10 Co-Teaching Models (Adapted from Hurd \& Weilbacher, 2017)

2.11 Co-Teaching Models Designed for General Educators and Language Educators (Dove \& Honigsfeld, 2010, pp. 7-8)

2.12 Levels of Collaboration in Partnerships Between General Education Educators and Language Specialists (Adapted from Davison, 2006; McClure \& CahnmannTaylor, 2010)

4.1 Pre and Post-responses to Category 1 (Description of CLD Learners)

4.2 Pre and Post-responses to Category 2 (Assets of CLD Learners) 
4.4 Pre and Post-responses to Category 4 (Identity of the Teacher) 118

4.5 Pre and Post-responses to Category 5 (Identity of the Student) 120

4.6 Pre and Post-responses to Category 6 (Overall Professional Development Needs) 122

4.7 Pre and Post-responses to Category 7 (Math and Science Professional Development Needs)

4.8 Alignment of Themes and Categories to the Research Questions 


\section{FIGURES}

Figure

$\begin{array}{lrr}2.1 & \text { State Math Scores } 2019 & 18\end{array}$

2.2 State’s Science Assessment Scores 2019

$\begin{array}{lll}2.3 & \text { Social Equity frameworks } & 38\end{array}$

$\begin{array}{llr}3.1 & \text { Module Structure } & 80\end{array}$

3.2 Module Progression 81

4.1 Initial Group Responses to Theme One (Prior to Any Module Completion) 129

4.2 Initial Group Responses to Theme Two (Prior to Any Module Completion) 130

4.3 Final Group Responses to Theme One (Following all Module Completion) 133

4.4 Final Group Responses to Theme Two (Following all Module Completion) 134 


\section{CHAPTER I: INTRODUCTION}

Our school population is constantly changing in both size and demographics. In the year 2000, white students made up the majority of students (61.2 percent); however, this majority shifted as students of color represented the majority (51.1 percent) of the school age population in 2015 (Snyder et al., 2019). When looking at the overall number of students in our public schools, the population of our public schools continues to increase. From 2015 to 2019, the number of total students enrolled in public elementary and secondary schools rose from 50.5 million to 50.8 million students. However, when looking closer at this statistic, the number of white students dropped from 24.8 million to 24 million students, and the number of students of color rose from 25.7 million to 26.8 million (Snyder et al., 2019).

By looking at projections from 2019-2026, this trend continues as white student enrollment is projected to decrease to 23.4 million students, while students who identify as Black, Hispanic, Asian/Pacific Islander, American Indian/Alaska Native, or Two or more races will increase to 28.3 million students. Therefore, in the year 2026, the school population is projected to be composed of 45.2 percent of students who identify as white and 54.2 percent of students who identify as a student of color (Hussar \& Bailey, n.d.).

The current teacher workforce does not reflect the same ethnic diversity of the classrooms in which they serve. Although the percentage of white teachers to the total teacher population in the United States decreased from 86.9 percent in 1988 to 80.1 percent in 20152016 (Snyder et al., 2019), white educators still remain the majority of educators in the classroom. This means that many educators are teaching in classrooms in which they do not reflect the backgrounds of their students and may put their students at risk of not having an education or educator that reflects their cultural background. Furthermore, few teacher education 
programs or professional development opportunities have been able to successfully tackle preparing their students and educators for the diverse classrooms in which they will or do serve (Herrera et al., 2013; Watson et al., 2006). In addition, because teachers' race, class, and gender inform their relationships with students, educational philosophies, and curricular choices (Brown, 2006), discussion of teacher identity is an essential step to creating more equitable school environments.

An area of our school population that is outpacing the growth of all other population groups is the Latiné population. Between 2000 and 2015, the number of Latiné students in the United States increased by 47 percent, which makes this group one of the fastest-growing segments of the US population (Foxen \& Mather, 2016). While Latiné students grew by 47 percent, the percentage of white and Black students both decreased by 13.9 and 4.2 percent respectively (Foxen \& Mather, 2016). Looking forward, by 2035, children of Latiné origin will make up more than $1 / 3$ of the population of our schools (Herrera et al., 2013).

According to the Annie E. Casey Foundation (2020), 12,132,000 students, or 23\%, of all school age children spoke a language other than English at home in 2018. Furthermore, as trends show, more linguistically diverse students are moving to nontraditional receiving communities that are not as associated with student diversity (Fortuny et al., 2010), and rural teachers are struggling with providing supports for their linguistically diverse students and families (HansenThomas et al., 2016). Thus, more educators across the United States are experiencing the need to have training in working with culturally and linguistically diverse (CLD) learners. In addition, the large and persistent gaps in academic outcomes for English learners (ELs) compared with other students indicate that something must be wrong with the teaching approaches we are using (Gándara \& Santibañez, 2016). 
Despite the growing number of Latiné students in our school system, their participation in STEM programs has not grown, and there remains a perceived achievement gap between Latiné students and their peers in both math and science (Aud et al., 2010; Huerta et al., 2019). Furthermore, Latiné students are overrepresented in lower level math and science tracks and less represented in STEM classrooms, programs, and fields (Aud et al., 2010; Feldman \& Malagon, 2017; Gholson \& Wilkes, 2017). In addition, once in the STEM career pipeline, students of color, including CLD students, leave at greater rates (Radunzel et al., 2016). Without specific training and focus on the language demands and content practices, educators are not likely to effectively respond to nor feel the need to meet the language needs of CLD learners as they engage in content area practices (Crandall \& Bailey, 2018). We must analyze how math and science educators and programs need to adjust to meet the unique needs and assets of our Latiné students, who vary based on their generational status, citizenship, family structure, education, and English-language ability (Foxen \& Mather, 2016). Furthermore, we need to look for ways to support and change math and science classroom experiences to further increase educational opportunities and reduce the educational disparities for Latiné students.

Taking into consideration that Latiné students are changing the demographic, cultural, and linguistic landscape of the schools in the United States, it is imperative that educators and administrators are provided with tools and recommendations to accommodate their students, specifically in the areas of math and science.

\section{Significance of the Study}

To meet the needs of our changing demographics of US schools, educators need direct professional development with CLD learners and identity. This action research qualitative study sought to explore and analyze the shifts in viewpoints, pedagogical practices, and identity of 
middle school math and science educators who work with CLD students when provided with targeted professional development, meaning that the development is specifically designed for middle level math and science educators.

As an educator of multilingual learners for almost two decades, many teachers have expressed that many of the professional development opportunities for English learner inclusion in the classroom are general and designed by experts in language development and that these strategies can be difficult to apply by general education teachers. In addition, these professional development opportunities may not build upon the practices that are unique to mathematics and science, and therefore, educators may be less likely to implement them. Most CLD learners spend the bulk of their time in general education classrooms with educators who lack the training and knowledge of the unique strengths and needs of English learners, which can lead to a lack of supports and leave educators feeling unprepared to meet their needs (Cosentino de Cohen \& Clewell, 2007; Spycher \& Haynes, 2019). This lack of implementation and training puts our CLD learners at a risk of not receiving the math and science instruction that research shows benefits them and puts both the educator and student at risk of feeling frustrated and ineffective. In addition, due to the cultural mismatch between the educators in our classrooms and Latiné students, it is critical that professional development also focuses on educator identity and the role that identity plays in the classroom and in decision making.

This action research study sought to bridge that gap by directly aligning professional development with the needs of CLD learners in the math and science middle school classroom through professional development modules. Furthermore, this study sought to disrupt the deficitlens that many educators may have of their CLD learners and explored how having targeted professional development focusing on science and math educators shifted the ways in which 
educators viewed their CLD learners. Additionally, this study sought to explore how an educator's own identity shifted as they took part in learning experiences and discussions about their students' experiences and needs. The following research questions guided this study.

\section{Research Questions}

1. How do math and science educators view CLD learners in their classroom when provided with targeted professional development that focuses on CLD learners in the math and science classroom?

2. How does the identity of a teacher shift when provided with targeted professional development that focuses on CLD learners in the math and science classroom?

\section{Limitations of the Study}

I conducted this study with four educators from one middle school in the Midwest. The population size was small as the study was qualitative as I sought to paint a clearer picture of the educators' journeys throughout the study. I am an educator in the school and viewed as both an expert in the needs of CLD learners as well as in math and science, which gave me credibility with the other educators who were involved in the professional development element of the study. Expanding these modules to educators in other areas is addressed in the implications section. Further limitations and delimitations are in Chapter 5.

\section{Definition of Terms}

Throughout this study, I used terminology that describes learners. The main term I used is culturally and linguistically diverse (CLD) learners. Schools seek to use a more asset-based approach to linguistically diverse students rather than defining them by their lack of English; terms such as English learner (EL), English language learner (ELL), or Limited English proficient (LEP) label the students from a deficit-based approach by focusing on what they do 
not have (English proficiency). Terminology such as bilingual, multilingual, and culturally and linguistically diverse (CLD) learner are terms that are asset-based by focusing on the linguistic skillset that they possess. However, students may be described as multilingual or CLD and no longer be classified by their state as qualifying for English language development programming (ELD), which may also be referred to as English as a Second Language (ESL) services or English Learner (EL) services. The ACCESS test, a test for English language proficiency, determines whether a student still qualifies for these services (ACCESS Tests $\mid$ WIDA, n.d.). In addition, the term CLD learners also describes many more students than the student group that is this study's focus; however, CLD has become a widely used term for students who have a native language other than English and/or speak a language other than English at home. Culturally linguistically marginalized (CLM) learners was also considered as a possible descriptive term for students with a native language other than English. CLM recognizes that in addition to being diverse in their linguistic repertoire, the education system marginalizes communities in which their native language is not English.

In this dissertation, I refer to people of Latin American descent as Latiné. To be more inclusive of gender neutrality, many have turned to the usage of Latinx or Latiné in place of the male and female terms of Latino/a. However, Latiné is used by many circles within Latin America as the e is used to symbolize gender neutral nouns and adjectives in Spanish (VidalOrtiz \& Martínez, 2018). As I take the view that intentional usage of more inclusive terminology is critical, I have chosen to use Latiné throughout this paper.

Additionally, my usage of capitalization is intentional. When addressing white, such as in reference to people who are white or in terms of critical whiteness, I have intentionally kept white lower cased while capitalizing other races and ethnicities; I have embraced wording by the 
Columbia Journalism Review in which they argue that to capitalize Black is to reflect a "shared sense of identity and community," while capitalizing white "carries a different set of meanings... risks following the lead of white supremacists" (Laws, 2020). Although this is debated, my perspective is that capitalizing Latiné or Latinx and not white, recognizes marginalization and empowerment and symbolizes the decentering of whiteness. 


\section{CHAPTER II: LITERATURE REVIEW}

This chapter focuses on the literature that guided this study. Because this study focused on the professional development of middle school math and science educators who service culturally and linguistically diverse (CLD) students, a comprehensive review of what the literature says about professional development, language, pedagogical shifts, identity, and curriculum recommendations was necessary to build a comprehensive plan. This literature review focuses on areas of professional development overall for educators who work with English learners (ELs), STEM education with CLD learners, mathematics strategies with CLD learners, science curriculum and strategies with CLD learners, educational models for unit planning with CLD learners, identity, social equity frameworks, funds of knowledge/funds of identity/smartness, teacher identity, professional development, and co-teaching models. Following these topics, I describe the theoretical frameworks chosen as the lenses for this study. The literature guided the development of a professional development opportunity through online modules and focus groups designed for middle level math and science educators who work with CLD learners. Through this literature review and program development, I focused on the following two research questions.

\section{Research Questions}

1. How do math and science educators view CLD learners in their classroom when provided with targeted professional development that focuses on CLD learners in the math and science classroom?

2. How does the identity of a teacher shift when provided with targeted professional development that focuses on CLD learners in the math and science classroom? 


\section{Areas of Professional Development}

The development of language for English learners (ELs) has predominantly been the work of English as a Second Language (ESL) and/or bilingual educators. With the amount of language support needed for students, ESL educators often feel overused and desire more support from general education educators (Batt, 2008). Language specialists, including ESL educators, often present language instruction embedded in content; however, the ESL educator's content knowledge limits the depth of the instruction (Lee et al., 2013). Furthermore, ELs spend the bulk of their time in classrooms with general education teachers; yet, the majority of general education educators have had little or no professional development on how to meet the needs and differentiate for ELs (Cosentino de Cohen \& Clewell, 2007). Few general education educators have taken courses related to issues pertaining to ELs and few have the experience of being proficient in a second language (Lucas et al., 2008). This lack of depth of content knowledge by ESL educators and lack of depth of knowledge of appropriate accommodations designed for ELs by general education educators can lead to CLD students not meeting their full potential in content area classes.

Lucas, Villegas, and Freedson-Gonzales (2008, p. 362) state, "an educator who has ELs in his or her class is best equipped to teach them if he or she has knowledge of some key principles of second language learning." Many general education teachers lack an understanding of how ELs' needs may differ from other students and be unsure of the supports that the students may need. Although research has differed on what strategies and knowledge professional development opportunities should provide, I conducted a meta-analysis of what the literature said to identify commonalities between the studies. 
Lucas, Villegas, and Freedson-Gonzales (2008) conclude that general education educators need training on the following essential elements for an inclusive classroom for ELs. These include:

1. Conversational language proficiency vs academic language proficiency

2. Comprehensible input

3. Social interaction fostering language development

4. Link between native-language skills and English language development

5. Importance of a safe, welcoming classroom for performing a new language

6. Explicit focus on linguistic form and function in the classroom

Although these concepts above are included in teacher education programs for educators seeking an ESL or bilingual endorsement, many teacher education programs for general education educators do not include these areas of focus, which support language growth for CLD learners. Educators need to have deep content knowledge and pedagogical content knowledge, and although educators who are content area specialists cannot be expected to be experts in language, they can identify and make explicit the language in their discipline (Lucas et al., 2008).

Lucas, Villegas, and Freedson-Gonzales (2008) identify five recommendations as strategies to scaffold learning for ELs. These include supplementing and modifying text, supplementing and modifying oral language, facilitating and encouraging the use of students' native language, engaging ELs in purposeful activities where they interact with others and negotiate meaning, and minimizing the anxiety of being an EL in a mainstream classroom. These recommendations can be areas of professional development for in-service or pre-service educators. 
In her study, Batt (2008) worked with general education educators to identify areas of need for professional development. These (EL/general education educators and directors) identified areas were parental involvement, EL curriculum development, Spanish language class, first and second language literacy methods, sheltered English instruction, EL methods, and how to establish a newcomer center. Batt concluded, "[t]he success of EL students cannot remain the sole responsibility of ESL and bilingual educators" (p. 5).

Lee and Buxton (2013b) say the focus of professional development for educators should focus on literacy strategies with all students, language support strategies with ELs, discourse strategies with ELs, home language support, and home culture connections. Although many of the areas overlap, there is still a difference in what researchers say the focus of professional development should be for pre-service and in-service educators who are servicing CLD students. As students experience more rigorous academic expectations, educators of ELs face a double challenge as they strive to meet both English development needs as well as academic standards across the content areas (Lee \& Buxton, 2013b). Despite there being differing foci of the necessary knowledge for general education educators, these studies show the need for general education educators to have a great depth of knowledge about how CLD students think, respond, and learn.

It is also critical that educators have an understanding of the unique linguistic capital that CLD students possess by having an understanding of their native language as an asset in which they possess. Simply teaching in a monolingual mode that reflects the language practices legitimized by the dominant group is harmful to children. It results in academic failure, linguistic and identity insecurities, and the inability to enjoy the critical metalinguistic awareness that 
enables students to become critical analysts and users of language in society (García \& Lin, 2017, p. 4).

When educators are working with students who have diverse language systems, they must also create a space in which different linguistic capital is viewed as an asset; therefore, general education educators must have an understanding of the importance of how students can and should use their native language as a way to connect to their learning and discourse within the general education classroom. However, when looking at many language programs, educators often view a student's language systems to work independently of one another in which a student moves within the domains of language, which include reading, writing, speaking, listening and thinking, in one language and then moves into the domains of language in the other language. In many general education programs, the expectation is that the student uses English in general education classrooms. The idea that a student is turning off their language systems as if they are flipping a switch is not in line with newer linguistic research. Programs that use one named language independently of the other may limit the usage of a students' full linguistic repertoire. On the other hand, when programs support translanguaging, educators show value and support to a bilingual student's linguistic capital and their identity as a bilingual speaker.

Translanguaging, a term coined by Cen Williams, provides a different lens to view the use of language by multilingual students by pushing back against systems that discourage the use of a student's full linguistic repertoire (García \& Wei, 2014). Translanguaging is the constant movement between the invisible borders/boundaries of their languages, and when educators support translanguaging, the educator shifts the power to the speaker as they choose the language they wish to use as they move through their conversations and experiences (García, 2009). 
Translanguaging goes beyond thinking of two languages and the mixing of those languages but rather refers to new linguistic practices (García \& Wei, 2014). Not to be mistaken for code-switching, translanguaging is the internal movement and meaning making with language and refers to what speakers do with language that makes it unique to themselves as the speaker (Yip \& García, 2015). Otheguy, García, and Reid (2015) define translanguaging as "the deployment of a speaker's full linguistic repertoire without regard for watchful adherence to the socially and politically defined boundaries of named languages" (p. 283). Furthermore, translanguaging views the diverse languages as an integrated system (Canagarajah, 2011; Cenoz \& Gorter, 2017).

Scholars in bilingual education argue that to fail to allow translanguaging in the classroom, an educator is not focusing on social justice as multilingual learners are allowed only access to less than half of their linguistic repertoire (Yip \& García, 2015) while monolingual students are allowed to access most of their repertoire; these inequities continue with assessment practices.

Educators must view themselves as learners as they seek to learn more about how the bilingual mind works when it comes to language usage and thinking even in spaces in which the instruction is primarily in English. Translanguaging recognizes that our language changes and adapts to new scenarios and affects identity and our experiences; furthermore, translanguaging recognizes that we use all our linguistic resources to unlock meaning and to communicate with others (Baker \& Wright, 2017). A translanguaging classroom validates the bilingual program practices and allows the use of translanguaging rather than the named language (García et al., 2017; García \& Wei, 2014). 
One of the universal forms of translanguaging is spontaneous translanguaging; this is the fluid movement between the languages in naturally occurring contexts inside and outside of the classroom. Due to a lack of understanding language, educators may refer to this translanguaging as a failure to have proficiency in either language. However, García (2009) proposes that educators should recognize spontaneous translanguaging as a legitimate practice as this may allow students to participate more fully in school situations because they are able to use their full linguistic repertoire. When viewed through a positive lens, translanguaging is a spontaneous way in which bilinguals can communicate, make meaning, and connect to their experiences and learning. Colin Baker (2001) proposes four possible educational advantages to accepting translanguaging in classrooms. This includes, promoting a deeper understanding of content, development of the weaker language, can help with home-school links, and it may help integrate fluent speakers and emerging speakers of a language. Scholars have argued that to develop curriculum and learning through a biliteracy lens, educators must view translanguaging as a necessity and a desirable educational practice (Hornberger \& Link, 2012).

Although much of the research surrounding translanguaging focuses on bilingual classrooms, translanguaging is not only applicable in a bilingual room as it is not something the students shut off. Therefore, general education educators should also have an understanding of the value of accepting translanguaging within their general education classrooms. As we seek to create spaces that are equitable and inclusive toward our bilingual and multilingual learners, the acceptance of and encouragement of translanguaging shows value to the multilingual community and to the student who possesses a diverse and complex language repertoire. In addition, due to many general education educators not speaking a second language, helping educators create a space where translanguaging is accepted and encouraged is a critical step in creating equitable 
spaces and experiences. Looking at co-teaching models that build upon native language use is an important step in building these spaces; I will address co-teaching models within a separate section of this literature review.

Much of the literature that focuses on professional development with educators in the content area centers on language development in the content area class and often focuses on English Language Arts or developed with an all content area type of approach. A focus on practices and strategies for ELs, specifically in math and science, are not as present within the research. Content area instruction of ELs in math and science has had limited attention within research communities, and the research has focused on building English proficiency and literacy, and the research fields of math and science have developed independently of research focusing on ELs (Lee, 2005; Martinez et al., 2011). Without focused professional development, math and science educators may struggle to meet the needs of CLD students.

\section{STEM Education with CLD Learners}

As the number of English learners (ELs) in classrooms increases, so do the number of educators who are instructing them. Besterman, Ernst, and Williams (2018) researched the growth in the number of ELs in STEM (science, technology, engineering, and math) disciplines, the credentials of the educators who serviced them, and the professional development of the educators who were teaching the ELs. From this survey, the researchers split the participants into groups based on the content area they teach (science, math, or technology) and looked at their responses to questions focusing on EL numbers, professional development, and credentials over time. The time periods they analyzed were responses from 2007-2008 and then from 2011-2012.

The findings showed that science, math, and technology secondary educators all saw an increase in the number of ELs in their classrooms, with the highest percentage occurring in math 
with $59.1 \%$ of educators reporting they serviced ELs; this was up from 51.3\% in 2007-2008. In science, the number of educators servicing ELs rose from 51.0\% to 58.4\%, and technology educators experienced the smallest increase with a growth of $47.2 \%$ to $50.8 \%$. Although all of the teachers saw an increase in the number of ELs they serviced in their respective STEM disciplines, most of the educators reported having less than 8 hours of professional development pertaining to meeting the needs of the ELs in their classrooms. This is a common concern in our schools. With the lack of the linguistic certifications and training, educators need professional development to meet the needs of ELs.

Although CLD learners are outpacing the growth of the overall PK-12 student population and represent about 5.3 million students, they are underrepresented in STEM programs (Aud et al., 2010; Feldman \& Malagon, 2017). As this population continues to grow, looking for ways to make classes in STEM disciplines more accessible to CLD learners via professional development for educators should be a priority. This study as well as the evidence that the CLD population is growing, show that both professional development and teacher education programs must grow to meet this need. As addressed by Peralta, Caspary, and Boother (2013, p. 916), "Many ELs are not prepared to meet general education requirements at the college level, and unless different ways of helping students are explored, the number of Latino students in the STEM fields will continue to decline." To meet the growing numbers of CLD learners in STEM classrooms and the desire to increase the number of Latiné students in STEM fields, pre-service and in-service educators must meet the unique needs and assets that CLD learners bring into the classroom.

ELs are frequently in classrooms in which they are attempting to confront the demands of academic learning with a yet unmastered level of English language development and without the instructional and linguistic supports that they need (Lee et al., 2008, 2016). In addition, ELs are 
more likely to drop out of school than their English-speaking peers (Sheng et al., 2011). Without providing adequate support in the content areas and in language growth, ELs may not be given equitable opportunities to grow and feel successful in their classes. Looking at ways that general education math and science educators can meet the needs of ELs is critical to help them grow in both their content knowledge and their language development.

\section{Math Curriculum and Strategies}

Although it is often stated that math is universal and that numbers are the same in all languages, this oversimplification of the language of mathematics leaves English learners (ELs) at risk of receiving less support in the mathematics classroom. Educators need specific strategies on how to make the language of mathematics more transparent and accessible for students.

When analyzing standardized assessment data, there continues to be an achievement gap within mathematics between ELs and their middle school peers. Using achievement data has implications that I will address later in this literature review; however, I recognize that standardized test data is problematic because there is well established research (González Canché, 2019; Koh et al., 2014; Saygin, 2019; White et al., 2016) that shows that this data comes from a biased assessment and continues the marginalization of minoritized population, including CLD learners. Although I will address some of the possible issues with measuring this gap solely with achievement scores later, the deep discussion of these biases is beyond the scope of this study. However, due to the implications that standardized test data has on the ways that schools make decisions and how schools are assessed, I used this data as a way to show differences in EL's perceived achievement.

Because this study is focusing on middle school students, I focused my analysis on middle school data from a state in the Midwest. According to the state's report card (*State 
Report Card, 2019), among the EL population, only $4 \%$ of eighth graders, $4 \%$ of seventh graders, and 3\% of sixth graders met on the mathematics portion of the state's readiness exam (IAR), and no EL student exceeded on the assessment. Among all of the state's middle school students, $28 \%$ of eighth graders met and $4 \%$ exceeded, $25 \%$ of seventh graders met and $5 \%$ exceeded, and $22 \%$ of sixth graders met and $3 \%$ exceeded (See Figure 2.1). This discrepancy in scores suggests that instruction needs to change to continue to address the opportunity gap between ELs and their middle school peers in mathematics.

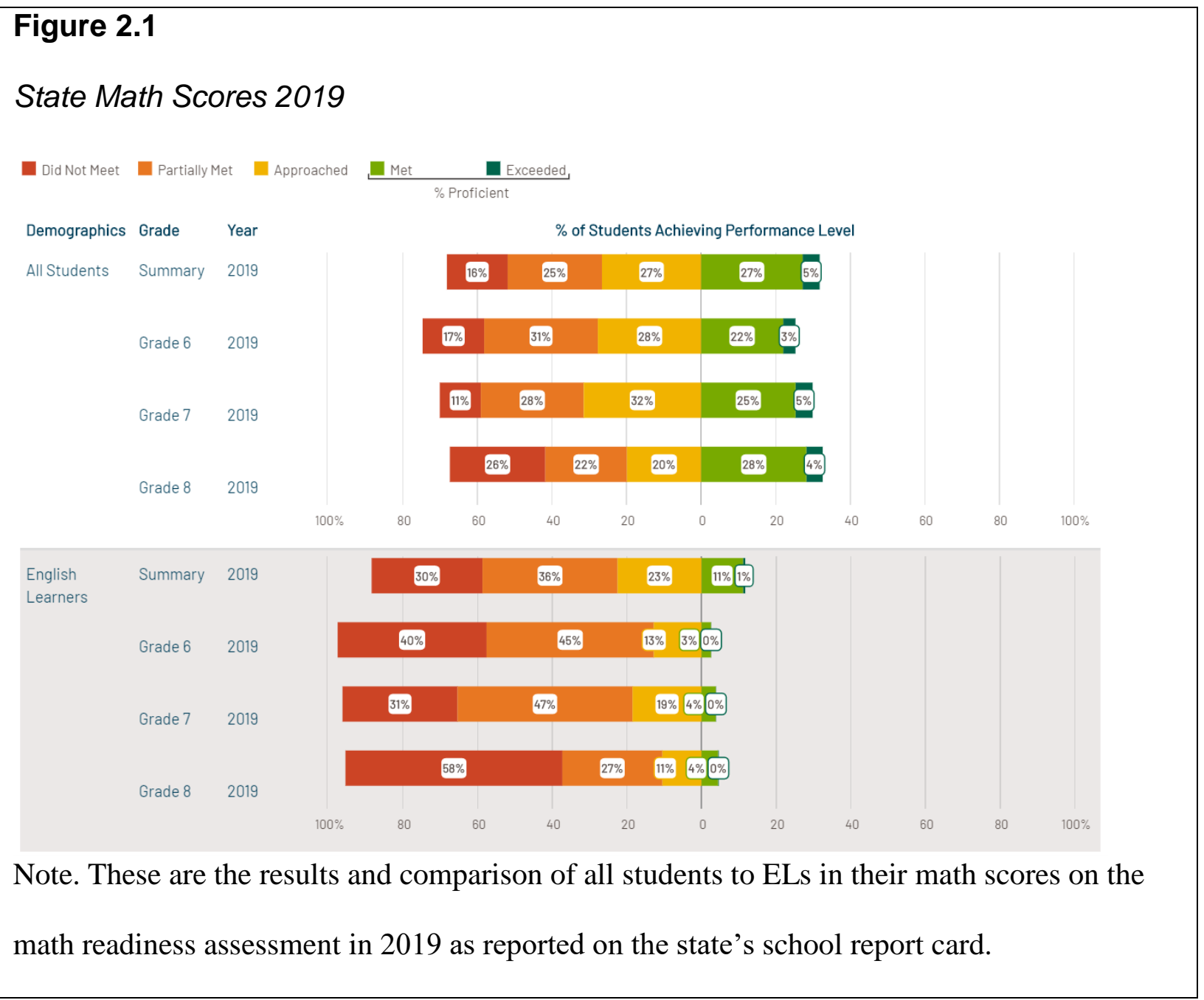


To begin to address this gap, educators must look at both pedagogical and instructional practices as well as their curricular choices. In addition, they must look at literacy development within the content areas. Building academic literacy in mathematics includes three components, which include mathematical proficiency, mathematical practices, and mathematical discourse (J. N. Moschkovich, 2015). Mathematical literacy, as a combination of both practices and discourse, enables educators to view language and content to work together, in unison. Separating language from the thinking and practices of mathematics can have negative consequences for English learners (Moschkovich, 2015). In addition to an explanation of mathematical literacy, scholars seek to explain mathematical proficiency. In a Framework for re-envisioning mathematics instruction for English language learners, the Council of the Great City Schools (2016, p. 8), broke mathematical proficiency down into five intertwined strands of both skills and knowledge in mathematics. These include conceptual understanding, procedural fluency, strategic competence, adaptive reasoning, and productive disposition. Table 1 provides a further breakdown of each strand.

\section{Table 2.1}

Strands of Mathematical Proficiency as outlined by The Council of the Great City Schools

\begin{tabular}{cc}
\hline Strand & Description \\
\hline Conceptual understanding & $\begin{array}{c}\text { Comprehension of mathematical concepts, } \\
\text { operations, and relations }\end{array}$ \\
Procedural fluency & $\begin{array}{c}\text { Skill in carrying out procedures flexibly, } \\
\text { accurately, efficiently, and appropriately } \\
\text { Competence in formulating, representing, and } \\
\text { strategic competence }\end{array}$ \\
Adaptive reasoning & $\begin{array}{c}\text { Logical thought, reflection, explanation, and } \\
\text { justification }\end{array}$ \\
Productive disposition & $\begin{array}{c}\text { A habitual inclination to see mathematics as } \\
\text { sensible, useful, and worthwhile, along with a } \\
\text { belief in diligence and one's own efficacy }\end{array}$ \\
\hline
\end{tabular}


To build mathematical proficiency and literacy for CLD learners, educators must put supports in place that encourage the growth of both mathematics and language usage. This requires mathematics educators to focus on all parts of mathematical literacy together and not in isolation. In addition to mathematical proficiency, educators also connect with the mathematical practices.

The Common Core state standards (2009) outline eight mathematical practices:

1. Make sense of problems and persevere in solving them

2. Reason abstractly and quantitatively

3. Construct viable arguments and critique the reasoning of others

4. Model with mathematics

5. Use appropriate tools strategically

6. Attend to precision

7. Look for and make use of structure

8. Look for and express regularity in repeated reasoning.

By being attune to the mathematical practices as a platform for pushing CLD learners to a higher level of mathematics, discourse surrounding mathematics will also improve. To engage students to grow both linguistically and mathematically, educators must move beyond simplified vocabulary and language by engaging English learners in productive and engaging math discussions (Council of the Great, 2016). In addition, if CLD learners are encouraged, taught to explain, and given opportunities to communicate their mathematical understandings, students will also advance their English proficiency. Furthermore, by giving them opportunities to use their native language within the mathematics classroom, they are able to use their full linguistic repertoire to build upon their math knowledge. 
By meeting the expectations of mathematical practice three (construct viable arguments and critique the reasoning of others) and mathematical practice six (attend to precision), student discourse should be a focus. However, many CLD learners may be hesitant to engage in conversations within the classroom or may have few opportunities to fully engage in mathematical discourse. Often teachers refer to the IRE model of teaching in which the educator initiates, students respond, and the educator evaluates the response. Thus, most classrooms consist of the teacher lecturing, and discussions are limited to educators posing questions to students in which a simple or known answer is expected (Chapin et al., 2013). This model of classroom discourse does not fully allow students to build upon each other's ideas nor afford them the opportunity to evaluate their own ideas and the ideas of their classmates. When educators commit to teaching for understanding, classroom discourse and discussion play a key role in developing a student's literacy and proficiency in that classroom (see Table 2.2).

\section{Table 2.2}

Importance of Talk (Chapin et al., 2013)

\begin{tabular}{ll}
\hline \multicolumn{1}{c}{ Five major reasons that talk is critical in teaching and learning } \\
\hline \multicolumn{1}{c}{ Reason } & \multicolumn{1}{c}{ Deeper explanation } \\
\hline $\begin{array}{l}\text { Talk can reveal understanding and } \\
\text { misunderstanding }\end{array}$ & $\begin{array}{l}\text { Educators can see more clearly what the } \\
\text { students understand and not understand as } \\
\text { formative assessment }\end{array}$ \\
$\begin{array}{l}\text { Talk supports robust learning by boosting } \\
\text { memory } \\
\text { Students have the opportunity to hear and talk } \\
\text { about concepts, applications, procedures, and } \\
\text { ideas; this gives them more opportunities to } \\
\text { remember the information }\end{array}$ \\
It takes practice to develop the skill of \\
ralk supports deeper reasoning & $\begin{array}{l}\text { logically and to work out problems and ideas } \\
\text { Students can develop a richer understanding } \\
\text { Talk supports language development }\end{array}$ \\
Talk supports the development of social skills & $\begin{array}{l}\text { Students are able to learn about respect and } \\
\text { kindness as they listen to others' ideas and } \\
\text { reasoning. }\end{array}$ \\
\hline
\end{tabular}


However, educators must make careful considerations about how they facilitate mathematical conversations within the classroom. Often educators view CLD students through a deficit lens as educators focus on the student's lack of vocabulary as the barrier for carrying out mathematical conversations in the classroom. Moschkovich (2007) discusses three perspectives educators maintain when carrying out mathematical discussions, which include an emphasis on vocabulary, an emphasis on multiple meanings, and an emphasis on participation in mathematical discourse practice. She concludes that focusing on vocabulary provides a narrow view of mathematical conversation and focusing on multiple meanings can send the message that the two registers of language are separate; these perspectives can have a negative impact in the assessment, instruction, and achievement of CLD learners in the mathematics classroom. Although educators can use both as analytical tools, focusing on these areas can have a negative effect on equity in the classroom. Furthermore, Moschkovich postulates that focusing on mathematics through a sociocultural perspective with the emphasis on participation in mathematical discourse practice allows students to draw upon their linguistic repertoire and their experiences to take part in discussions. These discussions also give opportunities for students to translanguage, move freely between their languages, as they discuss and engage with tasks.

If educators give students opportunities in which they engage with complex and rigorous mathematics instruction, discussions, and high cognitive tasks with appropriate supports, ELs will develop a deeper level of mathematical understanding of concepts as well as procedural fluency (Council of the Great, 2016)

The developers of the Achieve Project (2019) outlined mathematical routines that can support both the language development and the mathematical development for English learners. These routines include stronger and clearer each time; collect and display; critique, correct, and 
clarify; information gap; co-craft questions and problems; three reads; compare and connect, and discussion supports. A mathematical language routine describes a "structured but adaptable format for amplifying, assessing, and developing students' language" (Achieve, n.d.). Table 3 explains the routines in more detail with their purpose and description.

\section{Table 2.3}

Mathematical Language Routines

\begin{tabular}{|c|c|c|}
\hline Routine & Purpose & Description \\
\hline $\begin{array}{l}\text { Stronger and Clearer each } \\
\text { time }\end{array}$ & $\begin{array}{l}\text { To provide a structured and } \\
\text { interactive manner for } \\
\text { students to both revise and } \\
\text { refine their ideas and } \\
\text { productive output }\end{array}$ & $\begin{array}{l}\text { Students have opportunities } \\
\text { to write and discuss, be } \\
\text { encouraged to revise and } \\
\text { expand their ideas, and use } \\
\text { new language in each draft. }\end{array}$ \\
\hline Collect and display & $\begin{array}{l}\text { To capture students' oral } \\
\text { language into a stable, } \\
\text { collective reference }\end{array}$ & $\begin{array}{l}\text { The educator captures the } \\
\text { words and phrases used } \\
\text { during students' discussions, } \\
\text { scribes the ideas, and puts } \\
\text { these words and ideas into a } \\
\text { display for students to refer } \\
\text { back to in future discussions. }\end{array}$ \\
\hline Critique, correct, and clarify & $\begin{array}{l}\text { To give students a piece of } \\
\text { mathematical writing that } \\
\text { does not belong to them so } \\
\text { that they may analyze, reflect } \\
\text { on, and develop the ideas } \\
\text { further }\end{array}$ & $\begin{array}{l}\text { This engages students in } \\
\text { meta-awareness as students } \\
\text { receive incomplete or } \\
\text { incorrect written arguments. } \\
\text { They seek to correct errors } \\
\text { and clarify the meaning } \\
\text { behind the problem and ideas. }\end{array}$ \\
\hline Information gap & $\begin{array}{l}\text { To create a reason for } \\
\text { students to communicate }\end{array}$ & $\begin{array}{l}\text { Students receive parts of } \\
\text { necessary information but not } \\
\text { all of the information. The } \\
\text { students need to communicate } \\
\text { with one another to fill the } \\
\text { gap of what they do not } \\
\text { know. This encourages } \\
\text { conversation, and requires } \\
\text { students to share information, } \\
\text { clarify, justify, and elaborate } \\
\text { on their ideas. }\end{array}$ \\
\hline
\end{tabular}

(Table continues) 
(Table continued)

\begin{tabular}{|c|c|c|}
\hline Routine & Purpose & Description \\
\hline $\begin{array}{l}\text { Co-craft questions and } \\
\text { problems }\end{array}$ & $\begin{array}{l}\text { To allow students to dive into } \\
\text { a text without feeling the } \\
\text { pressure to produce answers } \\
\text { by allowing students to create } \\
\text { mathematical problems and to } \\
\text { analyze different } \\
\text { mathematical forms. }\end{array}$ & $\begin{array}{l}\text { The students are able to use } \\
\text { their linguistic skills to } \\
\text { improve questions, problems } \\
\text { and mathematical contexts to } \\
\text { both develop meta-awareness } \\
\text { and language. }\end{array}$ \\
\hline Three reads & $\begin{array}{l}\text { To make sure that students } \\
\text { understand what they are } \\
\text { being asked to solve, and } \\
\text { create opportunities for } \\
\text { students to reflect on the way } \\
\text { the questions are being } \\
\text { presented and to teach tools } \\
\text { to help students negotiate } \\
\text { meaning. }\end{array}$ & $\begin{array}{l}\text { This supports reading } \\
\text { comprehension as students } \\
\text { negotiate information within } \\
\text { text by reading multiple times } \\
\text { and by being able to discuss } \\
\text { the meaning with a partner. }\end{array}$ \\
\hline Compare and connect & $\begin{array}{l}\text { To foster meta-awareness as } \\
\text { students identify, compare, } \\
\text { and contrast mathematical } \\
\text { problems, representations, } \\
\text { language, and concepts }\end{array}$ & $\begin{array}{l}\text { Educators prompt students to } \\
\text { reflect on the words used in } \\
\text { mathematics and respond to } \\
\text { their usage. }\end{array}$ \\
\hline Discussion supports & $\begin{array}{l}\text { To support quality } \\
\text { discussions about } \\
\text { mathematical ideas, } \\
\text { representations, and strategies }\end{array}$ & $\begin{array}{l}\text { Educators use multi-modal } \\
\text { strategies to help students } \\
\text { make sense of complex } \\
\text { language and classroom } \\
\text { conversations. }\end{array}$ \\
\hline
\end{tabular}

Note. The Achieve project outlined and described these eight mathematical language routines

to help both the mathematical and linguistic growth of English learners.

Although I will address unit planners, frameworks, and key elements of instructional practices with CLD learners later in this literature review, having an understanding of mathematical instruction of CLD learners is critical to improve the mathematical experience for all students. In addition to addressing the academic gaps in mathematics and in instruction within mathematics, CLD learners continue to lack equitable supports and well aligned science 
instruction to their experiences which may hinder their science development. To address the specific needs of CLD learners in science, specific curricular needs and strategies must be in place to work toward a more equitable experience in the science classroom.

\section{Science Curriculum and Strategies}

Due to the increased pressure of standardized testing, the focus of collaboration with content area educators and ESL/bilingual educators typically is on mathematics and reading rather than science instruction (Gamoran et al., 2003). As academic rigor increases, an achievement gap between ELs and general education students within standardized testing and classroom placement persists within science. According to the state's student report card for 2019 (*State Report Card, 2019), among all eighth grade students, 55\% were proficient and 45\% were not proficient on the state's standardized science assessment. However, among ELs, 13\% were found to be proficient and $87 \%$ were not proficient (see Figure 2.2).

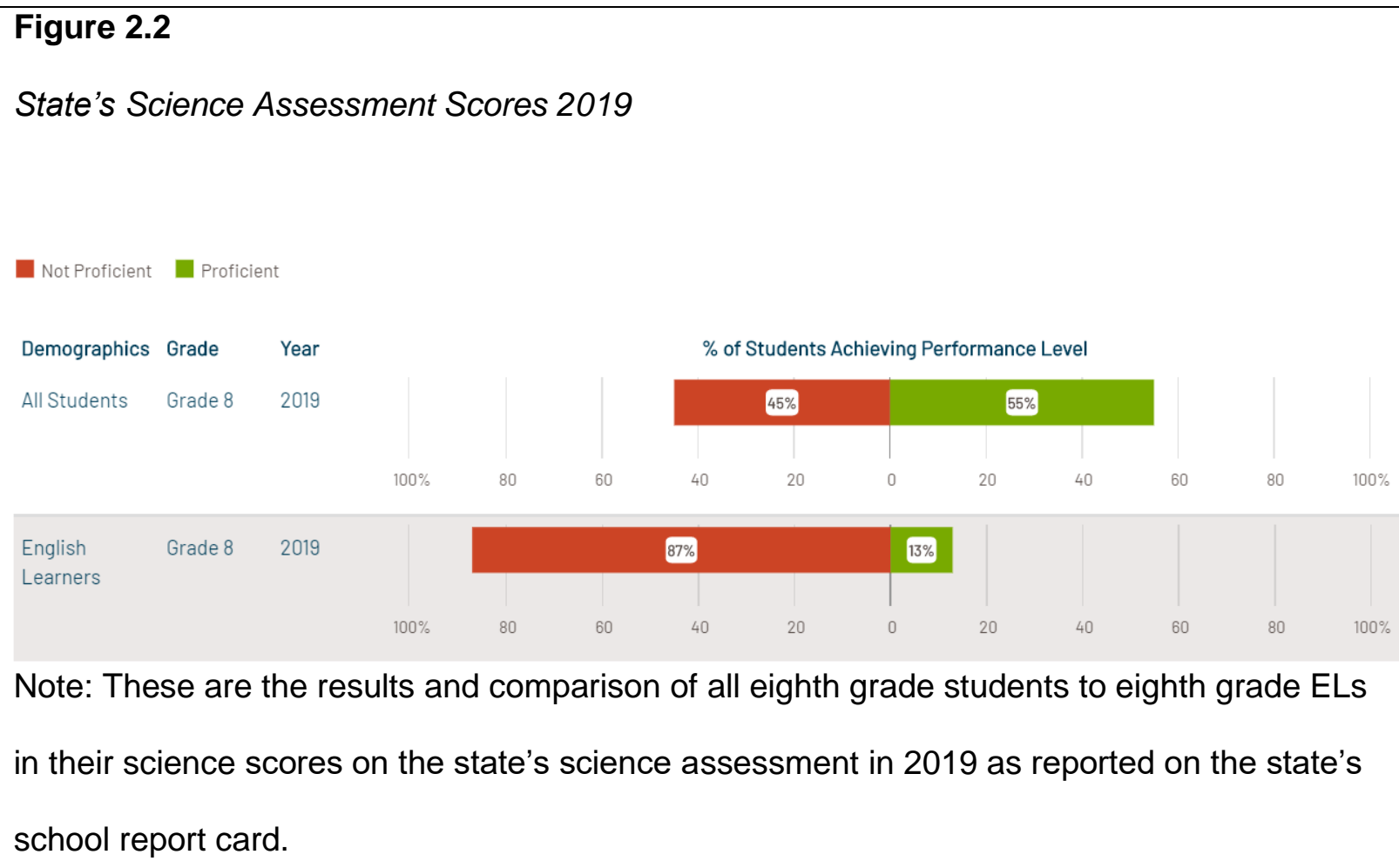

Note: These are the results and comparison of all eighth grade students to eighth grade ELs in their science scores on the state's science assessment in 2019 as reported on the state's school report card. 
This gap suggests that we need to do more with ELs in science classrooms to meet their needs. Lee and Buxton (2013a) outline four domains of strategies to integrate language and content in the science classroom. These include incorporating ESL strategies, facilitating EL's participation in discourse, focusing on a student's native language as an instructional support, and capitalizing on a student's funds of knowledge. "Learning science necessitates learning the language of science; the two are inseparable." (Gottlieb, 2016, p. 79). Effective instruction in the science classroom must consider both the students' cultural and language background in relation to the pedagogical aims. Furthermore, research supports that using a student's native language helps them grow in both content and language in the science classroom (Lee, 2005). Because English continues to be the main language of instruction, educators must adapt their instruction to make content and curricula accessible to ELs; this includes adding in appropriate supports to help them gain access to the key concepts and discourse (Artzi et al., 2019; Lucas et al., 2008).

General education pre-service and in-service educators need training on the integration of literacy and language into a science context. Professional development that shows educators how to imbed language development along with science content is effective in helping science educators meet the needs of ELs (Lee et al., 2008, 2016). However, professional development does not afford science educators these opportunities, and when provided, professional development may focus on ELs in general rather than in specific content areas. This professional development must occur as research shows that English language and literacy instruction within the context of content area instruction is essential to keep ELs from falling behind their non-EL peers (Lee, 2005; Lee \& Buxton, 2013a).

Because science involves discourse and a way of thinking about the natural world that may be new to students, it is key that educators consider the language and literacy needs of their 
CLD learners when planning science instruction (Irby et al., 2018). Embedding language instruction with content area instruction is difficult, and while using sheltered English instruction strategies is important in the science classroom, educators must use more strategies in the science classroom to make learning meaningful to students (Bueno Hernández, 2012). For example, by intentionally teaching the metalinguistic skill of identifying cognates, students' achievement in two languages improves (Gottlieb, 2016). In addition, research identifies vocabulary in one or more languages as a key tool for content knowledge and skill development (Graves et al., 2012). However, general education science educators need training on linguistic supports to help CLD learners make this growth. Learning through doing science not only provides conceptual development but also promotes language development (Miller \& MacDonald, 2015) .

For CLD learners to grow linguistically they must use all domains of language, which include speaking, reading, listening, and writing (Baker \& Wright, 2017); thinking is also included in some texts within these language domains. Furthermore, because the theoretical framework followed in this study is a socio-cultural lens, this study recognizes that social interactions are critical to learning. Therefore, students must have the opportunity to lead groups and to take an active role in their learning and talking; thus, discourse must be a central focus in classrooms. Furthermore, educators must focus on academic discourse as academic language skills mediate content knowledge (Aguirre-Muñoz \& Gregory, 2019).

To engage students as co-facilitators in discourse, many researchers have turned to "Talk Moves" to teach and facilitate classroom discussions. Within the Talk Science Primer, Michaels and O'Connor (2012) set four goals for productive discussions, which include allowing students to share, expand and clarify their own thinking; getting students to listen carefully to one another; getting students to deepen their reasoning, and getting students to think with others 
(p.11). In addition, they suggest nine talk moves to help guide classroom discourse to meet these goals within their science discussions (see Table 2.4 on p. 29). Developers refer to the use of these guiding principles for carrying out rich science discourse as "science talk." The talk moves and focusing on the usage of "science talk" shift classroom discourse from recitation to facilitation of discourse that supports reasoning and understanding of material to a greater depth (Michaels \& O'Connor, 2012). In addition, using “science talk" is a valuable way for teachers to learn about students' funds of knowledge (McLaughlin \& Barton, 2013), which is a key component that will be discussed further in this literature review.

The Next Generation Science Standards (NGSS) call for the use of phenomena and inquiry for science learning. The Framework of the NGSS defines three dimensions of science learning, which include the science and engineering practices, crosscutting concepts, and disciplinary core ideas (Framework, 2012). The practices of NGSS call for rigorous science discourse as they must read, write, and explain their models and explanations (Lee et al., 2013). Furthermore, Lee, Quinn, and Valdes (2013) argue that, "Educators implementing these practices need both understanding of the practices and strategies to include all students regardless of English proficiency" (p. 225). As science educators look for phenomena that they may use in the classroom, considering the backgrounds and experiences of their students is a necessity; this connection to their Funds of Knowledge will be addressed later in this literature review.

Because CLD learners need different learning supports and extensions than non-CLD general education students, educators need tools or strategies to tailor lessons and units for CLD learners. This has led to the development of instructional models designed for inclusivity of CLD learners. 
Table 2.4

Talk Moves

\begin{tabular}{|c|c|}
\hline Goal & Strategies - Talk moves use \\
\hline $\begin{array}{l}\text { Individual students } \\
\text { share, expand, and } \\
\text { clarify their thinking }\end{array}$ & $\begin{array}{l}\text { 1. Time to think } \\
\text { A. Partner talk } \\
\text { B. Writing as think time } \\
\text { C. Wait time } \\
\text { 2. Say more } \\
\text { "Can you say more about that?" } \\
\text { "What do you mean by that?" } \\
\text { "Can you give me an example?" } \\
\text { 3. Clarifying their thinking } \\
\text { "So, are you saying...?" } \\
\text { "So, let me see if I've got what you're saying. Are you saying...? }\end{array}$ \\
\hline $\begin{array}{l}\text { Students listen } \\
\text { carefully to one } \\
\text { another } \\
\text { Students deepen their } \\
\text { reasoning }\end{array}$ & $\begin{array}{l}\text { 4. Rephrase or repeat } \\
\text { "Who can repeat what said or put into their own words?" } \\
\text { "What did your partner say?" } \\
\text { 5. Asking for evidence or reasoning } \\
\text { "Why do you think that?" } \\
\text { "What's your evidence?" } \\
\text { "How did you arrive at that conclusion?" } \\
\text { "Is there anything in the text that made you think that?" } \\
\text { 6. Challenge or counterexample } \\
\text { "Does it always work that way?" } \\
\text { "How does that idea square with "What if it had been a instead?" }\end{array}$ \\
\hline $\begin{array}{l}\text { Students think with } \\
\text { others }\end{array}$ & 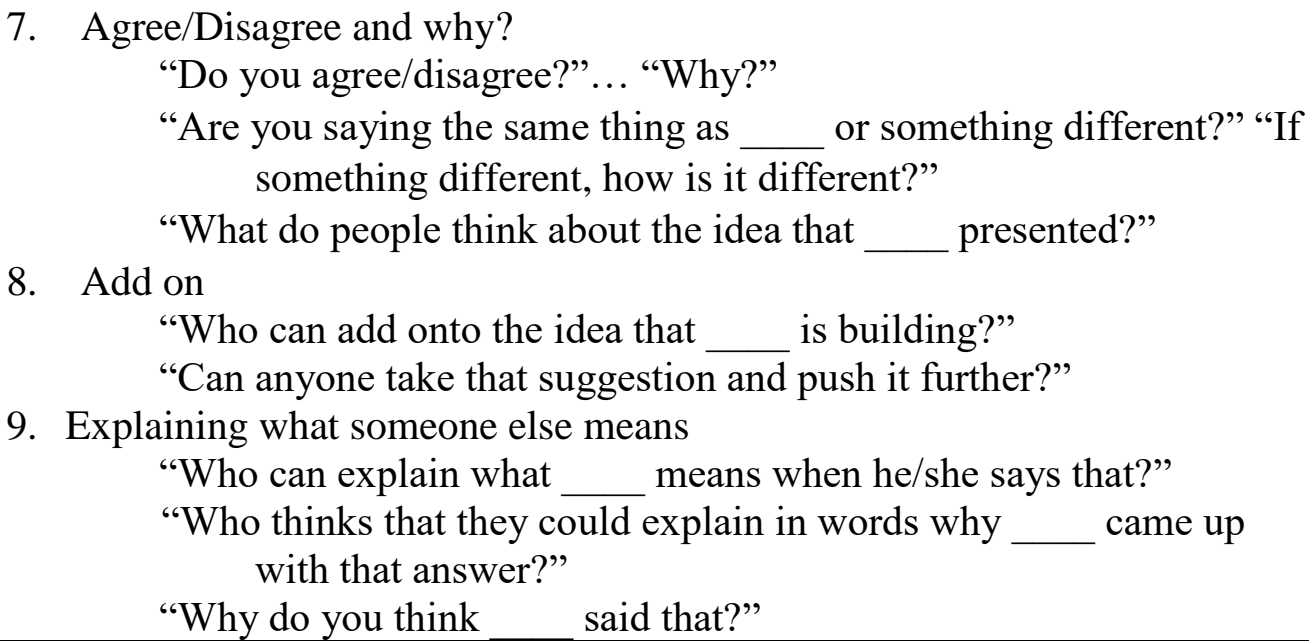 \\
\hline
\end{tabular}




\section{Different Education Models when working with CLD learners}

Although there are a few common models for unit planning for ELs, many general education educators are not familiar with the instructional models, and researchers have conducted little research to see the effectiveness of these unit plans with ELs specifically in science within the time of the implementation of NGSS. However, when looking at professional development for educators, looking at what unit planners may be most beneficial for the instruction of ELs in math and science is critical.

The Cognitive Academic Language Learning Approach (CALLA) is an instructional model that integrates content, and it builds upon the idea that for language growth to occur, classrooms must meet four condition. These four conditions include an environment with high expectations for language minority students, integrating academic language development with content area instruction, consistent and continuous professional development for educators focusing on advancing the academic success of ELs, and having an assessment approach that helps educators plan effectively for ELs (Chamot, 2009).

Within the CALLA model, educators plan for five phases, which include preparation, presentation, practice, self-evaluation, and expansion. This focus on development of language in the content areas of science, mathematics, and social studies, bridges language and content. The focus of the model is on three elements, which include content topics, improving academic language skills, and the teaching of language learning strategies (Chamot \& O’Malley, 1994).

Another instructional model that educators frequently use with ELs is the Sheltered English Observational Protocol (SIOP) model. The purpose of the SIOP model is to "systematically and consistently teach both content and language in every lesson" (Short et al., 2011, p. 13). This model includes eight components and thirty features and is a common model 
used when instructing ELs. The eight components of SIOP include preparation, building background, comprehensible input, strategies, interaction, practice/application, lesson delivery, and review/assessment.

When the SIOP model has been taught through intensive professional development and then carried out with support to ELs, reading achievement improved (E. McIntyre et al., 2010). Backward planning, intentional vocabulary development, and analysis of EL accommodations require educators to unit plan specifically for ELs. The SIOP model is designed to be functional for all content areas. However, one of the main components of SIOP is to frontload vocabulary and clearly state the learning objectives at the beginning of lessons, which is in conflict with the nature of inquiry-based science instruction (Weinburgh et al., 2014). The CALLA model also uses this strategy for making language comprehensible for ELs. However, for a science educator who is using inquiry-based instruction, these models may be difficult to layer into unit development.

The 5R Instructional Model integrates language instruction and content, specifically in the area of science (Silva et al., 2012). The 5R Instructional model stages include: replace, reveal, repeat, reposition, and reload. The strategy emphasizes the use of scaffolded science inquiry to provide a context for the development of language. The use of questioning, phenomena, and student engagement is also the foundation of the work of the Next Generation Science Standards' (NGSS) unit plan development. When the 5R model was used, ELs improved their math and science standardized test scores (Weinburgh et al., 2014).

Within this approach, the educator explicitly teaches language under each of the five Rs. During the replace stage, educators teach new academic terms to replace the words that the students currently use when describing the phenomenon they are observing. In the reveal stage, 
educators describe new language that the students do not currently have words to describe. In addition, the educator provides terms to the students as they observe the science content unfolding. In the reposition phase, educators are directly teaching the discourse of science versus the discourse of everyday language. Educators model this change in discourse in this phase so that students can make their descriptions of the science activity more concise as is modeled in science text. In the repeat stage, students continually repeat terms as language learners need the repetition of language and continual use. The repetition, both auditory and orally, is beneficial when acquiring new academic vocabulary. In the final phase, reloading, the students revisit all of the academic vocabulary, formally define the terms, and add them to a word wall. This is also when educators introduce cognates. Educators develop the academic language that is essential to the understanding of concepts in a supportive way. After conducting research with the 5R model and ELs, this model enables students to develop both the academic and transitional language to successfully engage in science discourse (Silva et al., 2012).

In addition to these frameworks is the biliteracy framework in which native language is layered into instruction and a focus on bridging is included within the content area classroom. "Effective biliteracy instruction enables bilingual learners to use reading, writing, listening, and speaking for a wide range of purposes in two languages" (Beeman \& Urow, 2013, p. 2).

Teaching for biliteracy (Beeman \& Urow, 2013) embraces three sociolinguistic premises that underlie how monolingual literacy instruction differs from bilingual or multilingual literacy instruction; these include:

1. Spanish in the United States is a minority language within a majority culture.

2. Students use all of the languages in their linguistic repertoire.

3. Spanish and English are governed by distinct linguistic rules and cultural norms. 
Although ideally this framework and bilingual support and inclusion is provided at all grade levels and within all content areas, for the purpose of this study for general education teachers, an awareness of a biliteracy framework is necessary as it can be layered into science and math classrooms and supported through co-teaching.

Educators must have knowledge about unit plans or unit frameworks that address the unique needs that CLD learners bring to the classroom. A few of these models have had research conducted with them, but there has not yet been a study to say which model is most or least effective. General education educators who are trying to lesson plan for CLD learners need guidance on unit planning uniquely designed to meet their needs. Having curriculum aligned to standards and that takes into account the unique characteristics that CLD learners bring to the classroom allows them to grow both linguistically and within their content knowledge. However, having a unit design that only addresses their linguistic needs is not enough to make connections to the math and science classrooms.

\section{Identity}

There is an equity problem in science and math that goes beyond adding in linguistic supports into math and science unit planning. When schools define the equity problem as an achievement gap, they imply that students simply need to know the content to "fix" the problem. Therefore, this implies that standardized test scores measure whether the problem is "fixed." This deficit lens does not account for other factors such as how a student connects with science (Carlone et al., 2011). However, because it is easier to measure and fix achievement, achievement is often described as the desired outcome of education (Carlone et al., 2011; Jordan, 2010). Earlier research studies that focused on identities suggest that a youth's perception about 
self, science, and the work of scientists need to be focused on to understand the process of developing STEM identities (Aschbacher et al., 2010; Kang et al., 2019; Kim et al., 2018).

Even when educators see a student as successful, possibly through test scores or grades, in STEM-based learning activities, many students of color are not pursuing STEM fields. Although many are finding success in the classroom, students do not identify with STEM fields, and they often do not feel recognized for the contributions that they bring to the STEM classrooms (Archer et al., 2013; Hill et al., 2010; Osborne et al., 2003). In addition, when students do not identify themselves within science and math or have educators who view them without a math/science identity, their engagement and academic achievement can be affected (Gholson \& Wilkes, 2017; Osborne et al., 2003; Singh et al., 2002).

When looking at science and math classrooms, educators must move beyond lesson planning that fails to challenge the curriculum they teach and the structures in place that either affirm or deny identity development in science and math. Educators must also take into consideration the institutional and social structures that may be barriers to the success of diverse identity affirmation is occurring within STEM classrooms. "Students may not see themselves as a part of that community, they may not feel welcomed, or they may not be recognized for the assets that they bring to STEM" (Kang et al., 2019, p. 419). Furthermore, identity development within math classrooms is critical because identity is "an integral part of mathematical proficiency and because of its relationship to persistence in the field" (Bishop, 2012, p. 37); I take this to also be true in the other STEM fields. I am taking from bodies of research with identity to define identity as one's affiliation and feeling toward mathematics and science as well as their sense of competency in mathematics and science (Turner et al., 2013). 
"Although the process of identity development is an individual one, it is a process that is socially situated, giving rise to meanings and positionings that are part of the social world." (Brickhouse et al., 2000, p. 444). "Students actions then become an expression of their social identities because it was their social identities that have organized their activity." In addition, identities affect how we engage or choose to engage in activities and play a key role in our attitudes, dispositions, emotional development, and sense of self, including in the content areas (Bishop, 2012).

Because I take the position that learning is a social activity, failure to address identity development within math and science classrooms, leads to less equitable learning opportunities for all students. Identities are dynamic and are situated and negotiated in our interactions with others and spaces; therefore, our identities are as much to do with not only our self but also in relation to others (Bishop, 2012). Because students' identities are not static, to fully grow, embrace, and learn mathematics and science, educators must affirm students' science and math identities in the classroom. Having a positive mathematics disposition or identity gives students the willingness to attempt challenging math problems (Bishop, 2012); I extend the importance of this disposition and identity into the science classroom as well. "Learning, broadly conceived, is identity formation, which occurs through agentic action, rather than identities being a byproduct of learning" (Hatt \& Urrieta, 2020, p. 3); identity and learning are intertwined and linked. When educators focus solely on a student's linguistic needs but fail to recognize their unique cultural and social needs, they neglect their cultural and social identity, which can help learners gain confidence and feelings of capability toward learning and enacting change in the classroom and world around them (Yoon \& Uliassi, 2019). “As students transform their identities, the requisite knowledge and skills for being a part of the new communities are learned. Thus, if students are 
to learn math and science, they must develop identities compatible with scientific and mathematical identities. Individual identity is not necessarily either single or stable" (Brickhouse et al., 2000, p. 443).

In addition, actions of the students are expressions of their social identities (Brickhouse et al., 2000). When designing activities that are affirmative toward diverse students, educators must look critically at the pedagogical practices in their STEM classrooms. Prior studies suggest that inquiry-based, problem-solving activities about relevant and issues that matter to students of color positively affect their identification with STEM (Barton, 1998; Brickhouse \& Potter, 2001; Kang et al., 2019). However, many classrooms continue to use projects and activities geared toward middle-class white students. To find ways to change their instruction and pedagogical practices in the classroom to affirm identity, educators must view their students through an assetbased lens and build upon their lived experiences to allow students to see themselves within the math and science classrooms and fields.

Researchers have linked identity and the perception of smartness. "The figured world of smartness is located inside us, not as a biological function connected to our brains, but, instead, as a cultural practice we use to give meaning to others and to ourselves" (Hatt, 2007, p. 158). Furthermore, smartness is tied to an academic identity that helps shape a student's perception of efficacy, ability, and success in relation to their academic potential, performance, and achievement (Hatt, 2012). Although linked, I will address smartness in more detail in a later section of this literature review.

In addition, challenging the models of who is presented as a math and/or science person is a critical component of STEM work. Breaking down the stereotypes of who is involved in STEM and their perceptions of STEM people can be critical in helping students feel they can 
identify with STEM fields (Banchefsky et al., 2016; Betz \& Sekaquaptewa, 2012). Making educators aware of the need to show representation of diversity in STEM as well as the importance of layering in different perspectives into the STEM curriculum places identity at the center of STEM classrooms.

When looking at a sociocultural perspective of education, educators must also analyze the frameworks in which we address learning and create experience for our students from diverse backgrounds. Without a deeper understanding of social equity frameworks, educators run the risk of continuing to marginalize our diverse students. By creating units and lessons that are equitable for students, educators move toward an affirmation of the identity of students.

\section{Social Equity Frameworks}

When thinking on schools' inclusionary practices, educators often refer to efforts such as months being set aside to recognize marginalized groups, such as Black history month, Hispanic heritage history month, and Women's history month. These are attempts within schools to show that all students are welcome and included in the classroom space. However, despite these attempts, many students from marginalized groups still feel unwelcome and not included in our $21^{\text {st }}$ century classrooms (Childs, 2017). In addition, these practices, created in the vision of embracing multiculturalism, often put students at risk of being part of a system in which students see their culture on display for a limited amount of time rather than woven throughout their entire education experience. These months are attempts to "connect" the curriculum with our diverse learners rather than include them in the entire curriculum. "Learning communities and educational systems must do better to include the values, perspective, and culture of all who are present and contributing members in that community [school]" (Childs, 2017, p. 32). 
To be effective educators for all students, we must move beyond creating lessons that are in risk of promoting tokenism and stereotypical examples of inclusion and seek to find ways to challenge the status quo and the systems in place that put our students at risk of not receiving an education that includes them. Furthermore, these inclusions of culture are often left out of the science and mathematics classrooms.

When looking at how to meet the needs of all students in diversified classrooms, we must equip educators to reach for educational equitability to make both social and academic growth. Educators must be prepared with strategies, mindsets, and tools to help students grow. Researchers focused on social equity frameworks seek to provide more equitable educational opportunities and experiences for students of diverse backgrounds. Although there are many social equity frameworks, I will focus on multicultural education, culturally responsive teaching, culturally relevant pedagogy, and culturally sustaining pedagogy (see Figure 2.3).

\section{Figure 2.3}

Social Equity Frameworks

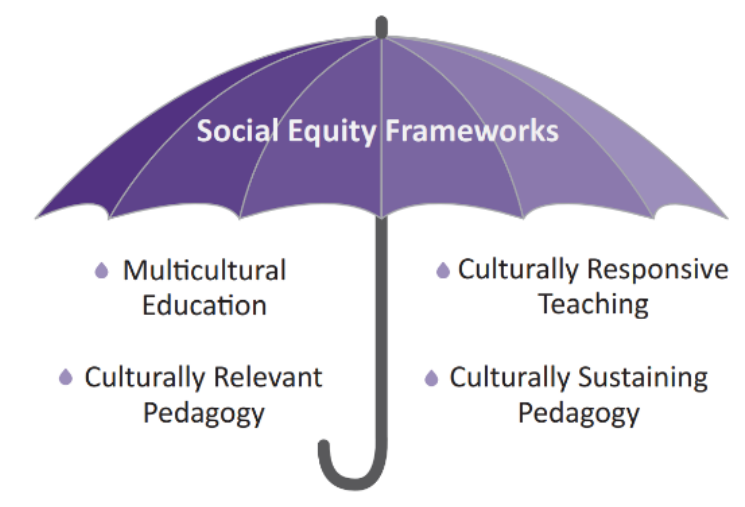

Note. Think of an umbrella in which social equity frameworks is the overarching term. This is not an exhaustive list of social equity frameworks but are the frameworks focused on in this literature review. 
These frameworks provide a deeper focus on developing cultural connections within the classrooms. To meet the needs of our students, educator education programs and professional development experiences must also evolve to meet the needs of the learners within our classrooms. Understanding the frameworks is essential as we encourage more equitable educational experiences for students within mathematics and science classrooms.

"Equal education has been just as elusive as equal justice, equal voting rights, and equal opportunities in general" (Nieto, 2017, p. 2). Throughout history, scholars have looked for ways to make education more inclusive of diverse students. Multicultural education emerged as a first step to "equalize" the education system by attempting to change the educational outcomes of African Americans and other children long denied an equal education (Nieto, 2017). It sought to challenge deficit thinking and deficit discourse that challenged communities and students of color.

In addition to race and ethnicity, movements within multicultural education have sought to expand the umbrella of multicultural education from solely race and ethnicity to the inclusion of gender, social class, language, religion, and ability (Nieto, 2017). Moreover, rethinking the goals and visions of education have transformed the earlier notion of what it meant to provide a multicultural education experience.

The goals of multicultural education may vary based on who defines it and as multicultural education continues to evolve.

Banks (n.d.) identifies five dimensions of multicultural education, which include content integration, knowledge construction process, prejudice and reduction, equity pedagogy, and empowering school culture and social structure (see Table 2.5). 


\section{Table 2.5}

Dimensions of Multicultural Education (Bank, n.d)

\begin{tabular}{ll}
\hline \multicolumn{1}{c}{ Dimension } & \multicolumn{1}{c}{ Description } \\
\hline Content integration & $\begin{array}{l}\text { Usage of examples, issues, and content that reflect a variety of } \\
\text { cultures } \\
\text { Knowledge construction } \\
\text { process }\end{array}$ \\
$\begin{array}{l}\text { Help students understand and break down their biases, frames of } \\
\text { reference, and perspectives within disciplines }\end{array}$ \\
$\begin{array}{l}\text { Prejudice and reduction } \\
\text { Ability to create lessons that help students to develop a positive } \\
\text { view toward diverse groups }\end{array}$ \\
$\begin{array}{l}\text { Present when educators adapt their teaching to promote the } \\
\text { academic achievement of students from diverse cultural, racial, } \\
\text { and social-class groups }\end{array}$ \\
$\begin{array}{l}\text { Empowering school } \\
\text { culture and social } \\
\text { structure }\end{array}$ & $\begin{array}{l}\text { Created when the school transforms the culture and organization } \\
\text { of the school to create a space of equality for all students }\end{array}$ \\
\hline
\end{tabular}

This approach brings content and pedagogical practices that are inclusive of traditionally marginalized groups to the center of curriculum rather than the edges so that educators approach concepts, events, and issues from a perspective that is inclusive to more than the mainstream group. When looking at improving the experience of CLD learners in our classrooms, educators must have an understanding of the importance of these frameworks.

At the center of every child is their culture and culture is a central component for all learning (Gay, 2010). As the research evolves, so have the frameworks, as scholars seek to create better and more inclusive learning environments for all learners. Culturally relevant pedagogy (CRP) and culturally responsive teaching (CRT) build upon the ideas presented by multicultural education. Educators who celebrate and adopt CRP and CRT practices recognize that students who come from diverse backgrounds bring unique experience and knowledge into the classroom and seek to build on these experiences and knowledge banks. They seek to build bridges between 
their experiences, what students need to learn, and their cultural backgrounds. "In an increasingly diverse society, all students benefit from learning to honor their own and one another's cultural heritage and lived realities" (Muñiz \& America, 2019, p. 11).

Although related, culturally relevant pedagogy and culturally responsive teaching differ. Ladson-Billings $(2002,2007)$ coined the term culturally relevant pedagogy to describe the ways and forms in which educators look to engage students whose backgrounds, cultures, languages, and experiences differ from the "majority" culture. Schools unintentionally and intentionally exclude minority students from the mainstream settings. Educators make a commitment to cultural competencies, high expectations for all, and position themselves as both facilitators and learners when they embrace a culturally relevant pedagogy (Samuels, 2018). Ladson-Billing's original work focused on the successes a student must feel. Her three main themes included that teaching must yield academic success, must affirm and develop positive cultural identities, and must support a student's ability to understand and critique inequities.

Geneva Gay built upon this framework but placed a greater emphasis on the practices and strategies employed by educators to meet the needs of diverse learners. This emphasis on the teaching practices used by educators we refer to as culturally responsive teaching. Culturally responsive teaching recognizes that academic knowledge and skill development is more meaningful and comprehensible when students themselves experience the learning or when learning occurs in the framework of the student (Gay, 2002; Özüdogru, 2018). Cultural responsive teaching is about "weaving together rigor and relevance" (Muñiz \& America, 2019).

Within this framework, educators empower students to grow intellectually, emotionally, politically, and socially through using cultural connections to grow knowledge, skills, and attitudes toward learning (Ladson-Billings, 1994). Furthermore, specific content areas have 
embraced this responsiveness into their content frameworks, such as Responsive Middle Level Mathematics Teaching (RMLMT) which focuses on mathematics teaching for "all young adolescents that advances their mathematical thinking, promotes equity and social justice, and attends to their developmental characteristics, needs, and interests" (Ellerbrock \& VomvoridiIvanovic, 2019, p. 47). This framework combines developmentally responsive teaching with culturally responsive mathematics teaching. Educators who embrace a culturally responsive classroom focus on instructional engagement, culture, language, and racial identity, multicultural awareness, high expectations, critical thinking, and social justice (Aceves \& Orosco, 2014). See Table 2.6.

Table 2.6

Themes of Culturally Responsive Teaching (Aceves \& Orosco, 2014, p. 9-12)

Theme

Description

Instructional

Educators integrate students' cultural knowledge within lessons.

engagement

Culture, Language, Educators understand that the aspects of their own culture a student's and Racial Identity cultural and linguistic background affect how they learn.

Multicultural Educators are critically aware of their own culture and use a

Awareness multicultural lens to better appreciate and seek to understand the aspects of their students' cultures such as history or lifestyle.

High Expectations Curricula should contain activities that are rigorous, engaging, and take careful considerations of students' cultures.

Critical Thinking Educators encourage the development of critical thinking skills through culturally and linguistically challenging tasks.

Social Justice Educators should challenge and guide students to become more aware of social inequities and should encourage students to seek to find solutions to these inequities. 
As both in-service and pre-service educators focus on understanding the elements of cultural responsiveness, professional development opportunities will need to emerge. Villegas and Lucas (2007) identify six areas of focus to include in this type of professional development.

1. Understand how learners construct knowledge

Support student learning through building bridges between what they already know and what they will be learning by taking a constructivist view toward teaching.

2. Learn about students' lives

Go beyond surface level elements of culture and social groups that encourage the perpetuation of stereotypes and single-story narratives by learning about their students' families and personal lives.

3. Being socioculturally conscious

Have an awareness that life experiences and other factors, such as race, gender, ethnicity, and social class influence a person's worldview.

4. Holding affirming views about diversity

Have faith in students' ability to succeed and have an asset-based lens when viewing students' cultures and families

5. Using appropriate instructional strategies

Allow students to have voice, take a facilitator role in the classroom, and provide the needed supports for growth, such as native language support, social emotional learning, and relevant cultural examples.

6. Advocating for all students

See themselves as part of a larger community of educators who seek to make education more equitable for all students. 
Along with professional development, educators must actively seek ways to develop competencies (Table 2.7) that align with being a culturally responsive educator.

\section{Table 2.7}

Educator Competencies (Muñiz \& America, 2019)

\begin{tabular}{|c|c|}
\hline Educator Competency & Description \\
\hline Reflect on one's cultural lens & $\begin{array}{l}\text { Actively seek to develop cultural competency to } \\
\text { understand and appreciate the history and experiences of } \\
\text { other cultures. }\end{array}$ \\
\hline $\begin{array}{l}\text { Recognize and redress bias in the } \\
\text { system }\end{array}$ & $\begin{array}{l}\text { Seek to deepen the understanding of how different } \\
\text { social markers influence the educational experiences of } \\
\text { their students and advocate for equitability. }\end{array}$ \\
\hline $\begin{array}{l}\text { Draw on students' culture to share } \\
\text { curriculum and instruction }\end{array}$ & $\begin{array}{l}\text { Complement the traditional curriculum with texts, } \\
\text { lyrics, perspectives, and other resources to reflect the } \\
\text { cultural experiences of their students. }\end{array}$ \\
\hline $\begin{array}{l}\text { Bring real-world issues into the } \\
\text { classroom }\end{array}$ & $\begin{array}{l}\text { Connect how the knowledge and skills that educators } \\
\text { teach connect to the real world and the families of their } \\
\text { students. }\end{array}$ \\
\hline $\begin{array}{l}\text { Model high expectations for all } \\
\text { students }\end{array}$ & $\begin{array}{l}\text { Adopt the view that all students are capable of academic } \\
\text { success and understand that marginalized students are } \\
\text { vulnerable to stereotypes that may affect the student's } \\
\text { success. }\end{array}$ \\
\hline $\begin{array}{l}\text { Promote respect for students' } \\
\text { differences }\end{array}$ & $\begin{array}{l}\text { Create classroom environments that are respectful, } \\
\text { inclusive, and encourage learners to value the cultures } \\
\text { of one another. }\end{array}$ \\
\hline $\begin{array}{l}\text { Collaborate with families and the } \\
\text { local community }\end{array}$ & $\begin{array}{l}\text { See yourself as a member of the community, assume } \\
\text { that families all want to be involved in the success of } \\
\text { their children, and seek to give back to the community } \\
\text { in which you serve. }\end{array}$ \\
\hline $\begin{array}{l}\text { Communicate in linguistically and } \\
\text { culturally responsive ways }\end{array}$ & $\begin{array}{l}\text { Seek to understand how culture impacts both verbal and } \\
\text { nonverbal communication and work to } \\
\text { honor/accommodate the home languages of students. }\end{array}$ \\
\hline
\end{tabular}

As scholars seek to find ways to be more inclusive of all students, an expansion on this work continued with the development of culturally sustaining pedagogy (CSP). Paris and Alim (2014), argue that in addition to using culturally responsive practices, educators must also seek to 
"perpetuate and foster linguistic, literate, and cultural pluralism as part of the democratic project of schooling and as a needed response to demographic and social change” (p. 85). Furthermore, educators should "sustain the cultural and linguistic competences of youth while also teaching them about dominate cultural and linguistic competences" (Brinegar et al., 2019, p. 7).

Educators within classrooms that embrace the CSP framework move away from pedagogical practices aligned with cultural hegemony and find ways to recognize, validate, and honor the culture of students of color; they seek to decenter whiteness as the source of success and achievement within the classroom. Additionally, "CSP seeks to perpetuate and foster-to sustain-linguistic, literate, and cultural pluralism as part of schooling for positive social transformation" (Paris, 2017, p. 1). In addition to CRP and CRT, CSP pushes to reframe learning to emphasize the importance of maintaining and encouraging the maintenance of the diverse culture rather than simply acknowledging the other culture is present by valuing and maintaining the multiplicity of the students' cultural and linguistic identity (Wynter-Hoyte et al., 2019).

CSP also recognizes that not only is culture fluid and changing, but the ways in which students enact with culture is also dynamic, consistently changing, and educators should view these with an asset-based lens. To build an inclusive learning environment, students' cultural, social, educators must value linguistic resources (Wynter-Hoyte et al., 2019). Educators, who teach within a CSP framework, give opportunities for students to embrace and respect their culture while also giving opportunities for students to challenge the inequities in systems that oppress marginalized groups.

Within these frameworks, educators must understand that cultural connections are complex and necessary. Continuing their experience to understand intersectionality and critical pedagogy would be an essential next step. All four of these frameworks seek to create 
classrooms that challenge the way that schools and educators have operated. Social equity frameworks provide guidance for educators to challenge a system that attempts to create culturally hegemony that perpetually marginalizes our students of color.

To create spaces that utilize a culturally sustaining framework of teaching, educators must seek ways to build upon the vast amount of knowledge that students bring into the classroom. They must move beyond deficit-based thinking and change their view of how they define smartness and knowledge in their classrooms by tapping into students' lived experiences. Funds of Knowledge, Funds of Identity, and Smartness

"Unwittingly, educators perpetuate the notion that science is difficult, that one has to be smart, and that it is not for everyone" (Licona, 2013, p. 863). By tapping into only one type of learner and one type of background, we fail to build upon the vast amount of knowledge that our diverse students bring into the classroom.

When looking at the changing demographics of schools, the rise in the number of CLD students, and the perceived achievement gap between general education students and English learners, schools must continuously change to meet the changing needs of United States' classrooms. One approach to curriculum development is using the Funds of Knowledge approach. The concept of Funds of Knowledge is built upon the premise that people are competent, have knowledge, and have this knowledge because of life experience (González, Moll \& Amanti, 2005a). In addition, funds of knowledge are the knowledges that families pass down throughout the history of a family and encompasses their lived experiences. In addition, the term funds of knowledge refers to "historically accumulated and culturally developed bodies of knowledge and skills essential for household or individual functioning and well-being" (Moll et al., 1992, p. 133). 
The Funds of Knowledge approach not only actively seeks to rebut the model of deficit thinking within schools, but it also incorporates educators in conducting and applying research and linking theory to practice (Hogg, 2011). One of the main components of funds of knowledge work is for educators to visit some of the households of their students with the goal of discovering the families' funds of knowledge in a deliberate effort to connect the content of their curricula with the students' experiences, skills, and knowledge (Jovés et al., 2015). Within these visits, educators begin to build mutual trust and develop collaborative relationships with the family. Educators ask about the history of the family, focusing on work history, interests, literacy practices, hobbies, etc. (Esteban-Guitart et al., 2019). Following the discovery of this knowledge, educators create projects and curricula that build and connect to these funds. In a funds of knowledge classroom, these interests motivate much of the teaching and learning; furthermore, the students obtain knowledge rather than the teacher imposing the knowledge onto them (Moll et al., 1992).

Science instruction within the Next Generation Science Standards is built upon the concept of exploring and investigating phenomena (Framework, 2012). In addition, STEM projects focus on investigating phenomena and real-world problems. However, often educators and curriculum developers do not build upon and leverage the life experiences that students bring to the classroom and do not view these experiences as connected to the science nor math that is being taught in the classroom. This negative view of students' funds of knowledge lead to negative implications for lesson planning (McLaughlin \& Barton, 2013). Through this deficit lens, educators view students' cultural resources as incompatible with and barriers of deep understandings of natural phenomena (Lee \& Luykx, 2007). Furthermore, "knowledge gained from family, community, and peers interferes with learning because schools view this knowledge 
as a source of misconceptions, and lived experiences contradict or are otherwise incongruent with canonical science" (McLaughlin \& Barton, 2013, p. 30).

However, we must challenge educators to look at how they identify smartness in their classrooms and view the funds of knowledge that their students bring to the classroom. Because a funds of knowledge approach is driven by the view that students come with a vast amount of knowledge, "the purpose of instruction thus becomes to develop more robust scientific understanding through refinement of students' prior knowledge and experiences rather than through their replacement” (McLaughlin \& Barton, 2013, p. 15).

Due to deficit lenses that do not value the funds of knowledge that students possess, students are often navigating dual identities between their lived experiences and their perceived knowledge. Instead of building on these knowledges that families use on a daily basis, these skill sets are not recognized in US schools nor seen as a starting point to build on and to support immigrant students. Instead, schools relegate ELs to the non-gifted and lower track classes where science educators teach from an abstract, non-contextual, and therefore less engaged basis (Licona, 2013). A Funds of Knowledge approach enables education to move beyond rote-like structures of schooling and transform diversity in the classroom into pedagogical assets (González \& Moll, 2002). Furthermore, a Funds of Knowledge approach assumes a sociocultural conceptualization of both teaching and learning (Moll, 2014). The student is an active member of their learning, and their experiences build the foundation in which they learn.

Youth from non-dominant backgrounds have repertoires of cultural practices that are highly relevant to doing science and math. Educators should view cultural practices and knowledge as a part of the cultural identity of the classroom and they can leverage this toward developing practices in the science classroom that connects to both the discipline and home 
(McLaughlin \& Barton, 2013, p. 15). In addition, educators should use their funds of knowledge to lay a foundation for higher level thinking in the content areas. Moll, Amanti, Neff, and González (1992, p. 133) provided examples of funds of knowledge categories including agriculture and mining, material and scientific knowledge, economics, economics, medicine, household management, and religion. These provide the base for educators as they look for possible projects ideas when interviewing families and/or students. By capitalizing on household and other community resources, classroom instruction can surpass the quality of rote-like instruction students may experience in schools (Moll, et al., 1992). Students' everyday knowledge and experiences are foundational for meaning making in science (González \& Moll, 2002; McLaughlin \& Barton, 2013). I also hold the same regard to their ability to build upon this knowledge in math.

“Integrating students' out-of-school funds of knowledge into classroom practices is a powerful tool for supporting all students-but even more so for those from traditionally marginalized populations" (Johnson \& Johnson, 2016, p.117). When thinking on the inclusion of funds of knowledge into one's curriculum, educators must tap into the vast amount of knowledge that the student already possesses. Moreover, educators must develop the ability to both listen to and learn from their students; this ability helps educators transform their lens toward diverse students. "To take the cultural knowledge of less powerful 'others' seriously means to seek learning assets in these cultures" (Zipin, 2009, p. 319). Tapping into students' experiences, interests, and backgrounds leads to greater engagement and affirmation. By using a Funds of Knowledge approach, learners learn because they are motivated by their needs, interests, and curiosity (Esteban-Guitart, Subero, \& Brito-Rivera, 2015). When students are able to learn from their experiences, educators affirm their identities. 
Emerging from Funds of Knowledge is the development of a focus on Funds of Identity, which is a crucial component of funds of knowledge. Funds of identity is based on the premise that people have experienced not only their household's funds of knowledge, but they also have their own experiences that have helped them become who they are (Subero et al., 2017).

Focusing on funds of identity is a crucial component of funds of knowledge. Esteban-Guitart and Moll (2014) explain that, "identity is not a thing, rather a social construct vaguely referring to a vastly complex set of phenomena" (p. 32). By focusing on funds of identity through instruction that affirms their identities, students expand and amplify their identities (Subero et al., 2017).

Although funds of knowledge and funds of identity are related and intertwined, there are differences, but educators must integrate both to fully meet the needs of the CLD students they serve. Subero, et al., (2017) describe the differences by breaking apart their definition, unit of analysis (source) and who uncovers the information (see Table 2.8).

\section{Table 2.8}

Funds of Knowledge vs Funds of Identity (Subero et al., 2017, p. 253)

\begin{tabular}{lll} 
& Funds of Knowledge & Funds of Identity \\
\hline Definition & $\begin{array}{l}\text { Repertoire of resources (skills, ideas, } \\
\text { knowledges) that families accumulate } \\
\text { and use to maintain their way of life }\end{array}$ & $\begin{array}{l}\text { Significant people, institutions, } \\
\text { cultural artifacts, geographical } \\
\text { spaces and meaningful practices, } \\
\text { passions and interests encrusted } \\
\text { in a learner's self-definition }\end{array}$ \\
Unit of analysis: source & $\begin{array}{l}\text { Household (family and its social and } \\
\text { cultural networks, practices, and lived } \\
\text { experiences }\end{array}$ & $\begin{array}{l}\text { Learner meaningful practices } \\
\text { and experiences from his/her } \\
\text { transactions across time and } \\
\text { contexts }\end{array}$ \\
& $\begin{array}{l}\text { Ethnographic analysis of student's } \\
\text { Student's creation of identity } \\
\text { texts, mobile identity tools, } \\
\text { primarily to interview parents }\end{array}$ & $\begin{array}{l}\text { inscriptions such as self-portrait, } \\
\text { multilingual texts, etc. }\end{array}$ \\
\hline
\end{tabular}


Esteban-Guitart and Moll (2014, p. 37), note four critical components of identity. First, identities comprise those skills, people, knowledge, practices, and resources that people have accumulated and use through their activities and social interaction. Second, their artifacts (such as flags or crosses) are both internalized and externalized. Third, people form identities through these acquired resources by engaging in social activities and by watching other members interact; in addition, it is in these specific social institutions (work, school, church, etc.), in which they form their identities. Finally, identity is social in origin, and their discourse, narratives, or models of identity are cultural material.

This cultural material that people have access to is their funds of knowledge, but as people use these funds to define themselves, they are funds of identity (Esteban-Guitart \& Moll, 2014). Furthermore, Esteban-Guitart (2012) defines funds of identity as "a set of resources or box of tools" (p. 177). He describes that individuals accumulate the tools within the box over time and that these tools continually develop within your culture. In addition, these tools are socially distributed and essential for the construction of one's identity. Esteban-Guitart and Moll (2014) further describe identity by stating, "identity can be understood as a consciousness device, self-lived experiences, but should also be understood as the objects-technologies-as an externalization, and devices, of one's identity, what we call funds of identity" (p. 35).

While funds of knowledge includes the knowledge and the skills that an entire household has built for the well-being of all, funds of identity develop when people use that knowledge to define who they are (Esteban-Guitart \& Moll, 2014). When educators focus on students' funds of knowledge and funds of identity, learners learn because their needs, interests, and curiosity motivate their engagement and learning (Esteban-Guitart et al., 2015). Tapping into students' experiences, interests, and backgrounds leads to greater engagement and identity affirmation. 
Identities are symbolic, reflexive, and a source of motivation (Esteban-Guitart \& Moll, 2014). In addition, when students are able to learn from their experiences, educators affirm their identities. By focusing on funds of identity through instruction that affirms their identities, students expand and amplify their identities (Subero, et al., 2017).

While Funds of Knowledge focuses on family interviews, Funds of Identity focuses on the use of identity artifacts. These identity artifacts include "texts, drawings, pictures or other cultural tools made by the learners which can be incorporated in school by teachers to connect the curriculum with students' lives" (Esteban-Guitart, et al., 2019, p. 3). Moreover, it is through these artifacts that educators can learn about which people, spaces, and activities are most relevant to the learner, and thus, are constructs of their identity. Esteban-Guitart (2012, p. 177) subdivides funds of identity into five categories. Geographical Funds of Identity include any area or territory such as rivers and mountains. Practical Funds of Identity includes any activity such as sports, music, etc. Cultural Funds of Identity include artifacts such as flags or religious symbols. Social Funds of Identity include significant others such as friends or colleagues. Lastly, institutional Funds of Identity include any social institution such as family, marriages, or the Catholic Church.

The goal for both funds of knowledge and funds of identity work is to overcome deficitbased thinking (Esteban-Guitart, 2012). By drawing upon the research and practices of both Funds of Knowledge and Funds of Identity, educators view students through an asset lens and students are agents in their own learning experiences. "We must develop methodologies that allow us to capture the wealth to be found in the funds of identity..., along with the types of experiences people have, their origins and their sociocultural content" (Esteban-Guitart, 2012, p. 178). In both funds of knowledge and funds of identity work, educators are learners as they seek 
to connect to and learn about their students and their families at a deeper and more meaningful level. Furthermore, to understand funds of identity, one must understand that human beings and their social worlds are inseparable (Esteban-Guitart and Moll, 2014), therefore, human beings cannot separate their culture from the lens in which they are learning.

In addition, Yosso (2005, pp. 77-80) described the experiences that students brought into the classroom as elements of cultural wealth. She broke cultural wealth into six types of capital that students' possess because of their lived experiences. These include Aspirational Capital, Linguistic Capital, Familial Capital, Social Capital, Navigational Capital, and Resistant Capital (see Table 2.9).

\section{Table 2.9}

Cultural Wealth (Yosso, 2005)

\begin{tabular}{ll}
\hline \multicolumn{1}{c}{ Type of Capital } & \multicolumn{1}{c}{ Description } \\
\hline Aspirational Capital & $\begin{array}{l}\text { resilient nature of people who hold onto their } \\
\text { hopes and dreams }\end{array}$ \\
Linguistic Capital & $\begin{array}{l}\text { skills gained through experienced communicating } \\
\text { in more than one way/style }\end{array}$ \\
Familial Capital & the ways that family carry a sense of history \\
Social Capital & $\begin{array}{l}\text { networks of people and support given to } \\
\text { navigate through society's institutions and } \\
\text { more extensive system of relationships to provide } \\
\text { information and reinforce confidence }\end{array}$ \\
Navigational Capital & $\begin{array}{l}\text { skills to maneuver through institutions and the } \\
\text { ability to thrive in hostile/unresponsive } \\
\text { environments }\end{array}$ \\
Resistant Capital & $\begin{array}{l}\text { knowledge and skills fostered through } \\
\text { oppositional behavior that challenges inequality } \\
\text { and asserting oneself in the face of oppression }\end{array}$ \\
\hline
\end{tabular}


Educators should pay attention to how the idea of smartness operates in school to give the opportunity to reinterpret a student's academic performance especially as it relates to students of color (Hatt, 2007). The perception of smartness is often impacted by grades and other artificial artifacts that influence whether a student perceives themselves as "smart" or good at school. These artifacts, such as inclusion in advanced classes, high test scores and/or grades, affects the student's own sense of competency and ability in school (Hatt, 2016). Failure to embrace the identities of students of color paired with the continuation of lack of representation in higher level classes and overrepresentation in special education programming, continues this perception of who possesses smartness in schools. Notions of ability, although often believed to be natural or biological are socially constructed and reified in schools (Hatt, 2016). Furthermore, how a teacher structures smartness and identity impacts how the student envisions their own identity and perception of being smart; both of which are powerful influences on both achievement and engagement (Hatt \& Urrieta, 2020). Failing to center CLD learners' experiences, identities, and cultural wealth, continues this misrepresentation of who is "smart" in schools. This lack of concentration negatively impacts their educational experiences and fails to elevate them to their full potential in school.

"By empowering EL students as classroom leaders and honoring the wealth of cultural capital they bring to school every day, educators can counter the hegemony of academic and linguistic standardization that continues to marginalize culturally diverse students and communities in US schools" (Johnson \& Johnson, 2016, p. 117).

Furthermore, drawing upon students' lived experiences and knowledge enable a connection and engagement to form between their experiences and the school community (González et al., 2005a). Schools should not only seek to integrate more funds of knowledge and 
funds of identity into their classroom spaces, but they should also seek to integrate families into the school space. Family related variables, including parental involvement, are widely recognized as critical factors that influences students' choices, engagement, and identification with science (Archer et al., 2013; Aschbacher et al., 2010). To enhance the educational experience of CLD learners, educators must develop a relationship with the students' families (Johnson \& Johnson, 2016) and find ways to incorporate the family structure in the learning space. Building rapport between home and school is a focus within funds of knowledge work. This rapport helps educators learn more about the families and the students they serve. "The teacher, not the anthropologist, is ultimately the bridge between the students' world, theirs and their family's funds of knowledge, and the classroom experience" (Moll et al., 1992, p. 137). By providing opportunities for engagement by asking questions of families, educators foster the home-school connection and can find ideas for new projects (González et al., 2005).

This work of learning about students' lived experiences and their family's knowledge can change the way that educators view their students and the knowledge they possess through their lived experiences and stories. Rather than relying on stereotypes and assumptions, the Funds of Knowledge approach focuses on households' everyday practices as the best way to learn about the lives and backgrounds of diverse students (González et al., 2005). When working with educators who conducted funds of knowledge training, two distinct shifts occurred in how the educators viewed households. First, the educator's definition of the culture of households shifted, and second, their views on their deficit models of the household changed (González et al., 2005). This inclusion of family and students in the process of developing a comprehensive curriculum for our bilingual students is critical as more studies are linking the important role that family and school relationships can have on a student's school performance and growth (Crosnoe, 2012). 
"Inclusion of the community's language and cultural practices brings the school and the home closer together" (García \& Lin, 2017, p. 11). The use of these practices can also affirm the cultural identity of students and enhance relations between teachers, students, and their parents (González et al., 2005, p. 167). In addition, "involvement of families and elders in the education of their own children is an object of self-empowerment for minoritized communities" (García \& Lin, 2017, p. 11). Furthermore, building upon their funds of knowledge and identity can change their perception of their own smartness.

While focusing on the family and individual identity of each student, it is also important to understand the role of teacher identity and its development.

\section{Teacher Identity}

Teacher identity has been explored from a wide variety of angles including how teachers reinvent themselves during teaching, the narratives that teachers use to describe their experiences, the discourse styles that teachers take part in, and the contextual factors that influence a teacher's practice (Beauchamp \& Thomas, 2009). The role of identity in a teacher's work and practice is complex but a critical factor in how they interact with students. Six domains of teacher identity include self-image, motivation, commitment, self-efficacy, task perception, and job satisfaction (Hanna et al., 2019). Furthermore, Beijaard et al. (2004), identify the following features as components for teachers' professional identity: that identity is an ongoing process of interpretation and reinterpretation, implies both person and context, consists of subidentities, and the importance of agency. This agency is essential as it refers to the needs of teachers being an active member within their professional development.

Teacher identity is not static as their identity may shift due to emotional experiences as well as job and life experiences in different contexts (Beauchamp \& Thomas, 2009). The 
perception of one's identity is important in understanding how identities form and shift. Gee (2000) describes four ways in which identity might be perceived, which include: from one's natural state (nature-identity), from a position recognized by authority (institution-identity), from the discourse of others about oneself (discourse-identity), and from one's practices in relation to external groups (affinity-identity).

Multiple studies have connected a teacher's content knowledge and success to their identification of being a teacher of that content (Chen \& Mensah, 2018; Luehmann, 2007). For example, providing science teachers experiences in which they experience science, gain selfefficacy with science concepts and strengthen their science backgrounds helps the individual better identity as a teacher of science, therefore, shifting their identity to a science teacher. "Identity shifts may occur throughout a teacher's career as a result of interactions within schools and in broader communities" (Beauchamp \& Thomas, 2009, p. 175). Research supports that identifying as a science teacher involves having the educator engaging in practices and experiences that support their understanding of science and their strength as a teacher of science. This is not limited to the field of science; research on language educators finds that an educator's sexuality, race, gender, native language, and the intersectionality of those components affects their identity as a language educator (Lawrence \& Nagashima, 2020). It is critical to provide teachers with multiple opportunities to shape and reshape their teacher identities; this process makes teachers more aware of who they are and how their identities shift through reflection and examination of their changing identities (Avraamidou, 2019). Furthermore, educators must be provided with knowledge to build their self-efficacy with content, and this extends into effective strategies and mindsets when working with CLD learners. 
Identity is not static; thus, teacher professional identity shifts and reforms over time and the causes of these transformations is a result of a diverse range of influences (Noonan, 2019). As teachers engage in different communities, professional development opportunities, and discourse, these shifts may impact how they view themselves as teachers and how they view their students. Teacher communities in which teachers negotiate meaning for their stories and experiences may provide development of teacher knowledge and teacher identities (Schultz \& Ravitch, 2013). In addition, "people construct professional identities in relation to context and experience and in relation to one another" (Schultz \& Ravitch, 2013, p. 37).

Teachers' race, class, and gender inform their relationships with students, educational philosophies, and curricular choices (Brown, 2006); therefore, educators must analyze their own backgrounds to determine the impact that their race and other intersectionalities may have on their relationships within the classroom. Furthermore, teachers bring their racial notions, woven into their identities, into their classroom practices (Brown, 2006), making this a critical component of teacher identity work. However, just like other elements of identity, a teacher's meanings within their racial identities are not fixed and can be addressed through self-reflection and the alteration of their perceptions of their own racial identity and the identity of their students. As many educators do not represent the marginalized populations who they serve in their classrooms, educators must take steps to recognize these biases. To recognize the marginalization of populations by those in the dominant group, "they must examine the embedded racial self-meanings that feed their misrecognitions of the other and their selfconceptions" (Brown, 2006, p. 274).

As teacher identity plays an important role in the practices, choices, and biases of an educator, professional development that focuses on providing experiences that shift and analyze 
these identities may create more equitable experiences for students of color. Non-judgmental discourse spaces where teachers can discuss their ideas, needs, and alternative strategies can help facilitate teacher identity development and encourage the teacher to take risks (J. McIntyre \& Hobson, 2016). Professional development opportunities can give spaces for this discourse.

\section{Professional Development}

Professional development (PD) opportunities vary in type and impact. While one teacher can be greatly impacted by an experience, another can feel their time is being wasted. When activities are planned for educators, providers must consider that educators go through developmental stages within their careers (Trotter, 2006). Providing professional development that use an identity lens gives attention to the past experiences and guiding experiences that impact the ways in which educators teach and filter information (Noonan, 2019).

Professional development should strengthen the knowledge, skills, and practices of an educator, and in turn, the professional development impacts student learning (Bates \& Morgan, 2018). Effective professional development is often not specific enough nor powerful enough to alter a classroom or school (Fullan, 2007). Darling-Hammond, Hyler, and Gardner (2017) outline seven elements of effective professional development. These include focus on content, active learning, support for collaboration, models of effective practice, coaching and expert support, feedback and reflection, and sustained duration. Although professional development can focus on these elements individually, integrating all of these elements into professional development experiences creates more meaningful experiences for educators (Bates \& Morgan, 2018).

In addition to elements that should be woven into professional development, taking into experiences the needs of the involved educators should also be a factor for educator growth. 
Following her research into professional development, Trotter (2006) outlines central themes that should be considered when developing professional development opportunities. These include: adults use experience as a resource, and it cannot be ignored; adults need to plan their own educational paths based on their interests and their classrooms, and the aim of adult education should be to promote individual development be encouraging reflection and inquiry. In addition, effective professional development focuses on specific subject matter, is interactive, and is sustained over time (Parsons et al., 2019). Creating professional development opportunities that incorporate the elements of effective professional development and the critical themes to remember when working with adults is essential for professional development experiences.

In addition, technology has played a role in being able to create more targeted professional development that educators can more flexibly access. When educators perceive ownership of professional development, they are more likely to implement the strategies and online professional development opportunities promote this type of ownership as they can complete it in their own time (Polly \& Hannafin, 2010). For busy professionals, technology enables the learner to complete the training when they have time, and allows them to learn in privacy and pace their learning to meet their needs (Scott et al., 2017). In addition, completing professional development when they have time encourages full participation rather than taking place in the traditional method of completing professional development after school or during a school improvement day. Finally, educators are able to process through and revisit content within the professional development content at their own pace (Wynants \& Dennis, 2018).

To make meaningful development opportunities online, developers must consider format and supports. Best learning occurs when online professional development is embedded in their current work, flexible to make meaningful interactions, and reflection-focused (Parsons et al., 
2019). Breaking down concepts into short, achievable segments that allow the use of reflection and practice activities to provide automatic feedback and enables adaptive learning is beneficial for using technology within a learning community (Scott et al., 2017). Furthermore, online professional development can provide a space to challenge beliefs and create new understandings (Rodesiler, 2017). Educators who participate in online professional development in which there is a social presence and more interaction with others are more likely to participate fully in the online PD (Parsons et al., 2019). Based on the research, online opportunities allow teachers to gain content knowledge, skills, and practices because they participants can work at their own pace and schedule, but the PD is the most beneficial when time is given for reflection and engagement with other PD participants.

By providing professional development that builds the knowledge base and self-efficacy of educators while also providing space for reflection and dialogue, educators benefit. Online professional development gives this space to build knowledge that can be accessed at the convenience of the participant and then used for reflection and dialogue.

Furthermore, it is critical to recognize equity traps during professional development that is focused on equity and improving experiences for marginalized populations. McKenzie and Scheurich define an equity trap as, "ways of thinking or assumptions that prevent educators from believing that their students of color can be successful learners" (2004, p. 601). These conscious or unconscious biases, attitudes, and beliefs toward students of color lead to lowering expectations and the perception that their attitude or background knowledges inhibits their high achievement in school. As described by McKenzie and Scheurich (2004), equity traps include deficit-based thinking, racial erasure in which one is encouraged to not see race, avoidance and employment of the gaze in which teachers felt they were not being as closely watched in diverse 
schools and thus may employ different behaviors than in a predominantly white school, and paralogical beliefs and behaviors in which an educator's beliefs or behavior are internally justified due to the behaviors or attitudes of their diverse students. These four internalized and often unconscious thought processes limit the educational experience of students of color and other marginalized populations. Therefore, to create better conversations and professional development on equity, leaders must be able to recognize and reflect on equity traps in order to begin to reframe thinking by bringing the unconscious to the conscious.

Professional development is also most beneficial when it is sustained over time (Parsons et al., 2019). To train general education educators with strategies and mindset shifts to meet the needs of CLD students in their classrooms is critical to success for both the educators and the students. To continue their professional development, co-teaching with a bilingual or ESLcertified educator could provide this continuation. Co-teaching allows general education educators to learn from the specialist and the specialist can learn from the general education educator. Additionally, being comfortable with co-teaching models with language specialists

provides more self-efficacy for the general education teachers. By exploring different models of co-teaching, both educators and students can greatly benefit from this relationship.

\section{Co-Teaching}

Research defines co-teaching as two or more educators sharing instructional responsibility for all students assigned to a classroom (Villa et al., 2008). This type of relationship can occur between two general education teachers, a general education teacher and a specialist (special education, English as a second language, bilingual, etc.), or between two specialists. 
CLD students spend a large amount of their day with a general education teacher, and as addressed in other parts of this literature review, many educators are monolingual English speakers with very little training for working with students who have a native language other than English. As a result, many CLD students are in classrooms in which educators expect language acquisition within the content area to happen through inclusion, and students are supposedly gaining access to a rich and meaningful curriculum through this model (Leung \& Creese, 2008). Schools mean for this inclusion, through a push-in model, to give students full access to a content area specialist (the general education teacher). However, without the proper language supports in place, the student is at risk of not only lack of access to the curriculum, but this sink or swim mentality can lead to other issues such as frustration and shut down.

Educators who service CLD students in the mainstream classroom often feel unsure about how to incorporate the needs of ELs in their planning, decision-making, and lesson delivery (Dove \& Honigsfeld, 2010). In addition, many educators admit to a lack of understanding of the linguistic, emotional, sociocultural, and academic needs of EL students. Although professional development on the needs of ELs meets some of these needs, this approach then continues the problem of the general education teacher attempting to carry out these strategies and approaches within a vacuum. However, through co-teaching, educators can put these strategies in place while a language specialist guides and supports.

There has been much more extensive research conducted focusing on co-teaching relationships between a special education teacher and a general education teacher, but there has been much less research focusing on a co-teaching relationship between a bilingual or ESL teacher and a general education teacher. Despite the lack of research, many schools are moving toward less pull-out programs and more of a focus on push-in programming for CLD students. 
However, this can be a powerful professional development opportunity for both educators involved. Inclusion of CLD students without support is putting more general education educators having to increase and expand their relationships with educating our CLD students in which they are responsible for not only the content instruction but also the linguistic needs of their students. Furthermore, many of the general education teachers are unfamiliar with how to help students navigate the world of content learning through a language in which they have not fully or even partially developed (Pica, 2008). Through the development of a well-designed co-teaching model between a language specialist (ESL/bilingual educator) and a general education educator, educators can reduce this gap.

Although the normal struggles of scheduling and finding common planning time, grappling with critical questions concerning power, status, and differing pedagogical styles also need to be discussed and addressed (McClure \& Cahnmann-Taylor, 2010). Often the voice of the general education teacher gets valued over the voice of the ESL teacher's voice and discourse style (Creese, 2006). Another common issue is that the CLD students become the responsibility of the ESL/bilingual teacher while the general education educator maintains responsibility of the other students. Co-teachers need to account for all of these considerations in order to help coteaching be effective for both the students and the educators.

Co-teachers can utilize many different models of co-teaching. Each co-teacher pair needs to determine which type of co-teaching model best matches the needs of the students, the educators, and the content in which they teach. In their work with pre-service teachers, Hurd and Weilbacher (2017) described four models of co-teaching, which include one teach, one assist; station teaching; alternative (differentiated), and team teaching (see Table 2.10). 


\section{Table 2.10}

Co-Teaching Models (Adapted from Hurd \& Weilbacher, 2017)

\begin{tabular}{ll}
\hline \multicolumn{1}{c}{ Co-Teaching Models } & \multicolumn{1}{c}{ Description } \\
\hline One Teach, One Assist & $\begin{array}{l}\text { One educator has the primary responsibility } \\
\text { for teaching the material while the other } \\
\text { manages behaviors, checks assignments, and } \\
\text { supports/monitors the students while working. } \\
\text { The two educators divide the instructional } \\
\text { material into parts/chunks, and each educator } \\
\text { teaches at one station while the students rotate } \\
\text { between the different stations. } \\
\text { The educators use two different instructional } \\
\text { strategies/approaches to teaching the same } \\
\text { information. The learning outcome is the } \\
\text { same, but the pedagogical strategy differs. } \\
\text { Educators co-plan and team-teach the lesson } \\
\text { with no prescribed division of authority. Both } \\
\text { educators are actively involved in the } \\
\text { instruction for the entire class. }\end{array}$ \\
\end{tabular}

In addition to the co-teaching models listed, Dove and Honigsfeld (2010)adapted and expanded on these models to connect the models to the ESL context. They grouped their coteaching models into three groups; the first group of models (1-3) center on both educators (general education educator and linguistic specialist) working with the same group of students, typically the entire class, which has the general education students and the ELs. The second group of models (4-6) center on the two collaborating teachers working with two groups of students, who educators divide between them; educators may group students heterogeneously or homogeneously by their linguistic needs. The third group includes only one model in which the educators divide the class into multiple groups in which both collaborating educators facilitate, direct, and monitor all groups. For the descriptions of the models, see Table 2.11. 


\section{Table 2.11}

Co-Teaching Models Designed for General Educators and Language Educators (Dove \& Honigsfeld, 2010, pp. 7-8)

Model Type Description

1. One student group: One lead teacher and another teacher teaching on purpose

2. One student group: Two teachers teach the same content

3. One student group: One teacher teaches, one assesses the same content

5. Two student groups: One teacher preteaches, one teaches alternative information
4. Two student groups: Two teachers teach

The mainstream and ESL teachers take turns assuming the lead role. One leads while the other provides mini-lessons to groups or individuals to pre-teach or reinforce a concept.

Both teachers direct a whole-class lesson and work together collaboratively to teach the lesson at the same time.

Both teachers are engaged in conducting the same lesson; one teacher leads while the other circulates throughout the room and assesses students.

Teachers divide the students into two learning groups; the teachers engage in parallel teaching, but they present the content using different pedagogical strategies.

Teachers assign students to one of two groups based on their readiness levels related to a designated skill or topic. Students who have limited prior knowledge of the target content or skill are grouped together to receive instruction to fill the gap in their background knowledge.

6. Two student groups: One teacher reteaches, Flexible grouping gives students at various one teaches alternative information proficiency levels with the support they need for specific content; the composition of the student groups change as needed.

Multiple grouping allow both teachers to monitor and facilitate student work while targeting certain students with assistance for their learning needs.

Although educators can choose a model, this is not enough to address the concerns that researchers have found when working with general educators and ESL teachers. From her work with general educators and ESOL educators in Taiwan, Davison (2006) developed a 5-stage model of collaboration that explained the characteristics of levels of compliance with a co- 
teaching model, which include pseudo-compliance or passive resistance, compliance, accommodation, convergence, and creative co-construction (see Table 2.12). By reflecting on the levels of collaboration between the general education educator and the language specialist, educators can maximize the benefits of the co-teaching relationship. Without reflecting and time to plan, push-in models run the risk of staying in level one (pseudo-compliance or passive resistance). 


\section{Table 2.12}

Levels of Collaboration in Partnerships Between General Education Educators and Language Specialists (Adapted from Davison, 2006; McClure \& Cahnmann-Taylor, 2010)

\begin{tabular}{|c|c|}
\hline Level & Distinguishing Characteristic \\
\hline Pseudo-compliance or passive resistance & $\begin{array}{l}\text { Rejection of collaboration, preference for the } \\
\text { traditional pull-out program } \\
\text { Little to no true time or knowledge investment of } \\
\text { teacher collaboration } \\
\text { No positive outcomes occur/are recognized } \\
\text { The expectation is that that this collaboration will } \\
\text { go away and that "this shall pass" }\end{array}$ \\
\hline Compliance & $\begin{array}{l}\text { Positive attitude and good intention toward trying } \\
\text { Model is primarily externally imposed but efforts } \\
\text { are made to implement roles and responsibilities } \\
\text { Limited understanding of the full impact of } \\
\text { collaboration } \\
\text { Expectation of external professional development } \\
\text { and dependent on rewards }\end{array}$ \\
\hline Accommodation & $\begin{array}{l}\text { Positive attitude and willingness to experiment } \\
\text { Efforts are made to meet the needs of both of the } \\
\text { educators involved } \\
\text { Achievements are described in terms of strategies } \\
\text { and techniques } \\
\text { Expectation of practical and teacher-specific } \\
\text { professional development (external) }\end{array}$ \\
\hline Convergence & $\begin{array}{l}\text { Highly positive attitude and embrace the } \\
\text { opportunity to learn from one another } \\
\text { Efforts are made to embrace both educators' } \\
\text { ideas, and both educators initiate discussions and } \\
\text { experimentation } \\
\text { Some adopting of one another's ideas and } \\
\text { pedagogical strategies, and increasing } \\
\text { acknowledgement of the rewards of collaboration } \\
\text { Increasingly seeking out opportunities for peer } \\
\text { collaboration, including in professional } \\
\text { development opportunities }\end{array}$ \\
\hline Creative co-construction & $\begin{array}{l}\text { Highly positive attitudes; co-teaching is seen as } \\
\text { the preferred approach for working with CLD } \\
\text { students } \\
\text { Educators' roles are interchangeable but yet } \\
\text { distinct } \\
\text { Responsibilities and roles are consistently } \\
\text { analyzed and negotiated } \\
\text { Teachers engage in action research and reflection } \\
\text { upon their co-teaching }\end{array}$ \\
\hline
\end{tabular}


A well-developed co-teaching relationship can allow for professional development for both teachers, allow students to use native language as a tool in the classroom, and can create additional opportunities for students. With professional supports, educators can become more knowledgeable about using strategies for students and will be more likely to be empowered to use them with their CLD students. When co-teaching with a bilingual educator, the bilingual student can share insights and ideas that the general educator or student missed had they only had the opportunity to express their understanding in English (Apodaca et al., 2019). The most effective way to overcome the challenges that are present with co-teaching is for educators to engage in ongoing, regularly scheduled collaboration (Dove \& Honigsfeld, 2010). This will enable educators to progress through the levels of collaborative relationships.

Weaving together the concepts included in this literature will be the framework used to develop the professional development modules for the middle school math and science educators.

\section{Theoretical Framework}

The perspective of the researcher in this study is through the theoretical lenses of Sociocultural Theory, Critical whiteness Theory, and Latiné Critical Race Theory (LatCrit).

Sociocultural Theory recognizes that learning is a social endeavor and that learning takes place within social contexts. Furthermore, taking a sociocultural perspective in the science classroom identifies that learning science is both a social and cultural process, and that it involves enculturation of the students into the practices and norms of science (Carlone, HaunFrank, \& Webb, 2011); I take the position that this idea is true also in mathematics. Changes in participation are the results of shifts in social and cognitive functions (McLaughlin \& Barton, 2013; Lave and Wenger, 1991). Therefore, for true learning and inclusion in math and science 
classrooms to occur, educators must change their instructional and pedagogical practices to reflect the social and cultural needs of all students. Furthermore, because learning takes place through conversation and discussion, two interviews and six focus groups will also be included to give space for the participants to discuss and to debrief their ideas.

By taking a sociocultural perspective, the researcher also considers that values and emotions also are involved in learning (Carlone et al., 2011). Because these emotions and values can impact whether or not a student feels that mathematics and science are achievable for them, these factors may affect their overall feelings and attitudes toward both content areas, including their math and/or science identity and perception of their smartness.

A second theoretical perspective focuses on critical race theory. The position of the theoretical framework taken in this study focuses on the educators through Critical whiteness Theory $^{1}(\mathrm{CwT})$ and the importance of the professional development toward CLD students through Latiné Critical Race Theory (LatCrit).

"Critical race theory (CRT) sees the official school curriculum as a culturally specific artifact designed to maintain a White supremacist mast script" (Ladson-Billings, 2016, p. 24). To adopt CRT as the framework means to "expose racism in education and propose radical solutions for addressing it" (2016, p. 28).

CRT recognizes that "racism is normal, not aberrant, in American society. Because racism is an ingrained feature of our landscape, it looks ordinary and natural to persons in that culture" (Delgado \& Stefancic, 2000, p. xvi; Gillborn, 2016, p. 49). Therefore, to change the ways in which educators both view and teach their students, educators must critically analyze

\footnotetext{
${ }^{1}$ When discussing Critical whiteness Theory, I maintain my intentional capitalization of Latiné versus white as discussed in Chapter 1 unless it is a quotation. I have adopted the same capitalization as used by Corces-Zimmerman and Floramaria Guida (2019).
} 
their own biases and understand the roles of their biases when instructing their students. Within this study, I will layer in the five elements of critical race theory and methodology in education as outlined by Solórzano and Yosso (2016). These include the intercentricity of race and racism with other forms of subordination, the challenge to dominant ideology, the commitment to social justice, the centrality of experiential knowledge, and the inclusion of the transdisciplinary perspective. In addition, CRT "can be used as a tool through which to define, expose, and address educational problems" (Parker \& Lynn, 2016, p. 143).

As the number of middle class white teachers continues to dominate the teaching population of the United States, an analysis of the role that race plays in identity and teaching is a critical component when seeking to identify as a teacher of culturally and linguistically marginalized students. To begin to create more equitable lenses in which educators view their students who may differ in background from educators, I will use critical whiteness theory as a lens in which to carry out this study.

As the majority of teachers are white, it is critical that educators unpack how race impacts everyone. Without clearly analyzing the role that race plays in their teaching, educators may be unintentionally assuming the "white savior" role rather than successfully liberating their students of color from a problematic system (Matias \& Mackey, 2016). This white savior complex, in which white people "rescue" or "save" communities of people of color, is prevalent in education. Consequently, those who have had little training in culturally pedagogical practices and whiteness may still blame low test scores on factors such as poverty, student motivation and participation, home language, and family support rather than institutional structure, cultural match and poor teaching (Sleeter, 2017); this deficit mindset and failure to look at the role that whiteness and white systems have placed upon the education system continues to blame the 
students and their families rather than the consistent pervasiveness of whiteness in our education system. This pervasiveness continues to create disparities for our students of color.

Critical whiteness Theory emphasizes the importance of an analysis of whiteness within the individual and the effects of whiteness on the systems around us. Furthermore, many teacher education programs focus on celebrating differences rather than an analysis of the systemic oppression within our education system (Sleeter, 2017). I extend this to professional development that teachers take part in; this continues to play into the othering narrative that fails to break down why students of color continue to have to adapt to a white educational system to find success.

By using the lens of Critical whiteness Theory (CwT), educators can begin to process their own whiteness and the role their own whiteness contributes to the greater system at large creating conditions in which people of color must survive (Matias \& Mackey, 2016). CwT is used as a lens as I seek to connect whether an educator's teacher identity can be strengthened through discussion and professional development focusing on culturally and linguistically marginalized students. By having an educator analyze their own whiteness, identify within their practice where whiteness persists, the assets that culturally and linguistically marginalized students possess, and the mismatch between the whiteness and the cultures present in their room, I seek to explore how their white teacher identity may transform.

Within the critical race theory framework, Latiné Critical Race Theory (LatCrit) emerged. "LatCrit theorists aim to center Latinas/os multiple internal diversities and to situate Latinas/os in larger inter-group frameworks, both domestically and globally, to promote social justice awareness and activism" (Lat Crit, n.d.). Furthermore, due to the study's focus on Latiné students, "LatCrit provides the lenses to see the different forms of capital that Chicano and 
Latino students possess" (Valdez \& Lugg, 2010). Through the LatCrit lens, Latiné students are viewed for their unique assets and needs as learners and thinkers. Focusing on the wealth of capital as outlined by Yosso (2005), studies that embrace a LatCrit lens recognize that Latiné students not only need to have educational opportunities that build upon this capital but also encourage activism and provide opportunities to challenge the ways in which Latiné people are viewed and/or marginalized in society. This study seeks to improve the educational experience of Latiné learners; by providing training to the teachers who serve CLD learners, this study seeks to disrupt the current system. This lens will provide me, as the researcher, an opportunity to explore ways to make the current educational system more equitable and more asset-based for Latiné students. "When examining science education reform with a cultural lens, we do not view the endeavor as a matter of solely tweaking political and institutional variables or actors' behaviors, values, and beliefs. Instead we view the process of reform as (re)creating worlds" (Carlone et al., 2011, p. 481).

I will use these theoretical frameworks as my lenses for development, implementation, and analysis throughout this study. 


\section{CHAPTER III: METHODOLOGY}

The purpose of this chapter is to describe in detail the methodology of the study, including the structure, participants, data collection and analysis, researcher positionality, the ethical considerations, and the limitations of the study.

This action research study drew upon the research of what professional development (PD) is needed for serving culturally and linguistically diverse (CLD) learners in general, the specific needs of CLD learners in the areas of math and science, equity frameworks, Funds of Knowledge/Identity/smartness, and capabilities of co-teaching. In addition, I layered in the research focusing on teacher identity and effective professional development. As a doctoral candidate who is a certified math, science, ESL, and bilingual educator, I developed six online PD modules focusing on the literature. Each of the six modules consisted of a pre-questionnaire, annotated content in Google Slides (Google Slides, n.d.) through a video format using Screencast-o-Matic (Screencast-o-Matic, n.d.), a post-questionnaire, and a focus group session for reflection. I focused the modules on Spanish speaking CLD learners, as this is the dominant secondary language group in the United States (Zeigler \& Camarota, 2019). In addition, I carried out and aligned the responses of the four educators who participated in this qualitative study to the two research questions. I used the following research questions to guide the study:

\section{Research Questions}

1. How do math and science educators view CLD learners in their classroom when provided with targeted professional development that focuses on CLD learners in the math and science classroom?

2. How does the identity of a teacher shift when provided with targeted professional development that focuses on CLD learners in the math and science classroom? 
Qualitative researchers are interested in studying how people understand and interpret their experiences and attribute meaning to their experiences (Merriam \& Tisdell, 2016). In contrast to quantitative research, qualitative researchers are interested in "how people interpret their experiences, how they construct their worlds, and what meaning they attribute to their experiences" (Merriam \& Tisdell, 2016, p. 15). In addition, qualitative researchers study things in their natural settings as they attempt to interpret phenomena in terms of the meaning people bring to them (Denzin \& Lincoln, 2013). While quantitative researchers use mathematical analysis and statistical tools, the primary instrument for the qualitative research study is the researcher, themselves. In addition, qualitative research is often inductive, in which the researcher seeks to gather data to build hypotheses or theories, rather than attempting to test a hypothesis as in a quantitative study (Merriam \& Tisdell, 2016).

Within the qualitative framework, I took an action research approach as I carried out the study in my own school and community. As inferable by the name, action research centers on action. Action research seeks to understand how the participants create meaning in a specific phenomenon and to engage participants to help solve the problem to some degree (Merriam \& Tisdell, 2016). In addition, the goal of action research is to address a specific problem in a practice setting, such as a classroom space, and to improve practice (Herr \& Anderson, 2005; Merriam \& Tisdell, 2016). Furthermore, other researchers see the goal of action research as transforming practice and participants (Herr \& Anderson, 2005). Action research is oriented to some action or cycle of actions that organizational or community members have taken, are taking, or wish to take to address a problematic situation (Herr \& Anderson, 2005, p. 4). Additionally, the practitioners engage in action research for social or community development and social change. 
I chose an action research study as the framework for this study and followed the principles of action research as explained by Herr and Anderson (2015). These principles include that the focus is on a problematic situation in practice, the design of the study is emergent, researchers engage participants within the investigation, the degree to which the lead researcher as an insider or outsider to the group studied is a consideration, and the researcher collects and analyzes multiple forms of data in a systemic way as the process unfolds and continues. Moreover, educators can utilize their knowledge as practitioners to change and improve educational practices through systemic inquiry within action research studies (Craig, 2009). Furthermore, action research involves deep inquiry into the professional practice of the practitioner as well as reflecting on the study, the effects, and the collaborative effort of the participants (Riel, 2019).

Within this teacher action research, which is also referred to as practitioner inquiry or collaborative action research (Cochran-Smith \& Lytle, 2009; Merriam \& Tisdell, 2016), I was an educator in the building, and as a result, I was a complete insider to the school and the needs of both the educators and the participants. Because action research is a planned, methodical research related to one's teaching (Johnson, 2009), conducting action research to determine the impact that specifically designed professional development has on an educator's views and identity aligned with the questions that I investigated in this study.

The point of teacher action research is for the researcher to improve teaching practice at the same time that the researcher creates new information and knowledge with their participants (Merriam \& Tisdell, 2016); in addition, practitioner research places the practitioner/researcher at the center of the research (Herr \& Anderson, 2005). Through creating experiences in which educators are being exposed to asset-based practices and training as well as highlighting the 
unique needs that CLD students have, I sought to analyze how the professional development experience shifted the ways in which educators viewed their CLD students as well as their understanding of their own identities and the role identity plays in their classrooms. Throughout this action-research study, I used the feedback of the participants to adjust modules and the questions I asked within the focus groups.

Due to the nature of this research to challenge the current methods of teaching math and science to provide a more equitable learning experience for Latiné students, I applied critical research methods to this study as well. Critical research seeks to confront the injustices within society by looking for methods that disrupt the current system, which is designed for those populations in power (Kincheloe et al., 2011). As many of the curricula choices and pedagogical practices of middle school math and science classrooms, as well as identity affirmation, are geared toward a middle class white population, these practices and curricula choices must be analyzed and critiqued through a critical pedagogical lens to create equitable learning spaces for CLD students.

Furthermore, because research with an ethnographic critical perspective focuses on the implications to one group specifically (Merriam \& Tisdell, 2016), I chose this perspective as another lens to view the study. The focus of this study is to make educators more aware of how to design mathematics and science education through a more asset-based lens for one specific group of students, CLD students who have a native language of Spanish. Therefore, by looking closely at their needs as a population in math and science, the goal is to improve CLD students' educational experience in math and science and for educators to spend time developing their efficacy for teaching CLD learners while focusing on the role their own race and identity play within their teaching. The focus on this specific group allowed me to look for ways to influence 
the educational opportunities provided for this specific group of students. Due to critical research recognizing that all thoughts are mediated by power relations and are socially constructed, this study sought to disrupt the deficit lenses in which CLD students are viewed (Kincheloe et al., 2011; Merriam \& Tisdell, 2016) and the biases that educators hold due to their own identities. Researchers who embrace critical pedagogy understand that learners produce knowledge in diverse locations; in addition, they seek to connect places and structures to learning (Kincheloe, 2013). Disrupting the current educational practice for CLD learners is critical as we seek to create equitable opportunities for their growth in the classroom.

I view this research through a critical theorist paradigm. Viewing research through a critical theorist paradigm recognizes that reality is fluid and not one fixed truth. Additionally, the critical paradigm focuses on social change, structure, and power (DeCarlo, 2018). Methodology within the critical theorist perspective uses interactions between the researcher and the participants to have a more informed consciousness with a goal of "seeing how to change and improve this fluid reality" (Wilson, 2008, p. 37). In addition, research in this paradigm seeks to foster change within the participants to bring about changes to the system being explored as well as collect critical data as they seek to not only study but also to change power imbalances (DeCarlo, 2018).

Through this qualitative study, I sought to connect to the participants through the modules to not only gain a better sense of who they were but also their shifts as it pertained to their views of CLD learners and identity. As all of the participants have had different experiences prior to the modules, each participant brought their own stories and backgrounds to the study. As people view things from different angles, they have different realities and different shifts rather than one fixed reality as it connected to this professional development work. Through this 
paradigm, telling their responses and stories is critical to capture their shifts and the findings in this study.

\section{Structure}

This study sought to explore the role that professional development can have on an educator's identity and views toward CLD learners. Drawing from the research on professional development, I sought to find an effective way to give a space for math and science educators to critically think about their own teacher identity, what formed it, and to research how targeted professional development shifted their teacher identity to create more equitable and culturallysustaining spaces within their math and science classroom. Additionally, I sought to find out how their views toward their CLD learners shifted as a result of professional development.

Using the seven elements of effective professional development as outlined by DarlingHammond, Hyler, and Gardner (2017), which include focus on content, active learning, support for collaboration, models of effective practice, coaching and expert support, feedback and reflection, and sustained duration, I sought to create a space for educators to individually reflect, gain knowledge, and to have discussion with other educators. In addition, I wanted this space to be one that busy educators could do in their own time and space.

Due to the benefits of online professional development for flexibility as described in the literature review, I built online modules centering on CLD learners, math and science, and identity. Over four months, the participants completed the six modules at roughly bimonthly intervals with longer breaks taken around holidays or busy times for educators, such as guardianteacher conferences and semester endings. Due to the importance of coaching, collaboration, and active learning in professional development, discourse is an important component of professional development and identity work as supported within the literature review. Therefore, following 
each module, the participants met as a focus group to collaborate and discuss the content of the module as well as connections to prior modules. Each module consisted of a pre and postquestionnaire to allow for individual reflection, which was critical for providing their own feedback and thoughts (see Figure 3.1).

\section{Figure 3.1}

Module Structure

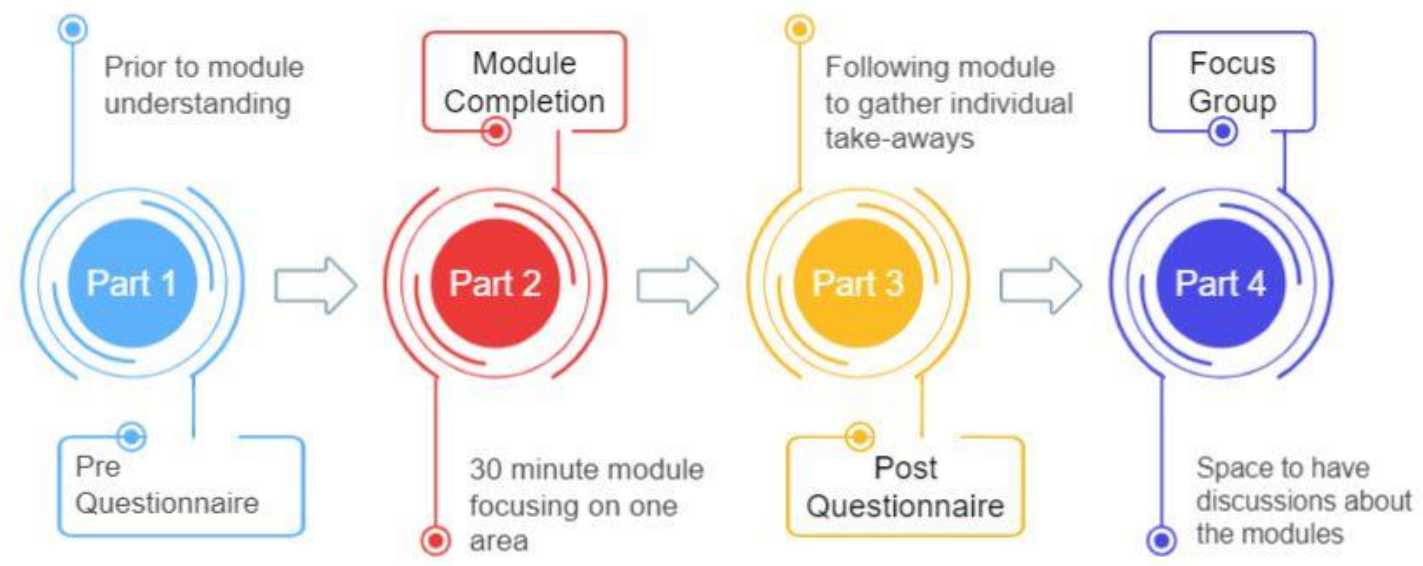

Each module consisted of a narrated set of slides created with Google slides (Google

Slides, n.d.) and then narrated using Screencast-o-matic (Screencast-o-Matic, n.d.) with videos, descriptions, pedagogical strategies, and questions to consider. These videos were then uploaded to YouTube (YouTube, n.d.) in an unlisted channel. These six modules focused on identity, culture and connections, an overview of CLD learners, lesson planning for CLD learners, science and math inclusion, and co-teaching and next steps for working with CLD learners and language specialists. See Figure 3.2 for the layout of the module progression and the driving questions for each module. 


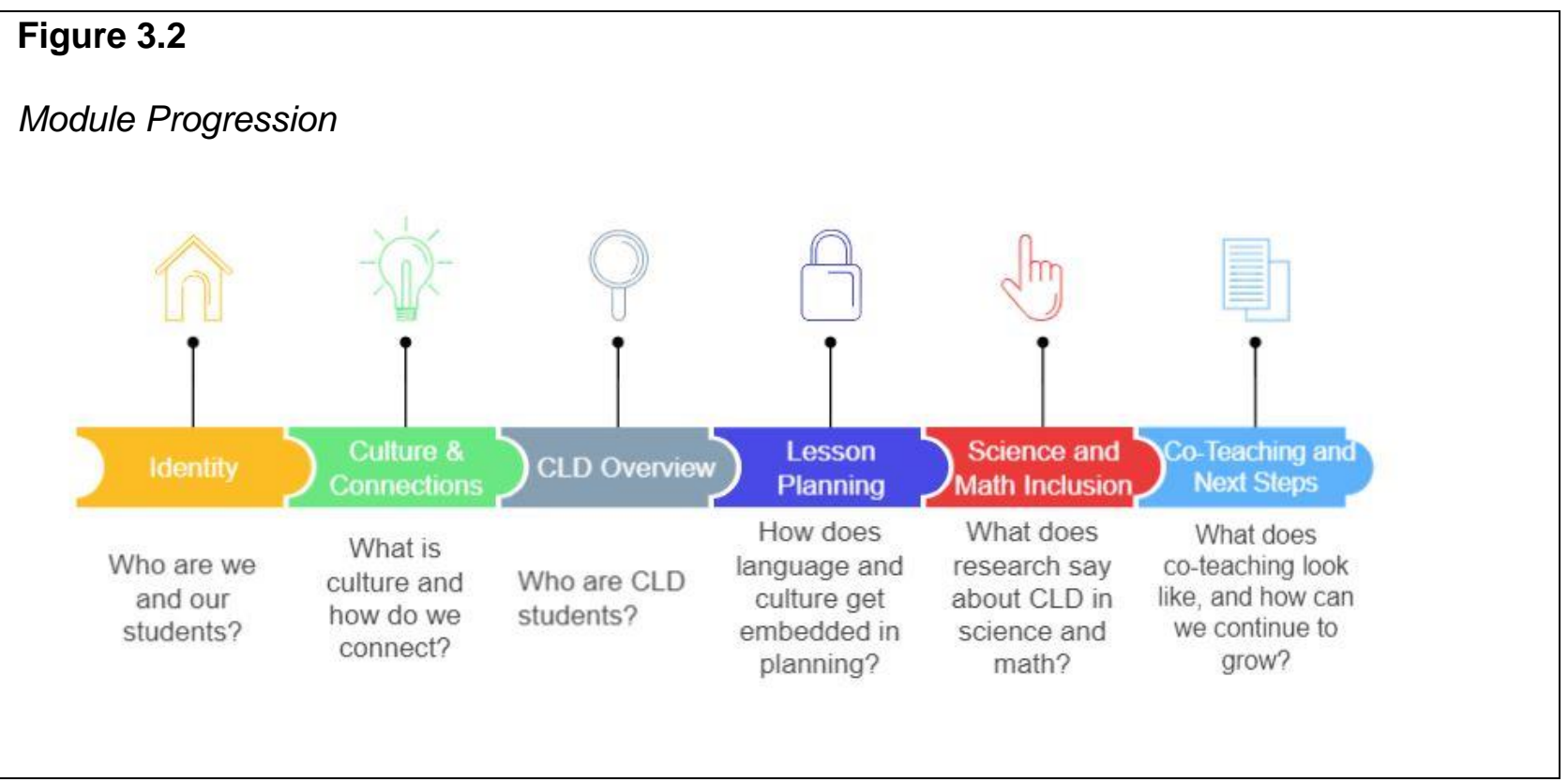

Furthermore, I drew upon the research focusing on teacher identity. By providing an educator community to discuss their own identity and experiences, educators negotiate their own meanings of their identity (Schultz \& Ravitch, 2013). This professional development study gave time for educators to reflect on their own experiences, backgrounds, and their teacher identity. Teacher communities in which teachers negotiate meaning for their stories and experiences may provide development of teacher knowledge and teacher identities (Schultz \& Ravitch, 2013) and to identify how through this identity, teachers bring their racial notions into their classroom practices (Brown, 2006). In addition, by seeking to build the self-efficacy of teachers through improving their content knowledge, in this case, the needs and assets of CLD learners, I sought to analyze the shifts within their identities and in the ways in which they viewed their CLD learners. As educators engaged in content learning through the modules, self-reflection through the questionnaires, and group discourse through focus groups, I explored the connection of teacher identity and their understandings of their CLD learners when provided with targeted professional development. 


\section{Participants}

I designed these modules for math and science general educators who service students who are both culturally and linguistically diverse and in middle school. To carry out this study, I used a mix of unique sampling and convenience sampling.

Due to the nature of this study and exploring the effects that training modules have on a specific demographic within our schools, I only sought out specific educators to participate. As a result of the specific parameters, unique sampling applied. Additionally, this study included four educators from one district. Although two districts were offered the opportunity, four teachers from one of the districts requested to participate. This is the district where I, the researcher/practitioner, teach. This enabled me to be an active participant in the professional development. As a result, convenience sampling also applies. This sampling is appropriate because in an action research study, the researcher is an active participant in the study, and I was looking to improve a problem and build upon the current body of knowledge of science and math inclusion of CLD students and the role that professional development can play in creating more equitable math and science learning spaces for culturally and linguistically diverse students in a profession dominated by white women.

The age group of the students was a key factor in my decision to use specific schools within these two districts. Middle school is the period in which interest and participation with science drops considerably even if students' grades are high (Christidou, 2011; Kang et al., 2019). To engage middle school students is a critical time to capture their interests in math and science. In their study with middle school girls, Kang et al. (2019) found that enhancing middle school students' active participation in school science lessons likely increases their selfperception of identifying with science. To create equitable programming for all students in the 
areas of math and science and to build their identity as mathematicians and scientists, focusing on educators at this grade level was a key component of this research design.

Through the use of pseudonyms, I kept the identities of the participants confidential. District and programing styles are less of a focus as each educator will begin the study from their own experiences and own identities. However, working with schools outside of my district would be an essential next step that I will discuss in the implications and further studies section.

The sample consisted of four general education math and/or science educators who currently serve middle school CLD students; these educators chose to be part of the study. Following permission to conduct the study in the district, I sent out emails to educators who met the criteria for participation, which included: being both a middle level educator who teaches math and/or science and also services CLD students in their classes. Included in the email was a video that described the elements of the study. Interested educators responded to the email, and I chose four participants based on creating as varied of a group as possible. I contacted these educators to further solidify their interest in participating. Due to the qualitative design of the study and the specific requirements of the involved teachers, I kept the number of participants low.

All participants taught in a middle school from one school district, which is located in an urban area in the Midwest. According to the state interactive school report card (2019), the district has 5,423 students. Of those students, 7.1\% are classified as English learners (ELs). This district has only one junior high, and within this school, $4.2 \%$ of students are classified as ELs. It is important to note that the junior high school has their ELs placed on specific teams, so those teams would have a higher percentage of ELs than the school average. In addition, this number (EL) would not reflect students who English Language Development (ELD) educators still 
monitor because of having recently exited ELD services nor students who are part of the bilingual program but no longer qualify for ELD services; these numbers include all grades (PK12).

A brief descriptions of the participants is in Table 3.1. A more detailed discussion of the participants is included in this chapter as well as in Chapter 4.

\section{Table 3.1}

Study Participants

\begin{tabular}{|c|c|c|c|c|c|}
\hline $\begin{array}{c}\text { Name } \\
* \text { changed to } \\
\text { provide } \\
\text { anonymity }\end{array}$ & Grade level & Content area & $\begin{array}{l}\text { Number of } \\
\text { years of total } \\
\text { experience } \\
\text { teaching }\end{array}$ & $\begin{array}{l}\text { Number of } \\
\text { years in } \\
\text { current } \\
\text { position }\end{array}$ & $\begin{array}{c}\text { Number of } \\
\text { years } \\
\text { working with } \\
\text { CLD students }\end{array}$ \\
\hline Kimberly & $6^{\text {th }}$ & $\begin{array}{l}\text { Math \& } \\
\text { Science }\end{array}$ & 6 & 6 & 1 \\
\hline Sarah & $6^{\text {th }}$ & $\begin{array}{l}\text { Math \& } \\
\text { Science }\end{array}$ & 30 & 2 & 3 \\
\hline Tamara & $7^{\text {th }}$ & Science & 17 & 5 & 9 \\
\hline Amanda & $8^{\text {th }}$ & Math & 18 & 1 & 4 \\
\hline
\end{tabular}

As a component of the pre-interviews, additional information was solicited that focused on their levels of professional development that they have participated in that focused on CLD learners. Speaking about their undergraduate experiences, three of the participants (Sarah, Tamara, and Amanda) did not remember having any training specifically for students whose native language was not English. Kimberly, the most recent graduate, has an ESL (English as a Second Language) endorsement, but she voiced that she did not feel prepared to meet the needs of CLD learners despite having the endorsement. 
In addition, all of the participants felt like they had had minimal opportunities for professional development focusing on CLD learners as in-service teachers. Amanda voiced that she felt that she thought that she would have more training when she "became a part of the EL team." Sarah has had the opportunity to co-teach with a CLD teacher, so she has had more opportunities to see more strategies in action when it comes to meeting the needs of CLD learners; this is the first year that she has worked with the CLD team although she had a total of three years of experience with CLD learners. In addition, Sarah is working on her doctorate and has training in critical pedagogy. Despite all but one participant having multiple years of experience working with CLD learners, all felt they had not been provided with many opportunities, past a meeting or a one-time presentation, for professional development focused on working with CLD learners. All four participants completed all questionnaires, attended all six of the focus group sessions, and completed the pre and post-interviews.

\section{Data Sources}

I used four steps for data collection, which included questionnaires, field notes/memos, focus groups, and interviews. These data sets were used to determine in what ways targeted professional development designed for middle school math and science educators shifted the views and pedagogical practices of middle school math and science educators as well as their ideas about their identity.

Measure 1: The first data source that I used were interviews. Research interviews help a researcher understand themes from the subject's own perspective (Brinkmann \& Kvale, 2015). Because I sought to find the impact that specific professional development had on educators, participants took part in one interview before the modules and one interview after the completion of all of the modules (see Appendices A and F). 
Interview Protocol: I used a semi-structured interview format. I chose this type of interview because the researcher has more flexibility due to being able to ask more questions or provide opportunities for clarification (Canals, 2017). In semi-structured interviews, "usually specific information is desired from all of the respondents" (Merriam \& Tisdell, 2016, p. 110); because I was looking for trends in responses, it was important to elicit specific information to questions. Interviews were an essential component of this study because this type of person-toperson interaction is a process that is active between an interviewer and interviewee, so knowledge is produced (Brinkmann \& Kvale, 2015). The interviews allowed the participants to expand on their questionnaire responses. The question order was determined based on the direction of the conversation, but I asked the base questions to identify the common themes.

I conducted the first interview as the beginning of the data collection. The first portion of the interview elicited background information from the educator on their teaching experience. The second portion of the interview focused on professional development opportunities and experience with culturally and linguistically diverse (CLD) students. The third portion of the interview focused on what they hoped to gain from this professional development opportunity. The final portion of the interview focused on teacher identity and their perception of their identity as a teacher and the role that their experiences may play into that development. The interview included questions to find what were pivotal moments in their development of their teacher identity (See Pre-Interview in Appendix A).

The final interview happened after the completion of the final online module. These questions focused on their views of CLD learners, their development in their views on race and teacher identity, and their description of their teacher identity following the professional development (See Post-Interview in Appendix F). 
To keep with a semi-structured interview format, I began with the base questions for the final interview (See final interview questions in Appendix F). However, I used this interview to allow the educator to have a narrative of their experiences, thoughts, and next steps. This also gave them an opportunity to explain more fully their needs and development. I audiotaped and transcribed each of these interviews. Audio recordings were deleted following the transcription completion.

Measure 2: The second instrument I used were field notes and memos. During each of the interviews as well as with the focus groups, I conducted field notes to gather sentiments and details during the focus groups and interviews. It was critical to consistently take memos to not only capture the participants' words but also their hesitations and their excitement or reluctance in discussing certain topics. Additionally, analytic memos played a critical role in capturing the feelings and tone of both the focus groups and the pre and post-interviews.

Measure 3: The third instrument used were questionnaires. Prior to and following each of the six modules, educators answered questionnaires that helped record both an idea of what they gained from the module and to show their pre and post data for each module. In addition, these questionnaires gave a space for self-reflection, which is a key component of professional development work. These questionnaires also helped develop the final interview questions as well as the focus group discussion questions (See Module Questionnaires in Appendices C and D).

Measure 4: The fourth instrument used were six focus groups. Focus groups were essential in this study to gain a variety of viewpoints of the impact the module had on their perception of their identity and their views toward their CLD learners. Each of the six modules included a focus group to give a space for reflection and discourse over the topic of the module. 
Focus group interviews may "bring forth more spontaneous expressive and emotional views than in individual, often more cognitive, interviews" (Brinkmann \& Kvale, 2015, p. 176). In addition, research on professional development shows that giving spaces to have discourse and reflection with groups allows educators to benefit more fully from the training. These focus groups (see appendix E) included all four of the participants to both give the participants a place to discuss as well as to have access to the expert. Additionally, these conversations, helped gain a better sense of how the professional development needed to be adapted to meet their needs. This model aligned with an action-research study as I sought to include the participants in the development of the study.

Due to this study taking a qualitative lens and the view that "reality is holistic, multidimensional and ever-changing" (Merriam \& Tisdell, 2016, p. 242), I focused on establishing validity and credibility through analyzing lenses and weaving in and out of the data sources (crystallization). To make sure I had discovered well-developed and credible findings, I analyzed my own lens as well as the lens of my participants (Creswell \& Miller, 2000). As qualitative research relies on the researcher as a tool for analysis, I engaged in reflexivity to reflect on how my own positionality affected the research and how the research process affected me as the researcher (Probst \& Berenson, 2014). I briefly discussed my own positionality/lens in this chapter, but I included a more thorough analysis in Chapter 6. To make sure I was thoroughly capturing the lenses of the participants, I utilized transactional validity through member checking (Cho \& Trent, 2006) by revisiting questions, clarifying statements, and confirming interpretations with the participants. This enabled participants to clarify and add to their responses in order to more thoroughly capture their lenses. 
In addition to credibility, I relied on my multiple sources of data to establish validity. Throughout the analysis of data, I looked for convergence among the interviews, field notes, questionnaires, and focus groups; this systematic process allowed me to see multiple forms of evidence rather than single incidences (Creswell \& Miller, 2000). This process of crystallization recognizes that in qualitative research, there is not a "fixed point" to discover (Richardson \& St. Pierre, 2005). This analysis of the lenses and responses across multiple data sources was critical to provide credibility and validity to the findings.

\section{Researcher Positionality}

As the researcher of this study, my position on why I sought to conduct this study is important. In addition, my background and experiences impacted my development of these modules and desire to create opportunities for educators to challenge their lenses. I believe that educators must look at their own identity to become aware of the impact it may have on their own teaching. Due to the focus of this work on teacher identity, I also took a critical look at my own identity as an educator and a researcher as well as my journey. I have included this within its own chapter (Chapter VI). In that chapter, I have outlined my positionality more fully as well as my own path in this journey of teacher identity.

\section{Data Collection}

I began by conducting the pre-interview. I used the set of semi-structured interview questions as described by measure one above. The interviews were recorded and later transcribed. From that point, I gave the educators access to the first of the training modules.

For individual reflection and to capture the thoughts of each educator, the educators completed the pre and post-module questionnaires as described by measure three. The participant completed each questionnaire directly before and then immediately after each of the modules. 
Following the completion of each module, we met as a focus group to discuss the module using the semi-structured focus group questions. These focus groups were recorded and then transcribed as described in measure four. Following all six modules, each of the participants participated in their post-interview.

I used these data sources to better understand the educators' views toward their CLD students and how the discussions and modules shifted their views surrounding teacher identity.

\section{Data Analysis}

For the purpose of analysis, I followed the use of terms as Corbin and Strauss (2015, p. 220) by using categories to label higher-level concepts, subcategories to label lower-level concepts, coding to describe the delineation of concepts, concepts to describe the "raw data," dimensions to describe the variations within the categories, and properties to define and describe the concepts.

Following transcription, I began with open coding. In open coding, the researcher is open to anything possible (Merriam \& Tisdell, 2016). I wrote analytic memos to capture my first thoughts as I read through the transcriptions, notes, and questionnaires. I then analyzed these memos, written as marginal notes. In addition, I kept analytic memos to capture my ideas and thoughts following each of the reading of each data source as "analytic memos and coding are concurrent qualitative data analytic activities" (Saldaña, 2016, p. 44). While reading through each interview, I kept an additional memo that included concepts that seemed to be carried over between each of the interviews and other data sources both in concepts and in participants' responses. These paragraphs and marginal notes were then used to aid in finding possible categories and eventual themes. 
Following open coding, I conducted a comparative analysis between the collected data. Within comparative analysis, concepts are compared against other concepts to develop categories within them (Corbin \& Strauss, 2015). I utilized axial coding to construct links between the data. Axial coding is used in qualitative research to reveal codes, categories, and subcategories within participants' words within the collected data (Allen, 2017) and to group the concepts from the open coding (Merriam \& Tisdell, 2016) into possible categories. Each concept provided additional dimensions and variations to that category.

I compared the codes in different chunks in order to find categories that emerged throughout the study. Furthermore, to make sure I made an exhaustive list of eventual categories, I used NVivo software (Qualitative Data Analysis Software | NVivo, n.d.) to pull out codes in the participants' responses to look for any missed codes within the interviews. I then compared codes between each participant's pre and post-interviews and looked for an overall picture of the group's pre and post-interviews by comparing the emerging codes and then categories as related to the research questions.

An essential component in constructing a narrative about the participants' journeys through the study was an analysis of each of the six modules. To do so, I did an open coding of both the focus group transcriptions and the pre and post-questionnaires for each of the six modules. I used the same procedure, via marginal notes and NVivo as described earlier, to discover the codes that emerged from the modules, which were geared to a specific topic as described earlier in this methodology section. Codes came from focus group transcriptions and the questionnaires. Using the NVivo software, I created mind maps to discover connections between the codes. These codes were then grouped into categories. 
Following the conceptual groupings into categories, I named each of the categories. The categories were then checked to see their alignment with the recommended criteria for category construction as described by Merriam and Tisdell (2016, p. 213), which states that categories should:

- Be responsive to the research questions

- Be exhaustive

- Be mutually exclusive

- $\quad$ Be sensitive to the data

- Be conceptually congruent

These modules created a better picture of the discussion and thought processes of the four participants as they participated in the research study. However, for the final connection back to the research questions, I relied solely upon the codes in the pre and post-interviews to analyze how the modules (professional development) shifted the educators' views of CLD learners and their identity. I grouped these codes into categories and then into themes as aligned with the two research questions. These codes fit into two main themes, which included CLD learners and identity.

\section{Ethical Considerations}

This study did not risk harm to any of the participants. However, to protect the anonymity of the participant, school, and school district, I coded all of the names. I assigned and changed the names within transcriptions, and I took all identifiable information out of the data. Once I downloaded information from the Google forms (as part of the questionnaires), I took out identifiable data and deleted the forms. Participants had the right to pull out of the study at any point, but all chose to remain in the study for the entirety of the research project. 


\section{Assumptions, Delimitations, and Limitations}

I am making the assumption that through using interviews and written questionnaires that educators were able to express their ideas about modules and their strengths when working with CLD learners. However, due to being professionals, it may be somewhat difficult for the educators to open up about their ability to meet their students' needs.

Due to using convenience sampling, one delimitation to this study is that I conducted this study in one geographical location. Because of conducting classroom observations and being both a researcher and full-time middle school educator, choosing one geographical location with multiple districts was the chosen study sample. However, next steps would be to try these modules with slight adjustments for rural schools and areas in different geographical locations.

Educator time and availability was a natural limitation to this study. Prolonged engagement over a longer period of time and spending additional time with each educator and in each classroom could yield more in depth insights. In addition, classroom observations would have been a key component of this study, but due to limitations of the COVID pandemic, classroom observations could not be conducted. By having classroom observations, I would gain more data about the changes in the educator's pedagogical and instructional practices, as well as the way they interact and include CLD learners in their classrooms throughout the study. 


\section{CHAPTER IV: RESULTS AND FINDINGS}

\section{Overview}

The purpose of this chapter is to present the findings of this study. This chapter will begin with a brief explanation and purpose of the study, the participants, and the data collection methods. Following this explanation is a description of the process in which I disseminated codes, created categories, and generated the eventual themes as aligned with the two research questions. I presented the data in the form of tables, figures, and descriptions that included anecdotes, a summary of the modules, and the two sets of interviews. These tables, figures, and descriptions include the codes and categories that emerged from the open and axial coding. At the end of the chapter, I described the findings of the study as two themes aligned with the two research questions. A deeper discussion of what these findings mean in connection with the theoretical framework and current research as well as their further implications will be included in Chapter Five.

The purpose of this study was to analyze the role that targeted professional development played in shifting the ways in which educators viewed their students who were culturally and linguistically diverse (CLD) and in their own identities. This action research study, which focused on professional development of math and science middle level educators, sought to explore through qualitative research the following research questions:

1. How do math and science educators view CLD learners in their classroom when provided with targeted professional development that focuses on CLD learners in the math and science classroom?

2. How does the identity of a teacher shift when provided with targeted professional development that focuses on CLD learners in the math and science classroom? 
The participants completed a six-module professional development study over a period of approximately four months. Each of the six modules included a pre-questionnaire, a video focused on the module topic, a 45-minute focus group, and a post-questionnaire. When referring to the modules, I am referencing all components of the modules including the pre and postquestionnaires, the training videos, and the focus group discussions. These six modules focused on identity, culture and connections, an overview of CLD learners, lesson planning for CLD learners, science and math inclusion of CLD learners, and co-teaching and next steps. For a more in-depth description of the structure of the modules, see Chapter 3.

\section{Participants}

Following research approval in the school district, I sent out emails to all qualified applicants, which included being a middle level math and/or science educator who serves culturally and linguistically diverse (CLD) learners; interested participants responded to the email. From those emails, I selected four participants to take part in the study.

The four participants included Kimberly, Sarah, Tamara, and Amanda. I have changed their names to protect their anonymity. All four teach at the same school but teach different grade levels and come to the study with varied experiences and training. I included more information about the school size and location in Chapter 3. Additionally, see table 3.1 in Chapter 3 to see the years of experience and additional information about each participant.

Kimberly is a sixth grade math and science teacher. She has an ESL endorsement but expressed that she did not remember learning useable strategies other than to include visuals in lessons. She has taught for six years all in the same building and in the same position, but this is the first year that she has serviced CLD learners in her math and science classroom. She has had a lot of opportunities to co-teach with a special education teacher but not a CLD teacher as she 
has been an educator on the teaching teams who service students with IEPs (individualized education program) up until this year. She was excited to take part in the professional development experience. She expressed that she wanted to service her students more effectively and following watching the CLD teacher interact with some of their shared students, she expressed that she wanted to be a "fly on the wall during bilingual class to see how different the kids were in there." Throughout the experience, there were moments when she was notably quiet. However, as reflected in the post-interview, her shift was measurable as she requested to take part in the modules again but with another group to continue to learn from others. Additionally, she had considerable shifts in her views toward her CLD learners and understanding of identity as evidenced by her responses.

Sarah has the most years of experience of the participants in the study. She has taught for 30 years but only two years in her current position as a sixth grade math and science teacher. However, she has taught sixth grade math and science as well as seventh grade math previously in her career. She is in her third year servicing CLD learners in her classroom. She has had more experience servicing students with IEPs. In addition, Sarah has completed coursework focusing on critical race theory and critical pedagogy and has a bilingual co-teacher for one of her science classes. Sarah is unapologetically vocal, and she is very comfortable pushing others to provide rational both for her own learning and also to help others grow. She recognized that she has not had much professional development nor experience with CLD learners, which brought her to this study. She was open to learning and was not afraid to say what she did not know. She had an asset-based view of professional development as she continuously vocalized that she felt like the professional development experiences were not prioritizing CLD learners. Furthermore, her critical race theory training in her doctoral program showed as she questioned why CLD learners 
were not a focus. To her, students come before content, and her shifts and responses reflect that philosophy as she described CLD learners as "onions" in her final interview. Her trajectory was different than Kimberly's as she latched shifted her views due to her previous experiences with critical pedagogy and asset-based teaching.

Tamara has been teaching for 17 years. She has varied experiences all at the middle level teaching science. She currently teaches seventh grade science and has been in the same position for five years. She taught for many years in another district that had high levels of CLD learners, and she has worked with CLD learners for nine years. Tamara highly values diversity, and she is a logical thinker. She was confident and slow to speak but thoughtfully questioned things and asked for clarification on things she did not understand. She is a whole picture thinker as she vocalized frequently that she did not feel that schools were doing enough to prepare teachers for working with CLD learners. As the study progressed, this feeling of unpreparedness was more elevated and more of a concern area for her. As a veteran teacher, she was comfortable in stating things she did not know and voicing that she needed more training, and as a leader in her building, she was confident voicing what she felt other teachers also did not know. She shifted considerably in the area of identity and its role in the classroom as well as what should be included in helping educators more effectively plan for CLD learners.

Amanda had the least amount of experience in her current position; however, she has almost two decades of teaching experience, but this is the most diverse school in which she has taught. She has been in her current position as an eighth grade math teacher for one year but has 18 years of teaching experience. She has worked with CLD learners for four years and currently teaches with a bilingual co-teacher in one of her eighth grade math classes. Amanda came across nervous in answering questions, specifically focused on identity, as she described that she was a 
private person. She was quieter than both Sarah and Tamara, but she became much more confident when responding to questions surrounding math and what she wanted to learn. She vocalized that she wanted to be better for her CLD learners as she recognized that she needed to do more for them. Although hesitant to talk about identity, she shifted to having a greater understanding of identity; in the pre-interview, she stated that she "felt like she was not answering the questions correctly." She was slow to answer as she listened to others' responses and often wrote more in her private reflections than she said in the focus groups. Her trajectory was different in that she had less experience in diverse schools and was less comfortable sharing in a less private space. Following this study, she enrolled in an ESL program to continue her growth.

These four participants varied in their teaching assignments, years of experience overall, and the number of years and experience with CLD learners. Throughout the tables and analysis of the pre and post-interview codes and categories, a clearer story of who the applicants are and their shifts emerged in relation to the areas of the study.

\section{Data Collection}

I began with initial interviews of each participant, and I refer to these interviews as the pre-interview throughout this analysis. Each module included pre and post-questionnaires using Google forms, a video of narrated slides, and a 45-minute focus group. Focus groups were recorded and later transcribed. Following all module completion, the participants took part in a post-interview. Chapter 3 includes a more in-depth discussion of the data collection.

\section{Data Analysis}

The purpose of this study was to analyze the shifts in both views that educators had about their culturally and linguistically diverse learners as well as in their own identities when they 
took part in targeted professional development designed for middle level science and math educators. I began with open coding, through taking marginal notes, of all of the transcriptions and the memos to capture original codes. To make sure I made an exhaustive list of codes, I used NVivo (Qualitative Data Analysis Software | NVivo, n.d.) software, to look for any missed codes within the data sources. Following the open coding, I analyzed the codes and began to create categories. Through axial coding, I created my final categories and eventual themes as aligned to the research questions. For a more in-depth description of the data analysis, see Chapter 3.

Throughout this chapter, I have included tables and figures to capture these codes and category development. The figures were developed as mind maps using the NVivo software (Qualitative Data Analysis Software|NVivo, n.d.). For the end analysis and connection to the research questions, I examined and relied upon the pre and post-interviews. Because this study focused on the shifts that occurred in educators' views of CLD learners and their own identities through targeted professional development, I used solely the pre and post-interviews as the individual indicator of shifts in connection to the research questions in the findings. However, it was also a critical component of the analysis to see the group discussions that occurred and the individual perceptions that came out throughout the modules. Therefore, I created codes and categories for each of the module discussions (focus groups and post-questionnaires), to give a fuller picture of the role that this professional development study had on the educators' perceptions and views. These module codes and categories provided insight into the shifts that emerged in the post-interviews.

\section{Module Analysis}

To understand the larger picture of the study and the participants' thoughts as a whole throughout the experience, an analysis of the module work was critical. I provided the 
professional development through six online modules, developed from research discussed in the literature review. Throughout the modules, I collected data from pre and post-questionnaires that were conducted prior to and after the module work as well as from transcriptions and field notes taken during and following the focus groups. Because I view the questionnaires and the focus groups for each module as spaces to reflect throughout the study, I used these to paint a clearer picture of the discussions that occurred throughout the length of this study. Additionally, because this study is an action-research study, I used the pre-questionnaires to also guide our focus groups. I led these focus groups and encouraged the participant voice throughout the discussion. However, at times, I needed to push the group to have certain discussions by asking questions or highlighting a portion of the module. For this reason, certain codes emerged that may not have shown in their post-interviews. Because I view the modules as the continued discussion as other group participants and I pushed one another's thinking, I did not include these codes in the final codes that were aligned to the research questions. Instead, I used the pre and post-interview codes because those were the elements that came from each individual without prodding. However, understanding the work and discussion of what occurred in the modules and in the focus group discussions provides a clearer insight into the study and the end findings.

When analyzing the focus group transcriptions and questionnaires, I went through the process of open coding and looked for codes through the transcriptions by writing marginal notes. I then grouped these codes into categories for each of the six modules. Because the modules each focused on different elements as connected to the research questions, a breakdown of the categories for each of the modules as a whole group is included in the form of a narrative. When participants were in the full group during the focus groups, some participants felt more comfortable sharing their ideas and take-aways than others did. For this reason it was critical to 
also look at the post-questionnaires for each module to layer in codes from their individual responses.

Following the open coding of the module transcriptions, the responses of the four participants' within the focus group discussions were categorized into exhaustive categories as described in the data analysis in Chapter 3. I aligned all six of the modules with components of identity and CLD learners as aligned with the research foci of this study. Although each module built upon the knowledge and discussions from the prior modules, the modules were analyzed separately for codes and then eventual categories.

I created a mind map to represent the emerging categories and the codes that made up each of those categories; these mind maps helped me to see the bigger picture of what transpired during each of the modules and aided in my written narrative. During the study and eventual analysis, I wrote analytic memos following the focus group, following the transcription, following the discovery of the codes during open coding, and finally following the development of categories. These paragraphs include information from those memos and pertinent quotations that capture the sentiments from the module work.

\section{Module 1}

The four main foci of this module that was titled, "Identity," included an identity overview, teacher identity, student identity, and identity affirmation/denial (intentional and unintentional). The goal of this module was to present the research on identity, the components of identity and how it affects our (both educators and students) teaching and learning. In addition, this module had reflection questions about how identity is affirmed or not affirmed in classrooms and their own identities. My perspective is that identity plays a key role in both how 
we teach and how we learn; thus, discussing identity and its development emphasizes its importance in the classroom.

I categorized the discussion that occurred in the questionnaires and focus groups into five categories. These categories included: parts of identity as identified by the participants, role of code switching, development of identity, reflection of teacher identity, and reflection of student identity.

This module focused on identity. The participants as a whole tended to stray from uncomfortable topics and stuck to elements of religion inclusivity (such as celebrations) and gender discrimination. Race and ethnicity were not mentioned by participants, and as they were broached, the topic turned back to gender and language. Sarah is the only one who mentions African American student and Latiné student experiences. Kimberly mentions that when a CLD teacher entered a parent-teacher conference, the tone of the conference changed. She attributes this to the power of language but does not mention relationships nor cultural understandings. Code-switching is brought up, and Amanda describes the amount that students code-switch depends on whether "they feel connected to their identity or do they feel separate from it;" while Sarah describes that code-switching depends on their sense of comfortability and inclusion in the space.

As the group discussed components of identity, they began by listing what they considered were components of their identities. As other participants shared, the others jumped in with agreement of things they had not considered. Through this ethnicity, race, religion, profession, character traits, gender, and family labels emerged. Areas like hobbies, religion, gender, family labels, etc., were more comfortable for most to discuss, while components like 
race were less discussed by all four participants. Gender identity was an area that participants freely discussed while they left racial and ethnic identity largely untouched.

The classroom environment and physical space was a comfortable topic for the participants as they discussed their physical space. As the discussion of holidays and classrooms posters was broached, Tamara voiced that she did not include any discussion of holidays to ensure none were left out, and Amanda focused on that she only had math posters that showed math concepts and math thinking. These were seen as not representing culture, but some of the participants explained this was safer because no one was left out and excluded. No one challenged that a space can never be totally free of culture. Throughout this module, the participants became more comfortable with talking about identity as they discussed their understandings of identity as woven with the research that was included in the module video. There is an overall sentiment that teachers did not knowingly deny representation of identity of other people, but they recognized that that did not mean that the denial did not occur. They left with the task that they were going to analyze their own spaces through the lens of whose identity is present in their spaces.

\section{Module 2}

The foci of module 2 titled, "Cultural Connections," were the culture iceberg, cultural wealth, Funds of Knowledge, Funds of Identity, and the acculturation model. The goal of this module was to present research on the role of culture in the classroom and in people's lives. My perspective is that research shows that educators can build upon the cultural backgrounds of students to better connect to students' experiences and language. This asset-based lens views students as vessels full of knowledge rather than empty vessels that need to be filled. This module connected culture back to identity and presented research on the ways in which educators 
can build upon diverse cultural backgrounds. Within the codes from this module, six categories emerged, which included the impact of culture, acculturation model, majority culture, cultural wealth, current level, and biases.

In the focus group for the second module, which focused on cultural connections, one participant, Kimberly, did not say one word. She was present and actively listened to the conversation but did not share her views. Another participant, Sarah, who has had more training and work in critical race theory and has had a CLD co-teacher for the majority of the school year, felt very comfortable sharing her viewpoints and is recognizably present in all of the focus group module transcriptions. Many in the group appeared to feel less comfortable discussing this module, and they stated that there was a lot of new information they had not considered.

The group focused a lot on the acculturation model, especially on assimilation and its roles in schools with one stating she thought that assimilation was the goal until this module. The group discussed ways in which they saw assimilation present in our education system. Sarah pushed the group to consider biases that teachers had about CLD learners. In many instances, the group would ask me to explain a concept in the module versus trying to explain a connection or describe a concept themselves.

When discussing cultural wealth, Sarah felt the most comfortable speaking about the different capitals that our diverse learners possess. She focused on navigational capital, while discussing navigating an English-dominated world, as well as social capital. Many voiced that they needed additional professional development to understand cultural wealth. In addition, Sarah was the only one who spoke about how to describe the "majority culture" despite being given wait time by both me as the researcher and Sarah. When comparing the focus group versus 
their post-questionnaires, individuals were more descriptive in their individual questionnaire than they were expressing their ideas in the open focus group.

For this module, I gleaned more information about the individual views of the participants through their post-questionnaires. However, that alone was part of the entire picture as the group seemed hesitant to discuss all components of this module in the discussion space. Many continued to voice that they tried to eliminate the exclusiveness of a space by simply not including cultural components in the classroom, such as decorations like Christmas lights or posters that might not include everyone. A further discussion of this idea is included in my analysis in Chapter 5.

Despite being pushed by Sarah to consider biases, none of the four participants voiced what their biases of CLD learners were but were comfortable to say that they needed more training and spaces to explore the components present in this module. However, the group discussed how the teacher culture impacts the decisions they make, and that they needed to make more opportunities and training to connect their content areas more to the students' cultures and identities in their classrooms. This shift was considerably different than their initial responses as a whole in their pre-interviews.

\section{Module 3}

Module 3 titled, "CLD learners," focused on the terminology used with CLD learners, classification of CLD learners, language development progressions, and culture shock. The goal of this module was to present research on asset-based terminology and to build the backgrounds of the participants on the assets and needs of CLD learners through a cultural, linguistic, and social-emotional lens. My perspective is that research shows that by building the capacity of educators to understand CLD learners as a whole, they (educators) will feel more confident 
meeting their CLD learners' needs and view them through an asset-based rather than deficitbased lens. The codes of this module were grouped to include five categories that included the impact of accommodations, BICS and CALP, linguistic repertoire, deficit terminology, and lesson planning.

This module was more comfortable overall for the participants than the prior module. This module focused on who our students are who are identified as culturally and linguistically diverse. Discussions centering on academic and conversational language lead to discoveries of misconceptions of the length of time it takes to acquire language, the spectrum, and the mistakes that educators make in not meeting the kids where they are linguistically. The conversation continued to steer toward linguistic needs rather than cultural connections and cultural mismatches. When discussing deficit-based languages, Kimberly stated that she had no idea there was so much different terminology connected with working with CLD learners but the group could navigate between the deficit and asset-based terminology.

As the group began to discuss deficit-based thinking, Sarah brought the conversation to translanguaging. This led to a discussion about standardized testing, and Tamara explaining that to only offer standardized testing in English or Spanish did not respect translanguaging. In addition, Tamara discussed teachers making assumptions about a student's language level from their conversational level and that leading to a lack of supports. However, no one connected that back to the navigational capital that we discussed in module 2 .

A discussion of culture shock led to times of discomfort that they have encountered but did not connect back to the discomfort and the stages of culture shock that a student feels and progresses through. But the participants comfortably shared times where they were unable to navigate in a space due to language and somewhat connected this to the experiences of a student 
who is navigating in uncomfortable spaces but did not discuss the teacher's role in creating/facilitating that intentionally or unintentionally exclusive space. However, through those stories, they expressed empathy and a different level of understanding of the challenges a CLD learner may feel in our school setting and once again stated that they needed more training.

\section{Module 4}

Module 4, titled, "Lesson Planning," focused on the 2020 WIDA (WIDA, n.d.)

Framework, language targets, the SIOP (Short et al., 2011) Model, and native language usage. The goal of this module was to build the background of the participants on how to lesson plan with CLD learners in mind through different frameworks, supports, and cultural inclusion. My perspective is that many of the participants had stated they had little training with how to plan specifically for CLD learners. Research supports that educators need to add in specific elements into their lesson planning to meet the needs of CLD learners to create equitable spaces for them to grow in the classroom. I grouped the codes from this module into four categories including language standards, curriculum, lack of professional development (PD), accommodations, lack of recognition, collaboration, and assessment.

Participants were comfortable in module 4 as they discussed lesson planning. They described feeling overwhelmed at the amount of information, and they spent a great deal of time talking about intentionality and the lack of focus that has been placed on meeting the needs of CLD learners in general education classrooms. As reflected in the other modules prior to this one, teachers said they "needed more training." In addition, they appeared frustrated that despite having been servicing CLD learners, they did not feel like they had been provided training to meet their CLD learners' needs. In addition, Sarah questioned whether enough intentionality had been placed on the training of teachers by the school and the district. Furthermore, Kimberly 
reflected that despite having an ESL endorsement, she did not feel like she had the training to successfully meet their (CLD learners) needs when it came to lesson planning.

Tamara discussed that too many are relying on special education accommodations and modifications and stated, "Well, we're modifying for CLD students. We're modifying for special ed students... okay, yep, I've got some modifications. Yep, I made some accommodations” when referencing educators overgeneralizing the use of these accommodations and modifications to extend to CLD learners. Sarah brings this back to the uniqueness of CLD learners by asking about translanguaging and her not considering making a CLD learner's work public and putting their language in front of the class unintentionally. This led to intentionality of teaching language in a classroom and the need for a paradigm shift in how we view lesson planning and inclusion of CLD learners, their languages, and their cultures in the general education classroom.

As the conversation veered toward curriculum, cultural connections and relevance were mentioned as needing to be present along with language and translation supports. This was one of the few connections in which information from the first modules focusing on identity and culture were brought up by the participants.

\section{Module 5}

Module 5 titled, "CLD Learners in Math and Science” focused on STEM and Latiné Representation, WIDA (WIDA, n.d.) and math/science, discourse, social equity frameworks, and putting it all together when lesson planning. The goal of this module was to focus on the research surrounding CLD learners in math and science to begin to identity how math and science classrooms can better meet the needs of CLD learners. My perspective is that despite the growth of CLD learners in our classrooms, their inclusion in STEM fields does not reflect this growth as described in Chapter 2. By tying in all of the components of culture, language supports and 
specific lesson planning for science and math, science and math educators will be more prepared to meet their needs. The module focused on how to build upon their backgrounds to elevate their capacity in science and math as well as promote linguistic growth. I categorized the codes into five categories including models, lack of focus, professional development, accountability, and inclusion.

Being math and science educators, the discussion of why there was a lack of representation of Latiné people in STEM fields and STEM programs was animated. In addition, the group overall was surprised by the data that I presented focusing on the research about the lack of representation of the Latiné population in STEM fields. They focused on the lack of models in the field and the lack of intentionality of hiring people of Latiné backgrounds. This led to a bigger conversation that focused on the lack of PD for general education math and science teachers as a contributing factor. At the beginning, their discussion focused less on curriculum that was relevant and inclusive. However, as the discussion turned to looking at new curriculum (as the school was currently looking at new curriculum for both science and math), the participants discussed that they should be looking at not only that the curriculum has translations of the text but also looks at relevance and inclusiveness.

As with many of the module focus group discussions, the group turned toward their needs and educators' needs for more training and intentionality of training. The participants freely shared that it should not be one and done and that it should be continual and guided. Sarah mentioned that "if you say CLD is a number one priority, then we get to make time" when discussing the need for more intentionality. Tamara felt that time should be provided and used better within their team times to meet the needs of CLD learners. Amanda expressed that she 
wanted to also have it with her math department where the teachers instructed the same content area and dedicating department meeting time to it.

The focus of the discussion still primarily tended to focus on language, language targets, and making their content more understandable, linguistically. However, elements of culture and relevance continue to increase in their conversations suggesting that they are shifting their mindset to include more than solely language.

\section{Module 6}

Module 6 titled "Co-teaching" focused on co-teaching, wrapping everything together, and next steps. The goal of this module was to present the research surrounding co-teaching to identify different models of co-teaching with a CLD educator and to connect all of the components of the modules through a review and reflection. The four categories of the codes from the questionnaires and focus groups included co-teaching, characteristics, training, and models. Module 6 wrapped up the modules and focused on the role of co-teaching with CLD teachers and content area teachers. Although all of the participants had experience with coteaching, only two of the four participants, Sarah and Amanda, have co-taught with a CLD teacher.

One of the big discussions that emerged from module 6 was the need for more CLD teachers so that general education teachers could do more co-teaching. Kimberly described, "it's helpful to watch them (co-teacher) teach." Many had felt that they had been placed with a coteacher with little training on what co-teaching should look like. Additionally, when discussing the levels of compliance, one participant stated, "I have never seen that, but it makes sense." Once again, the group turned toward their training and the need for more. They voiced the frustration with lack of consistency of time to prepare with their co-teacher. 
When discussing the need for pairing the CLD teacher with content specialists, the participants mentioned the importance of getting ideas for how to better support CLD learners from the co-teacher, but the CLD teacher lead teaching versus having a supporting role only is clearly absent in the conversation.

The conversation steered more toward co-teaching with a special education teacher as all of the teachers had more experience with co-teaching in that regard. However, when discussing co-teaching, all expressed interest in co-teaching with a CLD teacher and found that as a way that they could continue to grow and to learn strategies. They felt this was a component that could lead to more equitable spaces for CLD learners. As the module focus group wrapped up, and they discussed next steps for themselves as professionals, the participants demonstrated asset-based views toward CLD teachers' roles in the growth. In addition, intentionality, reflection, and training were all discussed as being important components of a healthy coteaching relationship that is beneficial for students.

\section{Pre and Post-Interviews}

Upon analyzing the codes from the interviews, seven categories emerged. Three of the initial categories were combined for the final analysis to end with five final categories; I provided a detailed description of this combination and rationale in the findings section. These categories were then aligned with the two research questions as described later in this chapter. I took the codes that were relevant to each of the categories and compared their responses in their pre-interview to the codes within the respective category of their post-interview to analyze the shifts in their views on CLD learners and identity as aligned with the research questions.

Each of the seven categories and the participants' respective pre and post-interview codes are included in the following tables. The seven categories included: 
1. Descriptions of CLD Learners (Table 4.1) - How they described who CLD learners were in general

2. Assets (Table 4.2) - How they described the assets of CLD learners and their contributions to the classroom space

3. Challenges (Table 4.3) - How they described the challenges CLD learners face and the challenges teacher's face in their instruction

4. Identity of the teacher (Table 4.4) - How they described their own identity and its role in connection to their teacher identity and practices/decisions carried out in the classroom

5. Student identity (Table 4.5) - How they described the role that a student's identity plays in the classroom

6. Overall professional development for educators (Table 4.6) - What type of professional development they felt was needed for educators who service CLD learners

7. Math and science professional development (Table 4.7) - What type of professional development they felt was needed in math and science

Following each table, I have included additional relevant analytic memos to capture some of the specific wording used by the participants. These analytic memos were components of memos taken following the interviews, following the transcriptions, and then following the analysis of the open coding and axial coding. These tables and memos provide a clear picture of each of the participant's journeys prior to and after the study. A deeper analysis of the interview data of the whole group as aligned with the two research questions is at the end of this chapter. Furthermore, a deeper discussion of these findings will be included in Chapter 5. 


\section{Table 4.1}

Pre and Post-responses to Category 1 (Description of CLD learners)

\begin{tabular}{|c|c|c|}
\hline Participant & Pre-response codes & Post-response codes \\
\hline Kimberly & $\begin{array}{l}\text { Someone in the process of } \\
\text { learning English } \\
\text { People in bilingual programs }\end{array}$ & $\begin{array}{l}\text { Someone who needs help or } \\
\text { support in their languages } \\
\text { English is not their } 1^{\text {st }} \\
\text { language }\end{array}$ \\
\hline Sarah & $\begin{array}{l}\text { Culture and language } \\
\text { differences } \\
\text { More than one language }\end{array}$ & $\begin{array}{l}\text { Multiple languages } \\
\text { Unique self } \\
\text { Unique cultural differences } \\
\text { and experiences }\end{array}$ \\
\hline Tamara & $\begin{array}{l}\text { Different language } \\
\text { Little formal education } \\
\text { Different perspective }\end{array}$ & $\begin{array}{l}\text { One or more different } \\
\text { languages } \\
\text { Varied cultures } \\
\text { Different life experiences } \\
\text { Culturally and linguistically } \\
\text { diverse }\end{array}$ \\
\hline Amanda & Different perspective & $\begin{array}{l}\text { Culturally and linguistically } \\
\text { diverse } \\
\text { Different perspective } \\
\text { Not white }\end{array}$ \\
\hline
\end{tabular}

Pre-interview responses to this category included a focus on lacking English, having different languages, and providing different perspectives. In addition, Tamara noted that some of the students may not have formal education and are learning how to be a student. Amanda stated, that they (CLD learners) "offer a different perspective that I am unaware of, able to not see things maybe the exact same way I am portraying them," and she concludes with, "somebody who is going to be able to open my eyes, I guess."

Post-interview responses included more cultural components than they had in the preinterviews. All participants still centered on students having a different native language with Kimberly stating, "I also think the fact that a lot of the children can speak two languages is crazy 
awesome.” Tamara stated, "Obviously CLD means culturally and linguistically diverse, so that means that they have a life experience that they're coming to us as a student with different cultural experiences and one or more languages that they are speaking.” Meanwhile, Sarah compared them with an analogy stating, "I would describe a CLD student like an onion, and there are different types of onions. You have some onions that have certain flavors. You have other onions that have other flavors, but each onion has layers to it that makes it its unique self."

Table 4.2

Pre and Post-responses to Category 2 (Assets of CLD learners)

\begin{tabular}{|c|c|c|}
\hline Participant & Pre-response codes & Post-response codes \\
\hline Kimberly & $\begin{array}{l}\text { Different perspectives } \\
\text { Compliant }\end{array}$ & $\begin{array}{l}\text { Different perspectives } \\
\text { Native language } \\
\text { Can speak two languages } \\
\text { Get to have classes in two } \\
\text { languages }\end{array}$ \\
\hline Sarah & $\begin{array}{l}\text { Culture and language } \\
\text { differences } \\
\text { More than one language } \\
\text { Family will support discipline }\end{array}$ & $\begin{array}{l}\text { Varied cultural backgrounds } \\
\text { Family support } \\
\text { Different perspectives } \\
\text { Unique cultural experiences } \\
\text { Translanguaging }\end{array}$ \\
\hline Tamara & $\begin{array}{l}\text { Supportive families } \\
\text { Families feel strongly about } \\
\text { education } \\
\text { Interested in learning }\end{array}$ & $\begin{array}{l}\text { Bring something unique I do } \\
\text { not have } \\
\text { Varied cultures } \\
\text { Different experiences } \\
\text { Different knowledge } \\
\text { Different languages }\end{array}$ \\
\hline Amanda & Different perspective & $\begin{array}{l}\text { Students know you care } \\
\text { Different perspective } \\
\text { Can have different cultural } \\
\text { connections }\end{array}$ \\
\hline
\end{tabular}


In pre-interviews, many respondents emphasized that they have not had much training when it came to working with CLD learners. Responses focused on assets that centered on having a different perspective, being able to speak more than one language, and compliance language, such as following directions, having cameras on during remote learning, and parents having high expectations and follow through. Most stated different languages, but only one, Sarah, elaborated and said, "Having more than one ability in more than one language is an incredible thing." In addition, although almost all stated that they had different perspectives, the respondents did not elaborate on what those perspectives might be or how that benefits the learner or classroom space.

In post-interviews, the respondents again focused on language and perspective differences, but more comfortably elaborated. Tamara stated, "they're bringing with them all of their experiences and knowledge..., and they're bringing all of that with them, that other students who are not perhaps in that same culture have not had." Kimberly stated, "I feel like they bring lots of different backgrounds from their lives to the classroom where like one of them this year was in Mexico..., and other kids just haven't even had that experience at all. I think their native language or their native homes and cultures is a cool thing they bring." In addition, being bilingual is mentioned in multiple interviews as being an asset that they bring into the classroom. Language continued to be the main asset mentioned. 
Table 4.3

Pre and Post-responses to Category 3 (Challenges of CLD learners)

\begin{tabular}{|c|c|c|}
\hline Participant & Pre-response codes & Post-response codes \\
\hline Kimberly & $\begin{array}{l}\text { Not all of them speak Spanish } \\
\text { Hard to communicate with } \\
\text { home }\end{array}$ & $\begin{array}{l}\text { Teachers do not speak their } \\
\text { native language }\end{array}$ \\
\hline Sarah & $\begin{array}{l}\text { Pushed into classes with } \\
\text { untrained teachers } \\
\text { Societal issues (like } \\
\text { deportation) }\end{array}$ & $\begin{array}{l}\text { Lack of intentionality of } \\
\text { teachers to meet their needs } \\
\text { Not enough training of } \\
\text { teachers } \\
\text { Assumptions and } \\
\text { overgeneralizations of CLD } \\
\text { learners }\end{array}$ \\
\hline Tamara & $\begin{array}{l}\text { Science has own language } \\
\text { Learning language and } \\
\text { content at the same time } \\
\text { Rely on others to translate for } \\
\text { them } \\
\text { Many not have formal } \\
\text { education nor education } \\
\text { vocabulary }\end{array}$ & $\begin{array}{l}\text { Cultural mismatches } \\
\text { Functioning in a different } \\
\text { culture } \\
\text { Struggle/pressure to } \\
\text { assimilate } \\
\text { Learning content within a } \\
\text { different social space }\end{array}$ \\
\hline Amanda & $\begin{array}{l}\text { Communication } \\
\text { Frustration because they } \\
\text { cannot ask for help }\end{array}$ & $\begin{array}{l}\text { Different customs } \\
\text { Teachers using idioms } \\
\text { Newness of the classroom }\end{array}$ \\
\hline
\end{tabular}

Within the discussion of challenges in the pre-interviews, most participants focused on linguistic deficits and being unable to speak English. In addition, culture was mentioned at points from a deficit perspective. When referring to elements to the classroom, Kimberly stated, "Their differences are a good and bad thing." In addition, most of the challenges focus on being unable to communicate. When asked about challenges, Amanda stated, "the communication, um, the frustration of maybe asking for help." Many of the challenges centered on not having the educational background or language to understand the content area. One respondent, Sarah, 
focused on the lack of training of teachers when she stated, "I think they are pushed into classes where the teachers have the knowledge, but performing the skills needed to appropriately differentiate for their needs specifically is a challenge."

In the post-interviews, linguistic differences continued to be a focus, but many shifted the challenges from the student to the educator stating that there were cultural mismatches, pressures to assimilate, and lack of training to meet the students' needs. Tamara said, "Many feel they have to assimilate to understand and function within this current culture." Sarah said that many teachers have a deficit-view of students and that teachers state that, students "don't know language" and that teachers do not know that they need professional development. Kimberly stated the biggest challenge was when their teachers do not speak the students' native languages. 
Table 4.4

Pre and Post-responses to Category 4 (Identity of the teacher)

\begin{tabular}{|c|c|c|}
\hline Participant & Pre-response codes & Post-response codes \\
\hline Kimberly & $\begin{array}{l}\text { Age, female, teacher, hobby, } \\
\text { family roles, character traits } \\
\text { Upbringing impacts how she } \\
\text { treats kids- somewhat } \\
\text { connected to teacher identity }\end{array}$ & $\begin{array}{l}\text { "Never thought about identity } \\
\text { before" } \\
\text { White, female, teacher, } \\
\text { character traits, family roles } \\
\text { Teacher identity and identity } \\
\text { are linked and not separate }\end{array}$ \\
\hline Sarah & $\begin{array}{l}\text { White, female, character } \\
\text { traits, middle class, citizen, } \\
\text { teacher and teacher leader } \\
\text { Identities are always present }\end{array}$ & $\begin{array}{l}\text { Advocate, family roles, } \\
\text { white, math/science, leader, } \\
\text { teacher } \\
\text { Identity and teacher identity } \\
\text { connected } \\
\text { Life-long learner }\end{array}$ \\
\hline Tamara & $\begin{array}{l}\text { Strong woman, character } \\
\text { traits, family roles } \\
\text { Similar to teacher identity } \\
\text { Likes diverse spaces } \\
\text { Communication }\end{array}$ & $\begin{array}{l}\text { Woman, American, family } \\
\text { roles } \\
\text { My identity is centered if I do } \\
\text { not allow spaces for other } \\
\text { identities } \\
\text { Impossible to separate } \\
\text { identity and teacher identity } \\
\text { Super complicated } \\
\text { Encompasses everything } \\
\text { Every component is linked }\end{array}$ \\
\hline Amanda & $\begin{array}{l}\text { Family roles, character traits } \\
\text { Has "no culture" } \\
\text { Teacher traits-likes kids to } \\
\text { discover things }\end{array}$ & $\begin{array}{l}\text { Teacher identity and identity } \\
\text { are linked } \\
\text { Affect how you view and } \\
\text { treat others } \\
\text { Social justice orientations }\end{array}$ \\
\hline
\end{tabular}

In pre-interviews, there was hesitation on questions that focused on their identity. Almost all participants mentioned that they were women, but only one participant mentioned that she was white. This was mentioned by Sarah, who as stated earlier, has had critical race theory training as part of her doctoral program. Many focused on family roles, such as aunt, mom, 
sister, etc., or their interests and character traits. Amanda mentioned culture but said that she did not have a culture while others did. When discussing teacher identity and its connection to identity, three out of the four participants felt that they were separate and did not necessarily impact each other but that sometimes their traits, such as organized, were present in both spaces. Tamara described that "they're very similar because you know the core of who I feel like I am is consistent through who I am as a teacher, colleague, so I would say those foundations are consistent..." She continued to describe wanting to challenge and having high expectations. In addition, Kimberly mentioned that her identity leaked into her teacher identity because she came from a good family, so she plays that role for kids because many kids do not come from good families. Amanda stated that she did not really know if she was answering the identity questions right and focused on it being a private thing.

In post-interviews, Kimberly mentioned that prior to this professional development, she had "never thought about identity before." Participants continued to list roles but elaborated on the complexity and evolution of identity. This wove into the way they also discussed student identity. Along with focusing on the earlier identity terms, they also included ethnicity, race, and the connection to how they were in the classroom. Amanda was still notably uncomfortable talking about identity, and she focused on safer topics like being hard-working and having a growth mindset. However, she stated that "beliefs on social justice and your beliefs on equality and things like that, or personal beliefs, and of course that's going to help how we treat each other." When discussing the connection between teacher identity and identity, Sarah stated that they are linked and cannot be separated, and Tamara stated that, "every component of yourself is linked... so those are parallel with one another.” Kimberly felt that this discussion of identity should be layered into our instruction and that her identity and teacher identity "go hand in 
hand." Additionally, Tamara said that if she "does not center other identities, her (the teacher)

identity is the one that is centered."

Table 4.5

Pre and Post-responses to Category 5 (Identity of the Student)

\begin{tabular}{|c|c|c|}
\hline Participant & Pre-response codes & Post-response codes \\
\hline Kimberly & $\begin{array}{l}\text { Age develops their identity } \\
\text { Identity changes except core } \\
\text { values }\end{array}$ & $\begin{array}{l}\text { Families, beliefs, culture } \\
\text { Should be a focus in } \\
\text { classrooms } \\
\text { Identity influences their } \\
\text { learning }\end{array}$ \\
\hline Sarah & $\begin{array}{l}\text { Impacts a lot } \\
\text { Gender identity } \\
\text { Academic identity }\end{array}$ & $\begin{array}{l}\text { Impacts learning } \\
\text { Pressure to assimilate } \\
\text { Assimilation is encouraged in } \\
\text { schools } \\
\text { Culture, race, multiple factors }\end{array}$ \\
\hline Tamara & $\begin{array}{l}\text { All focused on science: } \\
\text { Affects how we interact } \\
\text { Worldview impacts how they } \\
\text { take in info }\end{array}$ & $\begin{array}{l}\text { Permeates everything at every } \\
\text { moment } \\
\text { Permeates every experience } \\
\text { Cannot be separated }\end{array}$ \\
\hline Amanda & $\begin{array}{l}\text { Risk taker vs not } \\
\text { Personality }\end{array}$ & $\begin{array}{l}\text { Public vs private identities } \\
\text { Native culture may be } \\
\text { different from the typical } \\
\text { American culture } \\
\text { Affects assimilation vs } \\
\text { biculturalism }\end{array}$ \\
\hline
\end{tabular}

In the pre-interviews, the participants did not mention race or ethnicity of students as components of identity but were comfortable with labels like "personality type" and "core values." Sarah described the role that social constructs has on identity and focused her conversation on gender and academics. Two participants, Sarah and Tamara, were more comfortable sharing that identity impacts how the students view things and learn. However, Tamara focused this different lens in the context of science. Amanda stated that their willing to 
risk take, as a component of identity, impacted their learning. Two participants, Kimberly and Sarah, felt that their identity could change, one by age and one by experiences, respectively. In the post-interviews, the participants were more relaxed when answering the questions that focused on student identity and its role in learning. Multiple participants listed race, beliefs, culture, and other distinguishing characteristics of identity. In addition, three of the participants (Kimberly, Sarah, and Tamara) felt that identity and culture could not be separated from a student's learning experiences. Tamara described, "It (culture) permeates every moment of their day and every experience they have." Sarah stated, "We need to see kids of all backgrounds." Three participants, Sarah, Tamara, and Amanda reference assimilation as encouraged by school; with the fourth participant, Kimberly, mentioning that prior to this module, she "thought assimilation was the goal of the school." Furthermore, Sarah stated that, "care more about the whole kiddo... you care about everything that goes into their life." 


\section{Table 4.6}

Pre and Post-responses to Category 6 (Overall Professional Development Needs)

\begin{tabular}{|c|c|c|}
\hline Participant & Pre-response codes & Post-response codes \\
\hline Kimberly & $\begin{array}{l}\text { Learn from an expert in the } \\
\text { field }\end{array}$ & $\begin{array}{l}\text { New and different tools } \\
\text { Learn WIDA } \\
\text { Represent language in } \\
\text { multiple ways } \\
\text { Continuation of this PD } \\
\text { Go deeper into the modules } \\
\text { Teachers needs more training } \\
\text { Importance of identity and } \\
\text { culture } \\
\text { Co-teach with a CLD teacher } \\
\text { How to make learning more } \\
\text { accessible to CLD learners }\end{array}$ \\
\hline Sarah & $\begin{array}{l}\text { Learn Spanish } \\
\text { How to be intentional }\end{array}$ & $\begin{array}{l}\text { WIDA standards } \\
\text { Way to hold accountability } \\
\text { Co-teach with a CLD teacher } \\
\text { How to provide more } \\
\text { supports } \\
\text { How to analyze curriculum } \\
\text { for language and culture } \\
\text { How to change mindsets } \\
\text { CLD coaches } \\
\text { Connect to cultural } \\
\text { backgrounds }\end{array}$ \\
\hline Tamara & $\begin{array}{l}\text { Connecting content to } \\
\text { language acquisition } \\
\text { How to build vocabulary }\end{array}$ & $\begin{array}{l}\text { Incorporating language } \\
\text { standards } \\
\text { Being more intentional with } \\
\text { connecting to culture } \\
\text { Co-teaching } \\
\text { More training }\end{array}$ \\
\hline Amanda & How to support them & $\begin{array}{l}\text { How to allow more flexibility } \\
\text { in answer representation } \\
\text { How to more fully meet } \\
\text { needs } \\
\text { More time to learn from } \\
\text { others } \\
\text { Writing better lesson plans to } \\
\text { incorporate their needs }\end{array}$ \\
\hline
\end{tabular}


When describing professional development that is needed overall for all teachers focusing on CLD learners in general, the participants were all quick to answer and did not include much description. They were all open to professional development as many felt they had not had much training concerning CLD learners as described earlier in the participants section of Chapter 3. Kimberly simply stated that she wanted to learn from an expert in the field. Sarah was the most descriptive as she described how she "would love to learn Spanish." In addition, she also described that she wanted to learn to be intentional in her lesson planning with CLD learners in mind. Tamara's response focused on how to make learning more comprehensible by finding effective ways to build vocabulary and how to connect both content learning and language acquisition. Amanda wanted to learn strategies to support her learners.

In the post-interviews, all four participants were much more descriptive in what type of professional development was needed in general for teachers who work with CLD learners. All four participants mentioned training in language standards and writing language objectives into their lessons, and three of the four (Kimberly, Sarah, and Tamara) all mentioned that educators needed training on how to connect to the cultural backgrounds of students. All four expressed that they wanted to continue their learning, and Amanda said that she applied to be a part of a new ESL cohort program to continue learning strategies. In addition, three of the four expressed wanting to have the opportunity to co-teach with a CLD teacher to continue to grow. Kimberly "wanted more time to work with an expert to improve." Tamara stated that "there's a lot... I think it would be really important for us to have more training in order to meet these students' needs." In addition, having access to an expert for evaluation and discussion was mentioned. 


\section{Table 4.7}

Pre and Post-responses to Category 7 (Math and Science Professional Development Needs)

\begin{tabular}{|c|c|c|}
\hline Participant & Pre-response codes & Post-response codes \\
\hline Kimberly & $\begin{array}{l}\text { Math is the "same in the } \\
\text { whole world" } \\
\text { Science has more of a } \\
\text { language }\end{array}$ & $\begin{array}{l}\text { I thought math was math, but } \\
\text { it is not } \\
\text { Language of math and } \\
\text { science } \\
\text { Be intentional in supporting } \\
\text { their representation in STEM } \\
\text { fields }\end{array}$ \\
\hline Sarah & $\begin{array}{l}\text { Math is not just numbers } \\
\text { Science has its own } \\
\text { terminology }\end{array}$ & $\begin{array}{l}\text { Math is seen as universal, and } \\
\text { it is not } \\
\text { Each content has its own } \\
\text { language } \\
\text { How to support writing and } \\
\text { translanguaging in content } \\
\text { areas } \\
\text { Cultural views in math and } \\
\text { science }\end{array}$ \\
\hline Tamara & $\begin{array}{l}\text { Every content area is } \\
\text { different and needs different } \\
\text { strategies }\end{array}$ & $\begin{array}{l}\text { Connect to specific processes } \\
\text { and procedures in different } \\
\text { content areas } \\
\text { Meet their needs differently } \\
\text { than other students and in } \\
\text { different content areas }\end{array}$ \\
\hline Amanda & $\begin{array}{l}\text { Want students to discover } \\
\text { without frontloading } \\
\text { vocabulary }\end{array}$ & $\begin{array}{l}\text { How to include language } \\
\text { standards in the math } \\
\text { classroom } \\
\text { Resources for support in math } \\
\text { Writing better lesson plans } \\
\text { for CLD learners }\end{array}$ \\
\hline
\end{tabular}

In pre-interviews, participants expressed math and science classrooms as having specific needs. Tamara stated that, "every content area has its own strategies and processes." Amanda voiced that she has learned that frontloading vocabulary is important with CLD, but that she 
"wants students to discover math." This frontloading of vocabulary and concepts directly conflicts with discover and inquiry and was why she felt that math and science training needed to be different. While Kimberly stated that math is math and "is the same in the whole world," Sarah stated that "math is not just numbers." However both Kimberly and Sarah believed that science had its own terminology.

In post-interviews, the participants all emphasized the importance of having specific training for math and science educators. Kimberly expressed wanting to change the perception and lack of representation of Latiné students in STEM fields, while Sarah also addressed how to make cultural connections more intentional in math and science. Additionally, Tamara stated that because "content areas have different processes and procedures, supports for CLD learners should be different." Amanda described wanting professional development on adding in language standards, referencing WIDA (WIDA, n.d.) standards, into her math classroom and wanting to collaborate with math, science, and CLD specialists across grade levels.

When it came to professional development, all participants voiced in their interviews as well as in the modules, which will be described later in this chapter, that educators need more intentional professional development and that PD needs to be continuous with access to an expert who can monitor, support, and assess growth.

\section{Development of Codes and Themes}

When looking at the final themes and their development, I focused on the pre and postinterviews for the final alignment with the research questions. Although I found the codes and categories for the six modules as pulled from the pre and post-questionnaires and focus groups, I view these modules as the resources to develop the backgrounds of the four participants. These modules were guided by me as the researcher, and I pushed them to focus on different elements, 
For this reason, some codes emerged during the open coding of the module that was not present in the open coding of the pre and post-interview data. For this study, the focus was to explore the shifts in how math and science educators view CLD learners as well as in their own identities when provided with professional development. To do this, I wanted to see their shifts from the beginning of the study to the end of the study. However, to show the process that transpired in between the pre and post-interviews, I needed to provide an acknowledgement and awareness of the participants' discussions and thoughts as connected to each of the professional development modules to provide a bigger picture of the story that transpired through the study. In addition, providing the codes and categories of the modules provides credibility and trustworthiness to the final themes as determined by the pre and post-interviews.

Returning to the categories that I created from the codes generated from the pre and postinterviews, I looked for themes as aligned with the research questions. From the initial seven categories as broken up in Tables 4.1 through 4.7, I grouped assets and challenges with descriptions of CLD learners to make up the bigger category, CLD Learners, as the challenges and assets that the participants described reflected how they viewed CLD learners and their needs. Some of the challenges fit into needed professional development areas. This left me with five categories to group into themes as aligned with the research questions, which included CLD learners, professional development, components of identity, student identity, and teacher identity. From these five categories, I made two themes as aligned with the research questions, these included "Views of CLD Learners" and "Identity."

I grouped CLD learners, which included the descriptions, assets, and challenges, with professional development needs. Because the participants' descriptions of their professional development needs also showed what they (the participants) believed they should focus on when 
meeting the needs of CLD learners, this often reflected the way in which they viewed CLD learners and their "perceived" needs, and for this reason, I grouped professional development with CLD learners to make the theme, "Views of CLD Learners." This directly aligned with research question 1, which is, "How do math and science educators view CLD learners in their classroom when provided with targeted professional development that focuses on CLD learners in the math and science classroom?"

The last three categories include, components of identity, student identity, and teacher identity. Components of identity focused on the elements/classifications that participants used to describe identity. Student identity included both how participants described their students' identities and their views on how students' identities affect their learning. Finally, teacher identity included how they described their own personal identity and teacher identity as well as whether they believed the two were linked or separated, especially as it pertains to their decision making in their classroom. I grouped those three categories, components of identity, student identity, and teacher identity, to become the second theme, called identity, which directly aligned with the research question 2, which is, "How does the identity of a teacher shift when provided with targeted professional development that focuses on CLD learners in the math and science classroom?"

See Table 4.8 for a grouping of the categories and their respective themes as aligned with the research questions. 
Table 4.8

Alignment of Themes and Categories to the Research Questions

\begin{tabular}{|c|c|c|}
\hline Research Question & Theme & Categories/Subcategories \\
\hline $\begin{array}{l}\text { 1. How do math and science } \\
\text { educators view CLD learners } \\
\text { in their classroom when } \\
\text { provided with targeted } \\
\text { professional development that } \\
\text { focuses on CLD learners in } \\
\text { the math and science } \\
\text { classroom? }\end{array}$ & Views of CLD learners & $\begin{array}{l}\text { 1. CLD Learners- } \\
\text { Descriptions, Assets, and } \\
\text { Challenges } \\
\text { 2. Professional Development- } \\
\text { Needs of teachers and what is } \\
\text { included }\end{array}$ \\
\hline $\begin{array}{l}\text { 2. How does the identity of a } \\
\text { teacher shift when provided } \\
\text { with targeted professional } \\
\text { development that focuses on } \\
\text { CLD learners in the math and } \\
\text { science classroom? }\end{array}$ & Identity & $\begin{array}{l}\text { 1. Components of identity } \\
\text { 2. Student identity- role in } \\
\text { classroom and learning } \\
\text { 3. Teacher identity- Personal } \\
\text { identity, teacher identity, } \\
\text { connection between }\end{array}$ \\
\hline
\end{tabular}

The analysis of these overall themes was a compilation of all of the data following the individual analysis of the pre and post-interviews. To describe the findings of the shifts that the four involved participants had in both their views of CLD learners as well as their identity, I used the pre and post-interview comparisons of the entire group, which I developed from the codes of the interviews. Individual codes among the seven categories that were trimmed to five and then grouped into two themes are included in Table 4.1 through Table 4.7. However, Figures 4.1 and 4.2 give a bigger picture view of the group's codes as they were then put into the categories and then put into the themes. These four following figures $(4.1,4.2,4.3$, and 4.4) focus on the two main overall themes as aligned with the research questions focusing on views of CLD learners and identity. Figures 4.1 and 4.2 include the codes from the pre-interviews broken up into the two themes as aligned to the research questions. Figures 4.3 and 4.4 include the codes from the 
post-interviews broken up into the two themes. Following Figures 4.2 and 4.4, I provided a

further description of the group's pre and post-interviews, respectively.

\section{Pre-Interview Overview}

\section{Figure 4.1}

Initial Group Responses to Theme One (Prior to Any Module Completion)

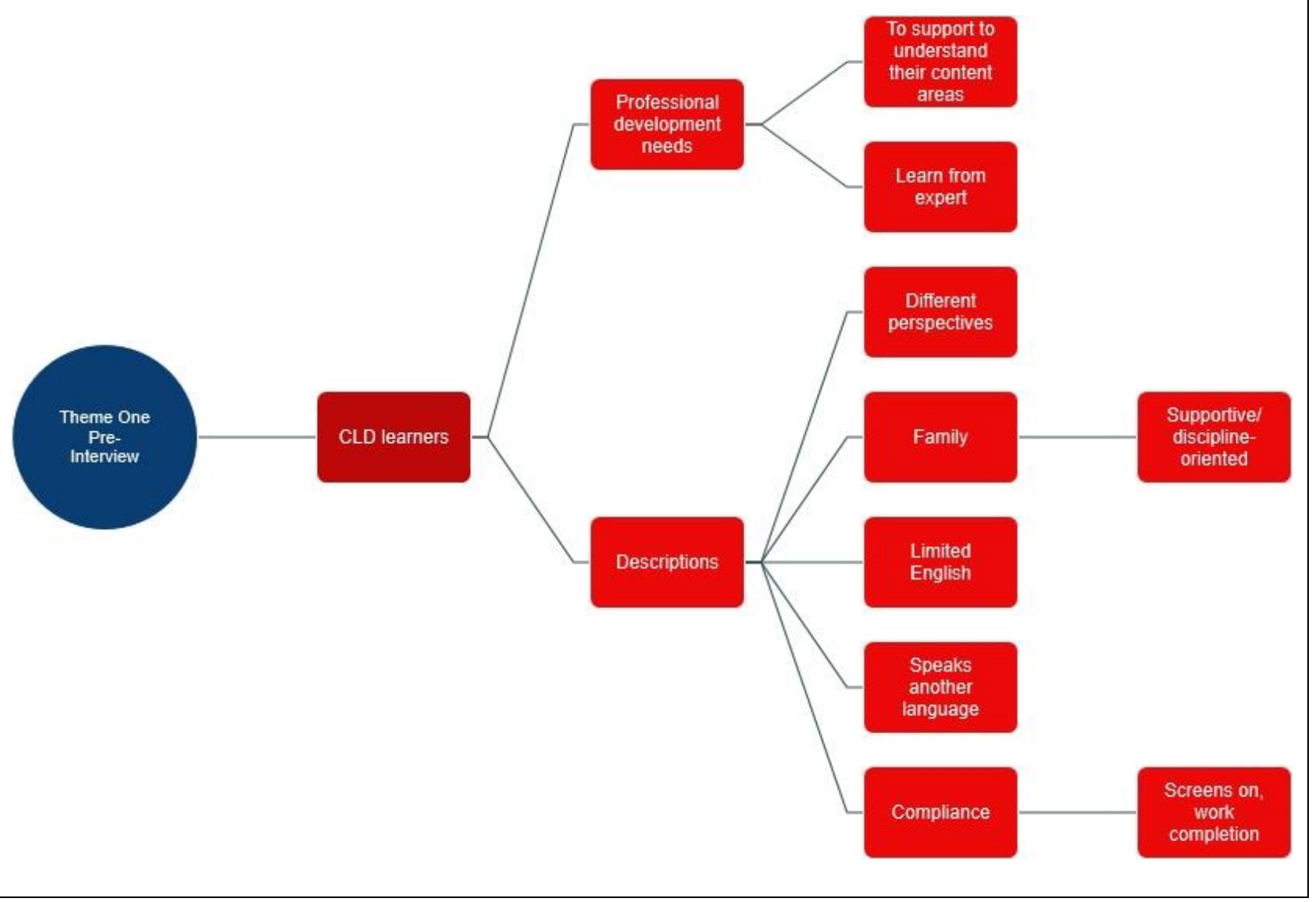




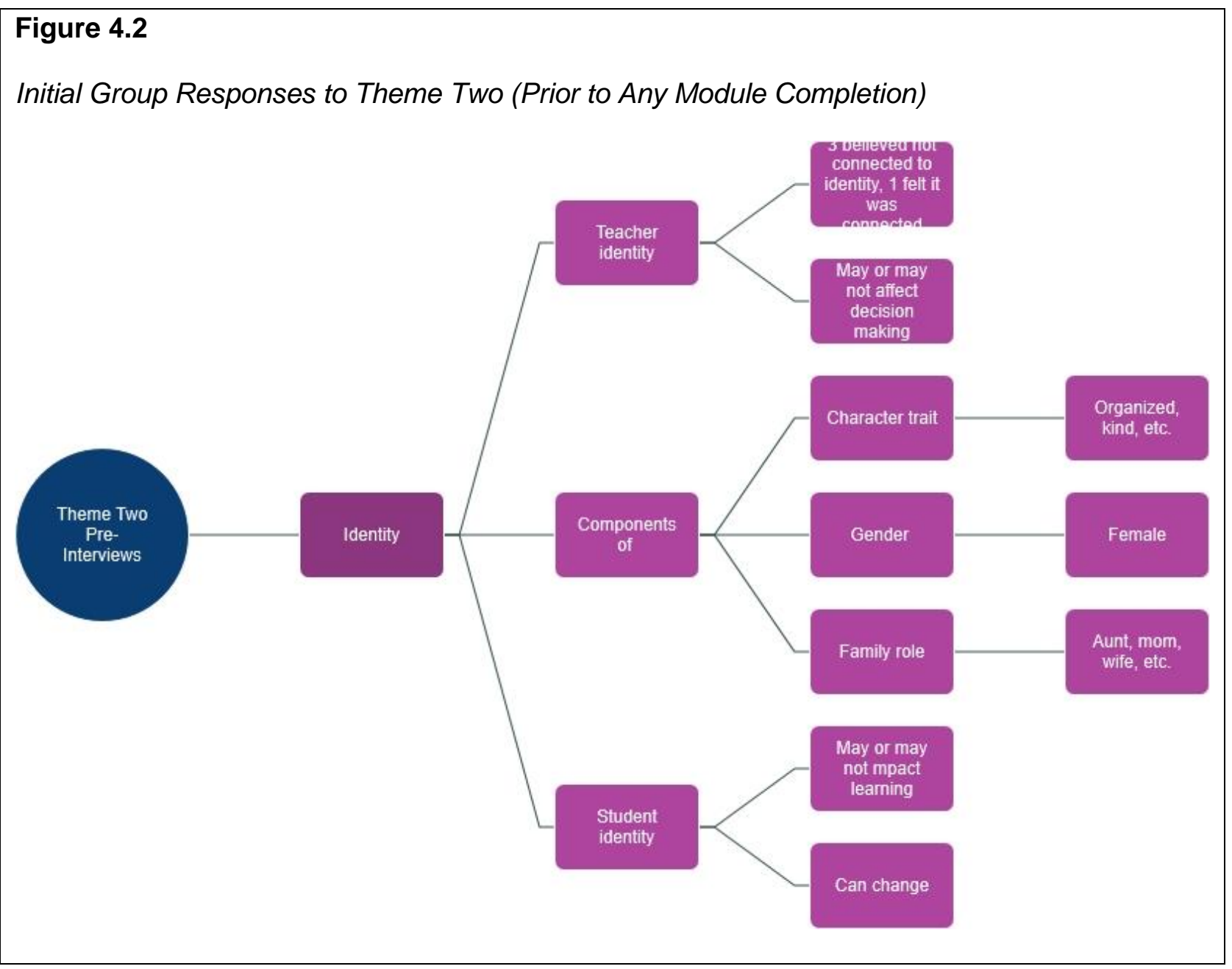

In the pre-interviews prior to any module completion, participants overall were more comfortable discussing their initial demographic data and discussing their own experiences with their own education and their professional development in connection with working with CLD learners.

When it came to discussing CLD learners and professional development, the participants were more at ease answering the questions as a whole. Although all have worked with CLD learners, all felt that they had not been adequately trained to meet the needs of CLD learners. The professional development focused on how to make their content more accessible to learners, spanning the request to learn about how to teach vocabulary to being intentional in learning 
strategies. One participant kept it simple by saying she wanted to learn about CLD from an expert (referring to me as the researcher and a trained CLD and math and science teacher). Their professional development needs were not very specific, but they were all clearly eager to learn more about how to meet the needs of their CLD learners.

When describing CLD learners, which reflects their views, most focused on language alone. However, three participants also stated that CLD learners provide a different perspective, and although they did not elaborate, this represented asset-based thinking when listing the assets of CLD learners. Many focused on that they were still learning English and that they needed additional supports. Almost all of the participants also focused on compliance as they listed that assets that the students brought were compliant behaviors, such as keeping their videos on during remote learning and having families who support respectful behaviors at school. Challenges focused on communication and their lack of English as well as issues with communicating with home.

When discussing identity, many were unsure of how to respond, with one participant stating, "I do not think I am answering these questions right." When it came to identity, the participants almost all stated they were women, but only one mentioned she was white. This is the same participant who has had training on critical pedagogy and critical race theory. Character and personality traits were heavily mentioned as the participants stated they were hard-working, organized, and had high expectations. In addition, many focused on their labels given by family in particular as they mentioned, mom, wife, sister, niece, etc.

When it came to their description of their teacher identities, many connected to their family roles, such as being a mom, or a personality trait, such as being kind. Only one believed that their teacher and personal identity were connected, and the other three believed that they 
could separate their two identities (teacher and personal) and that their identities did not necessarily impact the decisions that they made in the classroom.

When describing students' identities, all spoke less than when describing their own components of their identities with one participant stating that some people had public identities and some kept them private, so their identities, which were described as personalities, did not always impact their learning. In addition, one participant said that some people had a culture, but she did not, so her identity was private to the students. One participant felt that identities could change, but she referred primarily to age as they changed as they got older, and one participant felt that identities were developed by their experiences. This was the same participant who also felt that identities impacted their learning.

Following all of the interviews, they were all very interested in learning about how to make learning more accessible to their CLD learners and to receive training directly aligned with their content areas. See Figure 4.1 and 4.2 for the full breakdown of the codes, the categories, and their alignment with the two themes. 


\section{Post-Interview Overview}

\section{Figure 4.3}

Final Group Responses to Theme One (Following All Module Completion)

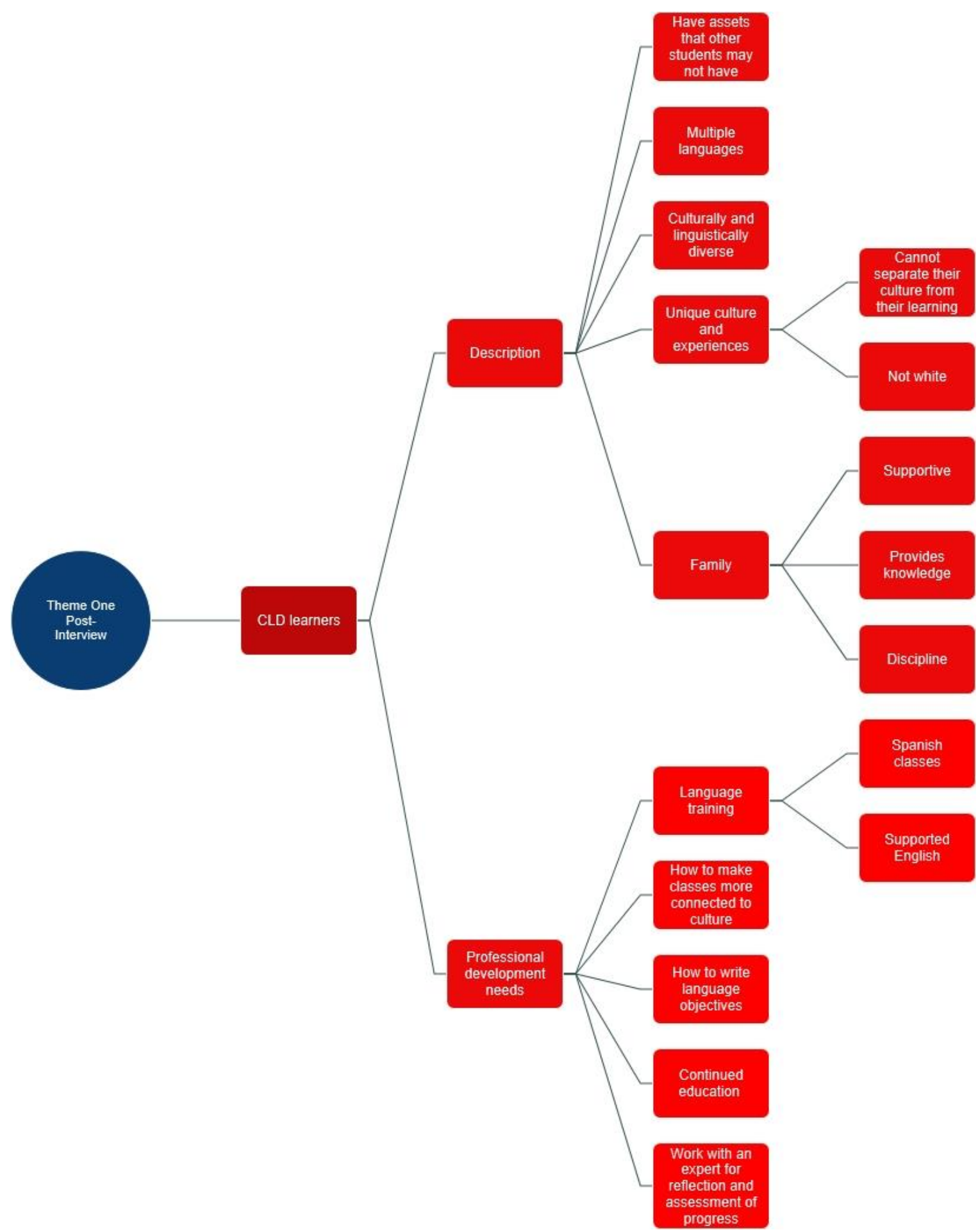




\section{Figure 4.4}

Final Group Responses to Theme Two (Following All Module Completion)

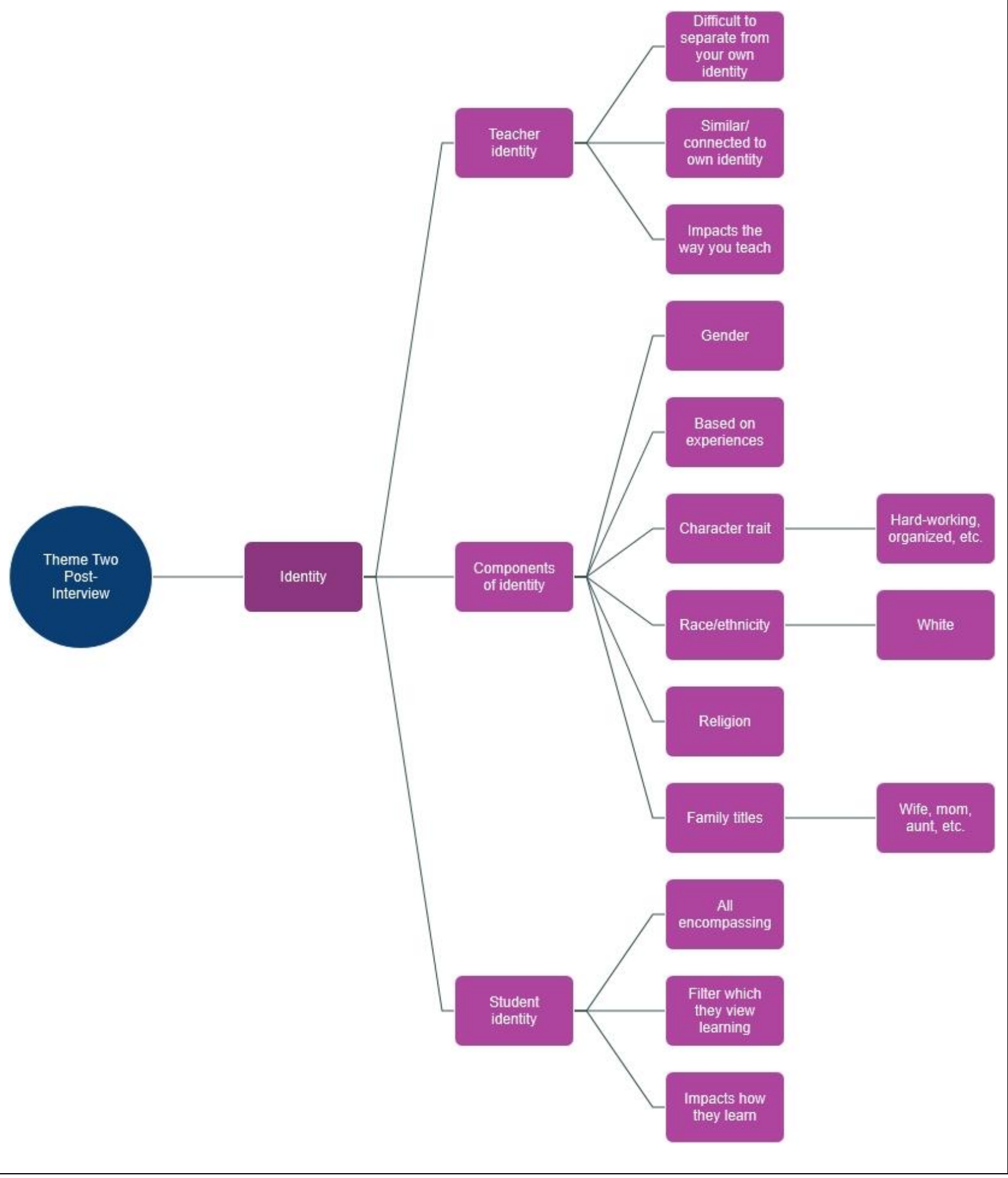


In post-interviews, participants were less focused on the lack of English when describing CLD learners in general. In contrast, the participants' responses included having different cultural backgrounds, having more than one language, and bringing unique and diverse perspectives into the classroom spaces. Rather than only mentioning these different perspectives when asked specifically about the assets CLD learners bring to the classroom, the participants now used this terminology in describing who CLD learners are.

Although participants still mentioned compliant behaviors as assets, the participants highlighted the students' multiple languages, backgrounds, and experiences as the ways in which the CLD learners enriched the room. In addition, the participants did not list the families as mainly a source of discipline and support of the teacher, rather as a source of knowledge and culture for the students.

When focusing on challenges, multiple participants described that one of the biggest challenges that CLD learners faced was the pressure to assimilate and that the structure of our school system adds to that pressure. This assimilation became one of the main foci of the challenges that CLD learners face instead of the lack of English. In addition, participants listed cultural mismatches and having teachers who could not speak their native language. The participants shifted the focus of the challenges to a system deficit or teacher deficit versus a "perceived" deficit of the student. Participants used more asset-based language and ideas when discussing who CLD learners are, the assets they bring, and the challenges that they face in the classrooms.

In the pre-interviews, the participants were all open and excited to receive professional development, and the training that they requested was fairly vague and centered on strategies that they could use to make their content more accessible. In the post-interviews, the participants 
expressed feeling "overwhelmed" but "wanting to learn more." One of the participants voiced that she signed up for an ESL cohort after taking part in the study because she wanted to continue growing in serving CLD learners. In addition, one participant said, she "wanted the world." Professional development topics included layering in the language standards and language objectives and building upon a student's linguistic strengths by showing language in multiple representations. Additionally, participants voiced wanting more training to connect to students' cultures, and within modules, participants voiced concern about vetting curriculum not only for translations of the English text but also inclusion of cultures and inclusiveness. One participant stated that she was unaware of the lack of representation of CLD learners in STEM programs, and said, "I would like to help with that (being intentional of seeing themselves in STEM spaces).”

An added shift was the ways in which the participants included the CLD teacher in their responses. Prior to the modules, CLD teachers were not mentioned as a part of the needs of the general education teachers. However, in the post-interviews, almost all of the teachers wanted to work more with the CLD staff as co-teachers and voiced that they could be partners to continue their education; an asset-based view of CLD teachers is evident as a participant stated that they wanted to have the opportunity to "work more with a CLD expert."

During the post interviews, most of the participants felt more comfortable talking about identity in general as well as and its role in their teaching and in student learning. One participant stated, "That was my favorite module. I had never thought about identity before." In addition, she added, "I would like to ask our students about their identities." One participant still felt visibly uncomfortable with talking about identity. She felt that identity was often something private, and because of this, she stated that she understood the students who were private with 
their identities as she felt that she was private about her own identity. She focused at first on being hard-working as a component of how her identity was linked to her teacher identity, but she then expanded to state that identity did impact how we view the world and how we treat one another, specifically looking at social justice issues.

When describing their own identities, most described the same components they discussed in their initial interviews but added on additional factors such as race, religion, beliefs, and citizenship, and they showed a deeper level of understanding of the complexity of identity work. In addition, they shifted the ways in which they spoke about their own identities as describing that "identities are complex," "permeates all aspects of ourselves," and "impacts us throughout, every moment of every day." All felt that you could not separate yourself from your identity and that your culture affected how you thought and how you viewed things. While only one person voiced comfortably that their own identities and their own beliefs impacted their teacher identities and their decision making in their classrooms at the beginning of the study, all believed they were connected with one stating, "they are parallel to one another," and another participant saying that identity was "all-encompassing and could not be separated." In addition, one participant stated, "I know that it's impossible to not bring my identity into the classroom, but also (I need) to be thoughtful about not having my identity not be the sole, primary focus in the room and know that can't happen unless you're intentionally choosing something different."

As the participants described identities, they described them as evolving and complex. This discussion also included the ways in which their identities showed up within their classrooms as they discussed topics ranging from their classroom set-up choices to the way that they teach. Multiple participants voiced wanting to have more languages present on their wall 
spaces and wanting to be more intentional when creating a warm, welcoming space, which involved including cultures.

This description of their own identities also then transferred into how they felt their students' identities affected their learning. Again, they used words like "all-encompassing," “always present," "their lens," and other asset-based terminology. Although I will discuss professional development as an included category within the ways that the participants view their CLD learners, many of the participants requested professional development that helped them connect to their students' cultures.

Throughout the interviews, the participants demonstrated language showing that they had a clearer picture of how their own identities as well as their students' identities were shaped by their own experiences and cultures and that even when we think they can be separated, they (our identities) are always present and evolving.

Furthermore, participants stated that "this type of training should be required of all staff," and that they "would like to go deeper into what we learned." Many focused on continuing their education by working with a co-teacher or being more intentional with team time and department meeting and wanted the district and school to provide more opportunities to learn about how to meet the needs of CLD learners. One participant mentioned that the school needed more CLD staff to make that happen and another mentioned having CLD coaches who were trained in content areas to work with CLD and general education staff. One participant said, "It is a lot. A lot. I just wonder if our district is even doing this and doing it right." The participants felt that “one and done," "a lack of accountability," and a "lack of supported growth," lead to a lack of supports and training for teachers who work with CLD learners. See figure 4.2 for the codes and categories of the post-interview. 


\section{Findings}

Research Question 1: How do math and science educators view CLD learners in their classroom when provided with targeted professional development that focuses on CLD learners in the math and science classroom?

When looking at the theme of how the involved math and science educators view culturally and linguistically diverse (CLD) learners, two main categories emerged with subcategories as identified through the interviews. These two categories included CLD learners and professional development needs. The first category, CLD learners, included the subcategories of how the participants described CLD learners overall, the assets they described, and the challenges that CLD learners had or brought with them for their teachers. The second category was professional development that the participants requested. The reason I included professional development as aligned with this research question focusing on the participants' views of culturally and linguistically diverse learners is because participants requested training that demonstrated an asset vs deficit-based mindset of how to meet the needs of CLD learners. As a result, this aligned with viewpoints more than it did with the second research question, focusing on identity.

Prior to the module completion, the participants focused on two main components when describing CLD learners, this included a focus on language and having a different perspective. Participants used different ways to include language as the difference by describing a CLD learner as someone who "is still learning English," "has more than one language," or "has a different language." Only one participant, who has had training in critical pedagogy, stated "they (CLD learners) would not only have the language differences, but they would also have some cultural differences that would be there for us to dig into." 
Following the modules, language continued to be listed by participants as they stated, "different language," "a different native language," and "has multiple languages." Participants used asset-based language and did not focus on the deficit-based language by focusing on their lack of English. Only one participant stated, that "they (CLD learners) need services to help them with language." In addition to language, almost all of the participants also listed cultural components when describing a CLD learner by stating "another culture," "not white (referring to the 'main stream' US student)," and "being a unique self." It is important to note that cultural components emerged in the pre-interviews as well, but these were only mentioned as part of specific questions focused on assets rather than on who CLD learners are. However, in the postinterviews, participants mentioned culture and background differences as an asset when discussing who the CLD learners are versus the questions specifically focusing on assets that CLD learners possess.

When discussing assets of CLD learners in the pre-interviews, participants focused on three main areas, this included language, providing a different perspective, and the supports that families provide. Language continued to be the focus of most of the pre-interviews with participants stating that CLD learners can "navigate in more than one language," and "speak another language." Although almost all participants mentioned that CLD learners provide "different perspectives," in their pre-interviews, most simply made this statement without elaboration, and this at times also became a challenge to some. One respondent said, "They (CLD learners) may not be able to see it exactly the way I portray it," but she also stated, "Able to open my eyes, I guess." Additionally, one participant listed these cultural differences as a challenge when stating, "They don't celebrate our traditions." Family support was mentioned by 
two participants and focused on the roles in which families support their child's education by "valuing education" and "supporting the teacher" if there were discipline issues.

These assets continued to be in place in the post-interviews but additional codes emerged. Assets continued to include that CLD learners provided a "different perspective" to the classroom space, but they elaborated to include "varied culture," "different experiences," "have knowledge that others don't," "unique cultural backgrounds," "being bilingual," and "have different customs." Language continued to be an asset mentioned but it was layered within statements about having a unique culture and lens.

When looking at the challenges that CLD learners face in the school system, participants primarily focused on the student in the pre-interview with only one participant stating that, "they (CLD learners) are pushed into classes with teachers who are not trained to meet their needs." Challenges focused primarily on the student's "perceived" deficits, such as language, education, and communication, centering on "not being able to ask for help," "not having formal education," and "not being able to understand the instruction." The challenges focused primarily on their difficulty in understanding curriculum.

In contrast, post-interview questions regarding the challenges CLD learners face were more structural and/or teacher focused. Although language and communication continued to be one of the first challenges mentioned, the participants said, "the teacher does not speak their native language," "the teachers do not have training in meeting their needs," and "teachers struggle with communicating with their families." This simple wording shifted the deficit from the student-deficit to the teacher-deficit. However, student needs continued to be present as one participant stated one of the biggest challenges is their (CLD learners) "fear of asking for help and speaking out." 
In addition, the participants stated structural issues as they stated, "pressure to assimilate," "assimilation is often the goal in classrooms," and "trying to interweave their native culture with the typical American culture." None of the participants mentioned assimilation in any of the pre-interviews, but all of the participants mentioned assimilation in all of the postinterviews. Additionally, participants listed and described that "cultural mismatches," "lack of intentionality," and "lack of cultural inclusion" were challenges CLD learners faced in classrooms. One also mentioned that "despite growing numbers, a focus is still not placed on the students' (CLD learners) needs and how to meet them."

The second main category that falls within this theme and research question is the professional development requested by the participants. The professional development was an indicator for the ways in which they (participants) viewed their CLD learners. One area, not mentioned in the study, but that emerged was how they viewed the CLD teacher.

In their pre-interviews, participants were fairly vague in their responses to what professional development teachers, including themselves, needed to meet the needs of CLD learners. Responses included "how to be intentional," "how to connect content to language acquisition, "how to build vocabulary," and "how to support them." In addition, one participant simply stated that she "wanted to learn from an expert." When discussing the need for science and math-specific training, the participants felt this was necessary as "every content has its own language." While one participant felt math was universal and "the same in the whole world," another stated that "math is more than numbers." Each felt that having specific training for their content area was needed.

Professional development descriptions in the post-interviews were much longer and detailed in comparison. Many focused on language as participants requested, "new and different 
tools," "want to grow and learn more," "continue working on teacher strategies, such as rate of speech and repetition," "how to allow more flexibility in student responses," and "how to layer in the WIDA (WIDA, n.d.) standards." In addition to these requests, the participants also included components of the whole CLD learner as they requested, "how to look at curriculum for language and culture," "more about identity and culture," "how to make students feel more welcome and included," "how to be more intentional about including culture," and "how to change the mindset of teachers." All of the participants still vocalized that they felt professional development was needed and voiced they wanted to continue learning, wanted to "co-teach with a CLD teacher," have "more opportunities for continued education," and to have practice and feedback from a CLD expert. In addition, one participant stated, she would "like to do the modules again but with different people because (she) liked discussing what people were doing and hearing their perspectives on the presented information." The overall feeling was that the teachers did not know what they did not know when it came to working with CLD learners, but they vocalized that they did not believe enough was being done to meet their (CLD learners) needs, and that teachers needed to have professional development. Additionally, they felt that schools and districts needed to be intentional in providing time and staffing to meet these professional development needs.

Upon looking at the presented codes and responses in the areas of CLD learners, through this professional development experience, the participants used more asset-based language, saw the students past only being able to speak another language and wanted to grow to continue to learn more about CLD learners. Additionally, they spoke more of the importance of cultural inclusion and spoke in specifics about the assets that the students' possess. Challenges shifted from being focused on what the students "lacked" to what the educators and schools "lacked." 
Through these categories and codes, the involved teachers ended with a more asset-based view of their students and their families than they presented at the beginning of this study suggesting that professional development can shift the ways in which teachers view CLD learners to a more asset-based mindset.

Research Question 2: How does the identity of a teacher shift when provided with targeted professional development that focuses on CLD learners in the math and science classroom?

For this research question focusing on identity, I had one main theme, which was simply called, identity. I included three categories within this theme, which included components of identity, student identity, and teacher identity.

Components of identity included codes that the participants used to describe a student or a teacher's identity, such as race, gender, etc. This category encompassed how they "defined" identity or an individual's identity. Student identity included codes that the participants used to describe their students, the role that identity played in how students learned, and how students form their identities. Teacher identity centered on the participant's personal identity, how they described their teacher identity, the connection or lack of connection between their own personal identity and their teacher identity, and the influence or lack of influence that their identity plays in the decisions that they make in their classrooms.

As mentioned in the earlier narratives in this chapter, participants were less comfortable discussing identity questions during the pre-interview. With the exception of one who said, "That's a fun question," participants took longer pauses when addressing the questions focusing on describing their identities. All participants identified as a female while the other descriptions included age, profession (teacher), family roles (aunt, wife, sister, mom, etc.), character traits 
(approachable, fun, organized, strong, logical, private, etc.), and also things that they like (working in diverse spaces). One participant stated that some are more private with their identities and that she did not have a culture like other people do. This statement will be discussed in Chapter 5. One participant who had coursework focusing on critical race theory included race along with her identity. However, she was the only one who mentioned race or ethnicity when discussing identity. In post-interviews, the initial characteristics as listed above stayed consistent. However, participants were much more comfortable answering the questions with one participant stating that she has "been thinking a lot about identity since the modules" and said the identity module was her favorite module. In addition to the above descriptions of identity, more participants mentioned race (stating they were white) and mentioned that identities were "super complicated" and "all encompassing." While in the module focusing on the identity, participants mentioned religion and privileges; however, these were not mentioned in the postinterviews.

When discussing the role that their own identity played within their teacher identity in the pre-interviews, most felt that they could separate their two identities. With the exception of the participant with critical race theory training, the participants were unsure how their identities would impact their classroom decision making. A common thought was that certain components would carry over, such as their "values," the way that they "mom," or that due to their family upbringing, they could provide that "stability to kids who did not have a strong family."

In post-interviews, all of the four participants stated that personal identity and their teacher identity were linked stating that the two identities were "similar," "parallel," "all encompassing," "linked in your core beliefs," and "not separable." Furthermore, one participant said that identity "permeates everything at every moment." This linked back to earlier 
conversations in the modules in which teachers considered whether classroom spaces could ever truly be culturally and identity neutral. One participant stated that "it's impossible to not bring my identity into the classroom, but also to be thoughtful about not having my identity be the sole, primary focus in the room and know that can't happen unless you're intentionally choosing something different."

When discussing student identity and the role it played in the classroom during preinterviews, with the exception of one participant who confidently stated, it (their identity and culture) "impacts a lot," the participants hesitated and took more time on this question as well. One participant stated that student identity affected their worldview, referring to science principles, and another said that identity changes except for core values, but she did not respond to the ways in which these changes or identity would affect their learning. The final participant said that she felt like she was not answering the questions correctly.

As with the teacher identity questions, the participants seemed more confident responding to the student identity questions in the post-interviews. Once again, one participant mentioned that identities were "all encompassing" and thus all of their learning was seen through their lenses. Another participant stated that the students' identities were impacted by their experiences and their cultures, and another felt that families and cultures impacted a student's identity. Participants stated that a student's identity "impacts learning," "can't be separated from the learning," and "influences their learning." One participant felt that the level to which they wove their identity into their school identity was connected to whether or not they embraced their native culture. In contrast, participants mentioned that schools encourage assimilation whether intentional or not. 
Returning to the research question as to how the identity of a teacher shifts through professional development, I did not see drastic ways in which the teachers' identities were transformed in the ways the participants described themselves. However, there is evidence of a shift in their overall understanding of identities (both of their own personal and their teacher identities as well as a student's identity). Additionally, the participants shifted their understanding of the role that identity plays in the education system both in their teaching and in a student's learning as demonstrated by their responses to the post-interview questions and discussion. In addition, the participants shifted from being hesitant and unsure about discussing identity and its role in education to being more comfortable sharing their perceptions of their own identities, their students' identities, and the roles (both positive and negative) that those identities affect classroom decisions and learning. Through this study, although inconclusive as to whether professional development shifts the identities of teachers, there is evidence that professional development shifts the ways in which teachers understand identity, its components, its complexity, and the role that it plays both in teaching and in learning.

In this chapter, I have described and analyzed the findings from this professional development qualitative study as aligned to the two research questions. I have provided a deeper discussion of these findings and their connections to previous research in Chapter 5.

Additionally, in the post-interview, participants answered questions that connected with the structure of the professional development with videos and discussion spaces in the form of focus groups; I addressed these questions within Chapter 5. Furthermore in Chapter 5, I discussed the further implications, limitations, and connections to the theoretical framework described in Chapter 3. 


\section{CHAPTER V: IMPLICATIONS}

The purpose of this action research, which I grounded in qualitative methodologies, was to explore the relationship that professional development had on the ways in which middle level science and math educators viewed their CLD learners and its (professional development) role in shifting teachers' identities. This chapter provides a summary of the findings of the study and a deeper discussion into the findings in relation to the research and theoretical framework. Also included is a discussion of future research and recommendations for educators and schools as they look at how to improve the science and math experiences of CLD learners as well as the limitations and delimitations of this study.

This chapter contains discussion and recommendations focused on the following research questions:

1. How do math and science educators view CLD learners in their classroom when provided with targeted professional development that focuses on CLD learners in the math and science classroom?

2. How does the identity of a teacher shift when provided with targeted professional development that focuses on CLD learners in the math and science classroom?

\section{Summary}

This qualitative study aimed to look at the shifts or the lack thereof of educators in two areas, the way that they viewed culturally and linguistically diverse (CLD) learners and their own identity. The theoretical frameworks that were the foundations for this study and its structure were sociocultural theory and critical race theory, more specifically critical whiteness theory and Latiné critical race theory. Through these theoretical frameworks and the layering of research focused on multilingual learners, science and math education, language acquisition and 
learning, identity, professional development, and social equity frameworks, I designed a professional development action research study to analyze the two research questions as listed above. Within this study, four middle school math and science teachers completed six modules over a four month period that each included pre and post-questionnaires, a training video, and a focus group. These six modules focused on identity, culture and connections, an overview of CLD learners, lesson planning for CLD learners, science and math inclusion of CLD learners, and co-teaching. The participants took part in a pre and post-interview before and after completion of the modules, and I analyzed the codes from these interviews to create the categories and eventually the themes as aligned with the two research questions. For a more detailed look into the code, category, and theme development, please see Chapter 4.

When looking at the first research question, one theme with two categories emerged. This theme was called, 'Views of CLD Learners;' this theme included CLD learners and professional development. When looking at the four participants individually and then as a group, the findings suggest that targeted professional development can shift educators to have more asset-based views of their culturally and linguistically diverse learners. The pre and post-interviews show that participants shifted their mindset to not only see the linguistic assets that the students possess but also their rich cultural background and its role in their students' learning. Additionally, they shifted their understanding of the family as simply being a supporter of education, through the view of helping with setting a tone of discipline and respect, to a view of the student's family as a source of knowledge. Concurrently, they requested professional development that reflected this respect for their students' cultures and native languages.

At the beginning of the study, the participants' first descriptions of CLD learners tended to lean toward lacking English proficiency, demonstrating compliant behaviors, such as being 
respectful and being direction followers, and bringing in different perspectives. However, at the end of the study, participants' descriptions layered in students' deeper linguistic repertoires and their different cultural connections, and the participants had a more complete view of what types of different perspectives the participants brought into the space. However, characteristics that emerged like, "not white," suggest further discussion centering on whiteness as a norm are needed. Additionally, the participants could more easily pinpoint what they (the educators) needed from professional development as they were beginning to understand more of what they did not know. These professional development opportunity descriptions were more asset-based as they sought to learn more about layering in cultural connections, writing language objectives, and wanting to build upon native language. In contrast, in the pre-interviews, these professional development requests focused primarily on how to make their content area more understandable and how to layer in learning English within their math and/or science classroom. Through this profession development study, participants shifted their views about CLD learners to be more asset-based.

Research question two focused on identity. From this question, there was one theme, which was 'Identity,' and three categories, which included components of identity, teacher identity, and student identity. As the participants explored and discussed identity, there was insufficient findings to see whether or not professional development shifts the ways in which teachers identify. However, there is sufficient support that educators, when provided with targeted professional development, shift their understandings of the complexity of identity, both for the educator and the student. The participants shifted their understandings from the perception that one could separate and compartmentalize their identities to the realization that identities were "all-encompassing" and ever present as we teach and learn. Additionally, all four 
participants shifted their understanding of the role that identity and culture has on a student's views and educational experience as well as how an educator makes decisions, looks at curriculum, and chooses the practices one uses in his/her/zir classroom.

When looking at the shifts that took place with the targeted professional development, all four of the participants shifted their views of CLD learners and how they perceived identity and its role in the classroom. This study supports that professional development shifts the way that teachers perceive their CLD learners and their understanding of how their own identities as well as their students' identities affect their teaching and learning, respectively.

\section{Discussion}

As the demographics of schools in the United States continue to diversify, it is critical that educators and those who provide professional development continue to analyze what training they provide and what professional development educators and those involved in education need. Pairing the statistic that $23 \%$ of all school age children speak a language other than English at home (Children Who Speak a Language Other than English at Home | KIDS COUNT Data Center, 2020) with the recognition that white educators still remain the highest percentage of teachers in the United States (Snyder et al., 2019), cultural mismatches require targeted professional development. This study focused on four middle school math and science educators and analyzed the ways in which they viewed their CLD learners as well as their own identity through the process.

Despite the growing number of Latiné students enrolled in schools, there continues to be a lack of representation and a perceived achievement gap between Latiné students and their peers in math and science (Aud et al., 2010; Huerta et al., 2019). Additionally, they are overrepresented in lower level math and science tracks and underrepresented in STEM programs 
and fields (Aud et al., 2010; Feldman \& Malagon, 2017; Gholson \& Wilkes, 2017). I posit that contributing to this gap and lack of representation is a lack of professional development that refutes deficit views of CLD learners and focuses on the assets that they bring to the classroom. As a result, general education math and science educators and the leaders within these fields do not have focused training on how to build upon the linguistic and cultural assets of CLD learners, which are critical components of more equitable spaces. As most CLD learners spend the bulk of their time in classrooms with educators who lack the training in their unique assets and needs, this leads to a lack of support and leaves educators feeling unprepared to fully meet CLD learners needs (Cosentino de Cohen \& Clewell, 2007; Spycher \& Haynes, 2019); this inclusion in the general education classroom is especially present in math and science courses. Additionally, those who have not had sufficient training in culturally inclusive practices, often blame low test scores solely on factors such as poverty, student motivation, lack of participation, home language, and family support rather than considering the role of institutional structure, cultural mismatch and poor teaching on these scores (Sleeter, 2017).

A primary focus of this study was addressing the assets and needs of CLD learners as I analyzed the views in which the involved math and science educators had of their CLD learners. At the beginning of the study, the participants were fairly vague about the assets of their CLD learners by focusing on "diverse perspectives" and families who supported education and discipline. When listing the challenges that CLD learners had in math and science, participants concentrated on the language deficits (of English) and lack of background knowledge. The educators as a whole did not demonstrate that they acknowledged (intentionally or unintentionally) that students' experiences, funds of knowledge, and cultural backgrounds were educational capital that students and educators could build upon. However, "integrating students' 
out of school funds of knowledge into classroom practices is a powerful tool of supporting all students-but even more so for those from traditionally marginalized populations" (Johnson \& Johnson, 2016, p. 117). Furthermore, educators voiced that they felt they lacked the tools and training to be able to incorporate adequate strategies to meet the needs of their CLD learners.

The listed assets and challenges of CLD learners shifted throughout the study. While in the pre-interviews, the participants had simplistic responses, they elaborated and seemed more thoughtful about their responses in the post-interviews about the importance of native culture and language, and the challenges shifted toward structural problems as they shifted fault from the students to the systems. Their requests for professional development shifted to add in more ways to represent language, suggesting they understood the importance of the different language domains and the incorporation of native language and students' cultures into the classroom. The deficit-based language shifted in the challenges of language from being a teacher/structural problem rather than the student's deficit.

Additionally, all of the participants addressed the issues with assimilation in their postinterviews. One participant stated that she had thought assimilation was the goal for schools prior to the discussion about the acculturation model. Failure to train educators on the role assimilation plays in our schools, allows for assimilation to continue. Although participants recognized that assimilation is a problem that needs to be addressed, the educators did not have clear steps about how they were going to challenge this. They once again turned to the lack of training and intentionality in meeting the needs of CLD learners.

Multiple participants mentioned that they wanted to include more cultural components and felt that curriculum used with CLD learners needed to move past simply having translations of text but should also focus on cultural representation and inclusion in science and math 
curriculum. This representation and inclusion was not included in any of the pre-interviews. Being able to recognize and start the steps to breaking down assimilation within all spaces of a school, and in this study, specifically in the science and math spaces, is critical in creating more equitable learning spaces for CLD learners.

In addition, as shown with these four participants, who are veteran educators, many lack the training needed as they did not have the opportunities for how to meet the needs of CLD learners at a deep level in their undergraduate programs as pre-service educators and do not have many opportunities past the basics, such as using visuals and providing materials in their native language, as in-service educators. Without specific training on language demands and content practices, educators will struggle with effectively responding to and will not feel the need to effectively meet the language needs of CLD learners as they participate in content area practices (Crandall \& Bailey, 2018).

Additionally, working specifically with math and science educators allows them to look at ways to meet their CLD learners' needs in their specific content areas. Instruction in math and science must take into consideration both the students' language and cultural background and how to layer those elements into the practices of math and science. Because English remains the main language of instruction, educators need specific training in discourse and how to imbed language into their content practices and instruction. This study reflects that professional development gives them a space to recognize the cultural and linguistic assets and needs in math and science spaces.

Educating monolingual educators about the backgrounds and assets that a CLD learner brings to the space also begins to recognize key elements of an inclusive linguistic and cultural space. As shown in the study, educators viewed having a second language as an asset, but they 
did not expand into why this asset is critical in the classroom space. However, during the focus groups and in their post-interviews, participants more deeply understood translanguaging, and as a result, the educators stated they wanted to allow and encourage the use of native language in their classrooms. To not encourage and allow translanguaging in a classroom space is to only allow access to less than half of a multilingual learner's linguistic repertoire while monolingual learners continue to get full access to theirs (Yip \& García, 2015). Due to a lack of understanding and training about translanguaging and the importance of native language usage in all classes, educators do not build on the rich linguistic repertoire that a multilingual student already possesses. Furthermore as stated by García \& Lin (2017), Simply teaching in a monolingual mode that reflects the language practices legitimized by the dominant group is harmful to children. It results in academic failure, linguistic and identity insecurities, and the inability to enjoy the critical metalinguistic awareness that enables students to become critical analysts and users of language in society. (p. 4) Therefore, failure to address this knowledge continues to allow monolingual English educators to have a deficit-view of native language usage in the classroom, whether intentional or not. Failure to address this deficit-based thinking is an equity trap that when unaddressed continues inequitable learning spaces for marginalized students (McKenzie \& Scheurich, 2004). Through these modules, all of the teachers requested further professional development focused on layering in native language usage, and all of the teachers stated high interest in having a CLD co-teacher to help provide more access to language development in both languages. This demonstrates a recognition of the importance of a student's native language. Without providing intentional training to general education teachers, they will continue to view their usage of language with a monolingual lens. 
At the beginning of this study, the educators did not expand into why the "different perspective" students bring into the classroom was an asset nor to how or why the students' cultures and identities affected their learning. As some expanded in the modules, they mentioned that they had different experiences that other students did not have. Providing a space to explore funds of knowledge as well as cultural wealth forced educators to address both their understanding and knowledge of their students as well as their biases within their curriculum and pedagogical choices.

Sociocultural theory recognizes that learning is a social endeavor and thus takes place within social contexts; therefore, to fail to recognize that social contexts look different in different cultures continues a structure that promotes assimilation. Additionally, because learning is a social and cultural process, it involves enculturation of the students into the practices and norms of science (Carlone et al., 2011); I extend this into the other content areas as well. As a result, to fail to recognize different cultures outside of the white perspective, schools fail to meet the needs of our diverse learners. Professional development in which white educators must challenge their vision of both their spaces and practices is a critical component of creating better science and math experiences.

When educators only focus on students' linguistic needs but do not recognize their students' unique cultural and social needs, they neglect the students' cultural and social identity, which helps learners gain both their confidence and feelings of capability toward learning and enacting change in their classrooms and the world around them (Yoon \& Uliassi, 2019). Additionally, Latiné Critical Race Theory (LatCrit) provides a critical lens to see the different forms of capital that Chicano and Latino students possess (Valdez \& Lugg, 2010) and provides opportunities to challenge the deficit views of and that continue to marginalize Latiné people. 
Without intentional training on the cultural wealth that Latiné students possess, students are not intentionally elevated in math and science. Therefore, failure to train educators to shift their lenses continues this marginalization and lack of elevation without any challenge.

In addition, as shown in this study, educators do not always consider the ways in which a student's identity and their own teacher identity plays a role within their math and science classrooms. Identities affect how we engage or choose to not engage in activities and also affect our attitudes and sense of self in content areas (Bishop, 2012). Therefore to not consider the role that identity plays in our classrooms, we fail to address a key element of learning and teaching. Additionally, failure to reflect on our own identities, as educators, intentionally neglects analyzing the lens through which we teach. The perception that identity does not impact teaching and learning must be addressed, and as evidenced in this study, educators are not always aware of the role that identity plays in their classrooms. At the beginning of this study, most educators felt that their identities could be separated. However, at the end of the study, they felt that "identity was all-encompassing."

Educators must have opportunities in which they view their own identities and cultures and their impact on their own views and choices. This study showed that through professional development, educators can better begin to understand and view their identities and cultural differences as a key component of their own teaching as well as a CLD learner's educational experience. To fail to challenge the whiteness of schools and connect to the cultural backgrounds and identities of diverse learners is to once again continue a system that promotes assimilation. During this study in pre-interviews, one participant said, she had "no culture." Additionally, in discussions about inclusive spaces, multiple participants viewed an inclusive space as one that had no evidence of traditions, such as Christmas, or one with solely content-focused 
decorations/posters. Critical Race Theory (CRT) recognizes that "Because racism is an ingrained feature of our landscape, it looks ordinary and natural to persons in that culture" (Gillborn, 2016, p. 49).

What the participants clearly demonstrated was the idea that spaces could be neutral of culture and that curriculum could be neutral. It was important to address these biases through Critical whiteness Theory. Critical whiteness Theory ${ }^{2}(\mathrm{CwT})$ emphasizes the importance on analyzing the whiteness both within the individual as well as in the systems around us. To create more inclusive spaces, education programs and professional development need to analyze the systemic oppression within our education system (Sleeter, 2017) as well as the role that whiteness plays in this system. Evidence of this emerged when one educator defined a CLD learners as "not white;" although she used this description as a way to describe that CLD learners have a more diverse background, this demonstrates further need for what whiteness means as it is often seen as the "norm." Furthermore, this familiar equity trap of "racial erasure" (McKenzie \& Scheurich, 2004), colorblindness, and the norm of the classroom must be recognized and addressed in professional development to begin to dismantle broken systems. This study showed that professional development can be a place to recognize and address these issues. This discussion is very timely as we look at the divide and fight surrounding critical race theory that is very much present and affecting school systems across the nation.

Additionally, at times throughout the study, many of the participants became more hesitant or quiet when topics focusing specifically on how being white in a diverse space impacted their space and their decision making within the classroom. As Robin DiAngelo (2011) stated, "Whites have not had to build the cognitive or affective skills or build the stamina across

\footnotetext{
${ }^{2}$ Please see Chapter 1 on the intentionality of capitalization.
} 
racial divides" (2011, p. 57). However, this study shows that professional development provides that much needed space to begin to build that stamina.

One participant, who had spoken strongly about not having elements of cultural traditions up in her room in order to not exclude anyone because "there is no way you can include everyone. You will miss someone," shifted her view to "it's impossible to not bring my identity into the classroom, but (I need to) also to be thoughtful about not having my identity be the sole, primary focus in the room and know that can't happen unless you're intentionally choosing something different." Her statement represented that by not choosing something different, your (the educator) identity and culture are taking up the space. This statement suggests that she has shifted her understanding of the role that her whiteness takes up in the classroom space. The "lack of culture" being seen as a neutral culture rather than the white culture of the room continues to play into the same camp as "not seeing color," and this thinking continues to plague our school system.

There is not sufficient support in this study to see if the professional development shifted the ways in which the educators identified themselves. However, their perceptions of the role that identity plays in their classroom spaces (both educator and student) shifted from thinking they could separate their identities and keep them private and unknown to the understanding that identities are "all-encompassing," "always present," "complex" and "evolving." Additionally, they broadened their understanding of the components that impact and compose our identities. To have a greater grasp on what identities are and the roles they play within our educational system is critical if we want to change the system and the identities valued. Providing educators with opportunities to shape and reshape their identities makes them more aware of who they are and how their identities shift (Avraamidou, 2019). In addition, teachers' race, class, and gender 
inform their relationships with their students, curricular choices, and educational philosophies (Brown, 2006); thus, professional development focusing on identity plays a key role in creating better math and science spaces for CLD learners. This study's findings support that educators' understandings of identity shift when provided with targeted professional development.

Through the lens of CwT, educators begin the process of analyzing their whiteness and the ways and roles that whiteness plays in the greater system in creating the spaces in which people of color must navigate and survive (Matias \& Mackey, 2016). Through this professional development, the findings suggest that when given spaces to question their own identity and how their whiteness controls a space, educators begin to shift their lens of the role of identity and culture in the space.

Furthermore, there is a connection between educators who find success in and feel knowledgeable about science and their identification as a teacher within science (Chen \& Mensah, 2018). I extend this to other content areas and their comfortability working with different populations of students. Therefore, by building the capacity of educators who work with CLD learners to understand how to develop language, build cultural connections, choose effective strategies, and plan with CLD learners in mind, they may identify more comfortably as a science or math teacher of CLD learners. This targeted professional development opportunity showed that teachers felt more comfortable with strategies and lesson planning specifically focused on their content areas. Additionally, by taking part in training focused on CLD learners, the participants could voice more clearly their needs to build this capacity showing that they did not know what they did not know, which is part of the criticalness of professional development work such as this study. 
This greater understanding of identity also extended into their understanding of how identity plays a key role in how their students also interact and learn in the math and science classroom. Just as in their own identities, many were unsure of how a student's identity impacted how they learned. This shifted to that a student, like an educator, could not separate their identity from their learning. Additionally, focusing on the importance of identity and perception of smartness in professional development experiences also shows educators that smartness is a key component of a student's academic identity as it helps shape the student's perception of efficacy, ability, and success in relation to their academic potential, achievement, and performance (Hatt, 2012). Furthermore, students who do not see themselves as part of the STEM community may not feel that they are welcomed nor feel that their assets are recognized (Kang et al., 2019). This lack of math/science identity can affect their achievement and engagement in those fields (Gholson \& Wilkes, 2017) as well as their continuation in these fields (Bishop, 2012). Providing targeted professional development at the middle level is critical to help educators understand the importance of identity in engagement and achievement in math and science.

As we look at breaking down the issues in the lack of representation in math and science fields by multilingual students and professionals, it is critical that we look closely at the training of our science and math educators. This study suggests that when science and math educators have spaces to challenge their views of CLD learners, are provided with training on both linguistic and cultural assets and needs of CLD learners, and learn more about both their own and their students' identities, educators shift the ways in which they view their CLD learners and their understandings of the role of all identities (including their own whiteness/identity) in their math and science classrooms. This shift is a much needed shift to create more equitable spaces 
for our CLD learners that can build upon their science and math identity and elevate them in STEM fields.

\section{Limitations and Delimitations}

I conducted this study in an urban middle school in the Midwest and only included four teachers. This small participant size was intentional but is also a limitation. I was also an insider to the school and came to the study already seen as an expert and trusted educator and researcher. This allowed me to push the teachers and their views in a way that an outsider might not have been able to push. Additionally, all educators taught in the same school within the same district, and the participants elected to be in the study. As a result, they may have been more open to change and to conversations focusing on CLD learners and the structural issues surrounding their educational experiences. Furthermore, all participants in this study were white females. Conducting this study with a more diverse group of gender and race would be an essential next step.

\section{Implications and Recommendations}

Looking at this study, all of the participants said that to have growth it needed to be "on going." They did not think that professional development for CLD learners should be "one and done." Additionally, these participants barely scratched the surface of identity work and whiteness. Critical next steps would be to look at how this professional development is actually layering into their classrooms and to create more opportunities for them to grow. Many stated they wanted to look at their classroom spaces and diversify them; did this happen? What is the long term effect without more training? One participant stated that she "wanted teachers to be held accountable" to make these changes. What does this look like? Professional development is most effective when it is sustained over time (Parsons et al., 2019). Therefore, a critical next step 
would be to create additional opportunities to build upon this professional development experience and to analyze the shifts in their views and identity.

Additionally, this study shows the importance of creating more experiences that discuss cultural connections and identity to in-service teachers. Spaces and training must be created to have these conversations or deficit-based views and lack of supports will continue to create spaces that are not inclusive of CLD learners. A simple one and done workshop model that is not specific to content areas does not work as it is not continual nor specific enough for educators to be able to implement as they will not find that it is tailored to their content practices. Furthermore, each educator had their own growth trajectory. Just as our students come with different experiences and identities, as do our educators. Further studies could center on how these varied experiences and identities shift their growth trajectories and mindset when provided with professional development of this type. Because the participant group was chosen to be as varied as possible, the educators had significantly different experience levels and thus further studies would be needed to look for patterns in trajectories.

If we want to create math and science spaces in which CLD learners thrive, we must strategically target the needs and assets within those spaces to be more specific with the math and science educators. This study shows that specific training designed for math and science educators shifts the perceptions that the educators have of their CLD learners and the role of identity in their math and science space. Additionally, due to the structure of this type of study, which was all done online via video modules and using the online meeting platform Zoom (Zoom, n.d.), as a result of the pandemic, this module type training could be carried out in schools who may lack access to a math and science-trained bilingual English language development specialist. 
This type of training should be conducted in all schools for all science and math educators. Although that is a lofty goal, failure to challenge the whiteness of spaces and create a different narrative of what a science and math experience can be for diverse learners is actively accepting the broken systemic structures in our educational system that continue creating spaces that perpetuate white privilege and assimilation within the math and science space.

\section{Additional Comments Regarding Professional Development}

COVID-19 impacted this study. As a result of the pandemic, I had to consider a way to carry out this study that would be beneficial for participants and still maintain the integrity of the research questions and the design. For this, I looked at research focusing on professional development (PD). Research on professional development shows that the best learning occurs when it (PD) is layered into their current work, is flexible, and is reflection-focused (Parsons et al., 2019).

Additionally, educators need to be able to process through their professional development and have the opportunity to revisit the content within the PD at their own pace (Wynants \& Dennis, 2018). This design allowed the participants to reflect in the pre-questionnaire, watch the video in their own time within the time parameters provided as well as rewind and review the video content and then reflect in both the focus groups as well as the post-questionnaire. To see the participants' thoughts on this type of professional development, I added a few questions during the post-interview to get the participants thoughts on the design. Through these questions, participants all were affirming that having the opportunities to preview the information and to complete the videos at their own time and pace benefitted them as busy educators.

In addition, giving space to reflect independently and then as a group also helped them understand and process the information in the professional development. Sarah stated she 
appreciated completing the videos and questionnaires "on my own time" and also gave her "time to digest." She also mentioned that discussion through the focus groups added a "communal piece," which let her "hear other people's experiences and views." Amanda felt that previewing the information and thinking ahead on questions was beneficial for her before we had the discussions, and she felt the style of the PD could be layered into her own classroom. Tamara felt that it helped "to chunk the information" to "break it down into manageable pieces." Kimberly said that the viewing the videos "on her own time while still having a deadline" was "huge" for her. Additionally, she stated that discussion groups "opened my eyes to other answers" and that she learned better "knowing there's a person in charge of it that knows the content really, really well." This type of online professional development could open up opportunities for areas, such as rural districts or areas with lower numbers of multilingual educators, who may not have the access to as many experts as well as meet the needs of busy teachers in a meaningful way. 


\section{CHAPTER VI: POSITIONALITY}

The purpose of this chapter is to provide my researcher and teacher positionality. I am a white female, which makes up the greatest percentage of public school educators. Part of the issue facing our students is that there is a lack of diverse representation in our schools; this is not the problem that I will be tackling in this paper, as it is outside the scope of this study, but I believe both the active recruitment and the retention of a diverse teaching force is essential. As a white woman, it is critical that I analyzed my own biases prior to and continuously throughout this research process. It is also critical that we continuously analyze whether our curriculum and teaching practices are evolving to teach a continuously changing school population. As someone who conducts professional development, has taught university classes, houses clinical and student teachers, has taught for almost two decades, and has fought for equitable practices in schools, I have seen the breakdown in instruction for our culturally and linguistically diverse (CLD) students. As this study also focused on identity shifts, it is critical that I also analyzed my own identity and journey as an educator.

I have worked with CLD students and their families for 18 years, and I have worked to find ways to be more inclusive within our curriculum and pedagogies for CLD students. My ability to speak Spanish has allowed me to communicate with my students and their families; however, listening to students and their families while sharing elements from their cultural is a key component of an inclusive learning space. Furthermore, giving families and students a space to express their experiences and ideas is critical for creating equitable experiences for our students. Educators must give spaces to hear alternate voices.

I have worked to look for ways to improve educational opportunities for CLD students. I took part in a Fulbright grant that focused on creating curriculum that builds upon the Funds of 
Knowledge of Mexico. This involved linguistic and cultural studies in Oaxaca, Mexico. I have a minor in Spanish and studied in Cuernavaca, Mexico. Furthermore, I have taught middle school for 16 years and elementary school for two years. Throughout this time, I have taught general education mathematics and bilingual mathematics, English as a Second Language, general education science, ESL science, English language arts, social science, ESL social science, bilingual resource, and a newcomer course, for students who have immigrated to the United States within the last two years. In addition, I have served as the science department chair, the multilingual department chair, and as a $6^{\text {th }}$ grade team leader. This diverse teaching palate provides a lens of both the needs of general education educators as well as bilingual and English Language Development (ELD) programming.

This description above is an outside view of and a snapshot of how I would describe myself. The irony and conflict of why a white woman should be conducting research with other white educators to improve the educational experiences of Latiné students is not lost on me, and this struggle is part of my story as an educator and researcher.

I grew up low income in a two-parent household. Although low income, food was never scarce, we never lacked housing, and we benefitted from the privilege that being white and Christian afforded us. We moved a lot in my younger years, moving from Illinois to Wyoming to Illinois to Florida and back to Illinois. Throughout all of this, education was always supported, and my parents, who were highly educated and white, easily navigated the educational system. Through these experiences, all of my educators were white, except for my $6^{\text {th }}$ grade math educator, and I do not remember ever questioning who I was as a student. My parents enrolled me in Spanish class as a child, and I remember feeling frustrated that that was the choice they made for me while my sister was able to take baton lessons. I always loved kids, and I remember 
from an early age buying teacher editions of teacher books from garage sales. Now as an educator, I wonder why those were sold, but that is a different conversation. I made my little brother do math facts to the point that he now tells me they made him have math nightmares. The point? I saw myself as an educator, but I never questioned why I envisioned myself in that way. My identity from a young age envisioned myself that way. This research is not meant to focus on why seeing myself in educators formed that early identity more that we must take a moment and see how those identities formed early on and may give us biases that have never been addressed.

Throughout my educational journey, I had ended up in honors classes that despite going to a very diverse high school included students who mostly looked like me; I remember in AP Calculus my first experience with intersectionality, when sitting with my friend, who was one of a few African American students in the room, I realized we were one of the few west side kids. I remembered thinking that my address separated me from most in the room and questioned how Peter* (name changed) who was both low income and African American must feel.

Fast forward, I went to college at a small college in Kansas. I began to consider majoring in biology, my early dreams of being a teacher from my childhood were long gone as I had a fascination with science. Following a course titled, 'Virus, Bacteria, and Higher Cells;' I decided to major in Communications and Journalism while minoring in Spanish as my early exposure to Spanish drew me into the language. While working at an internship with a local news station, I interviewed a family that had taken part in a tragedy. The family was white and low income. I wrote the story, but the anchor would not read it as written; she changed it to be more "newsworthy." She painted a picture of the family that played into the stereotypes of poor families. I was shaken; I saw myself in this family, and the way she portrayed them made me question the lenses in which society views "others." It is evidence of my white privilege that it 
took me that long to truly begin to question this othering not only in my classes but as a wider society. I vowed that day to change my major, and it was at this point, I began to consider my earliest career interest, education.

I met with my advisor, and I began tutoring. I was sent to a small, predominantly white, rural school to tutor an elementary student. She had recently immigrated to the United States, and the teacher was struggling to meet her needs as a young reader. Due to my ability to speak Spanish, I was placed with the young girl. She struggled with the books her teacher wanted her to read; they were in English. I brought in “¿Eres Tú Mi Mamá?” to match the book “Are You My Mother" that was given to me by the educator. The girl easily read through the Spanish book with pride, and at that moment, I realized that teaching was what I wanted to do. I look back now and think on all of the books by Latiné authors I could have brought in to challenge the usage of the majority curriculum to meet her needs, but that was where I was in my teacher journey. From that point, I completed my degree in K-9 education with minors in communications and Spanish. Following these experiences I was asked to interview in a small K-9 building on the south side of Chicago, near Cicero. The school was at the intersection of three neighborhoods, Polish, African American, and Latiné. The small school had started as a missionary school and had changed into a neighborhood school that was supported by money from churches and other fundraisers to support neighborhood kids to attend the school. I had the opportunity to teach $1^{\text {st }}$ grade and $4^{\text {th }}$ grade as well as Title 1 math and reading in an after school program through Chicago Public Schools. I bonded with students and families in the way you do within a truly neighborhood school. Living in the neighborhood gave me a different view of the assets my students and their families possessed and a view in which I had never had the opportunity to see 
even though I had attended diverse schools growing up. In addition, I challenged my deep seeded biases, especially as it pertained to the "white savior" role.

My desire to be closer to family drew me to the junior high in which I grew fully into myself as an educator. My first year teaching in the junior high, I taught math, science, and social studies to general education students. A new student immigrated to the United States the following year toward the end of the year, and he was placed on a team with non-Spanish speaking teachers. The special education teacher on the team sought to meet his needs with pictures, and our English as a Second Language teacher pulled him for classes. The next year, my principal asked me to work with students whose English language was in its early development since I spoke Spanish. It was this request that would open my eyes to my passion. The student's parents requested for the school to hold him back a year and place him on our teaching team. He spoke both Spanish and an indigenous language, and his funds of knowledge were powerful as he sought to understand the education system in the United States. I had the pleasure of having the rest of his siblings and working with his parents, and he braved a path that was one I did not respect to the level I do now.

As an educator, he taught me more than I believe I taught him. I learned that I had so much I did not know. In the years that followed, I had the privilege of teaching student after student who came with assets and linguistic repertoires much more full than my own, and looking back, I realize that I did not fully realize the value of what they brought to the classroom. A desire to learn more about my students had me returning to school to complete my ESL and bilingual endorsements; through these programs my eyes were opened to strategies, systemic issues, and conflicts that I had not known I did not know, and I continued to question how much 
my own limited experiences had limited my teaching as well as the experiences of the students who I had the privilege to teach.

My identity as a white woman who had always easily succeeded in school taught as my educators had taught me, playing music that I identified as appropriate with decorations that I thought were the best for the space, needed to open myself up to the realities that my identity had afforded me. I was making all of the decisions, and I was centering myself and my own identity with those decisions. It was in the journeys and stories that followed while listening to students and families that I evolved. I had to confront my own decision making, my own beliefs, and my own privilege to find my own white fragility and my own gains in a system that was built for students like myself. This is a process that I believe educators must open themselves up to if we are to change the spaces our students are a part of each and every day. It was not until I gave students more voice, more space, and more control of the space that I fostered better spaces that were more equitable for being open to more perspectives.

Although I had studied in Mexico in college and had backpacked through both Central America and Europe and had taught for many years, it was not until a Fulbright opportunity in Oaxaca, Mexico that focused on Funds of Knowledge that my educational lens was truly transformed. Having difficult conversations that centered on whiteness and privilege as well as questioning the why we see things as we do and the power of funds of knowledge, I grew in a way that I never anticipated. Although I had considered myself aware and felt I had checked my biases, I saw how much more work I truly needed to do to decolonize my own teaching and to further question why I taught what I did and how I did. Families teaching the trades and skills of their ancestors to their children and other assets were not embraced in our communities and schools. Whether intentional or not, our system was not seeing our students with an asset-based 
lens. I needed to be better, and I needed to challenge the educators around me to question their decision making as well. I realized the power of conversations and being exposed to opportunities that made me have to grapple with my own identity and my own privilege, as well as how that affected my classroom curriculum and my decisions within my classroom practices. Failure to do so was being compliant in a system that continued to promote systemic racism within our classroom spaces.

Following 17 years of teaching math and science as well as providing English language development services, I officially joined the Culturally and Linguistically Diverse (CLD) team. It was a position I had longed for, and following the retirement of our English Language Development (ELD) teacher, my principal hired me for the position. I desired to change the mathematical journey for students by adding bilingual mathematics to our bilingual and ELD program. I had taught bilingual math for a year and saw students who were building upon their funds of knowledge through cooking and money conversion, and students were building upon their linguistic repertoire by translanguaging in both the science and math classroom. Students have the knowledge and the experiences, but white lenses were deeming this knowledge as inapplicable or were failing to tap into knowledge by using examples and practices that were centered on whiteness.

Throughout this dissertation, I recognize that I have a long way to go as I continue to seek different spaces. Through this professional development experience, I was hoping to find out if professional development can begin these conversations that are so crucial to create more equitable spaces for our culturally and linguistically diverse students. Failure to get white educators to recognize their own privilege and the importance of understanding the role of culture, identity, and the capital that our students bring into our classrooms will continue to 
create inequitable experiences. When educators fail to continue to learn, to question their own biases/decision making, and to give spaces for alternate voices to be heard, we fail to create spaces that are more equitable and that break down the problematic systemic structures of racism and oppression within our school system. Education is a continuous journey, and everyone's path is their own but also intertwined in the paths of others. To elevate voices and identities of our educators and students, we must be open to other perspectives, difficult conversations, and change. This is my journey and my positionality. 


\section{REFERENCES}

ACCESS Tests | WIDA. (n.d.). Retrieved July 2, 2020, from

https://wida.wisc.edu/assess/access/tests

Aceves, T. C., \& Orosco, M. J. (2014). Culturally responsive teaching (Document No. IC-2). University of Florida, Collaboration for Effective Educator, Development, Accountability, and Reform Center. http://ceedar.education.ufl.edu/tools/innovationconfigurations/

Aguirre-Muñoz, Z., \& Gregory, M. (2019). Concept-based teaching in dual language science classrooms; Using oral language routines to develop scientific descriptions and arguments. In P. Spycher \& E. Haynes (Eds.), Culturally and linguistically diverse learners and STEAM: Teachers and researchers working in partnerships to build a better tomorrow (pp. 45-75). Information Age Publishing.

Allen, M. (2017). The SAGE Encyclopedia of Communication Research Methods. SAGE Publications, Inc. https://doi.org/10.4135/9781483381411

Apodaca, R., Bernstein-Danis, T., \& Demartino, S. (2019). In their own words: Native language in the classroom. Learning Professional, 40(2), 37-41.

Archer, L., DeWitt, J., Osborne, J., Dillon, J., Willis, B., \& Wong, B. (2013). 'Not girly, not sexy, not glamorous': Primary school girls' and parents' constructions of science aspirations. Pedagogy, Culture \& Society, 21(1), 171-194.

https://doi.org/10.1080/14681366.2012.748676 
Artzi, L., August, D., \& Gray, J. L. (2019). Fostering English learners' academic language in a science-themed summer school program. In P. Spycher \& E. Haynes (Eds.), Culturally and Linguistically Diverse Learners and STEAM: Teachers and researchers working in partnership to build a better tomorrow (pp. 27-44). Information Age Publishing.

Aschbacher, P. R., Li, E., \& Roth, E. J. (2010). Is science me? High school students' identities, participation and aspirations in science, engineering, and medicine. Journal of Research in Science Teaching, 47(5), 564-582.

Aud, S., Hussar, W., Planty, M., Snyder, T., Bianco, K., Fox, M. A., Frohlich, L., Kemp, J., Drake, L., \& National Center for, E. S. (2010). The condition of education 2010. NCES 2010-028. National Center for Education Statistics, Journal Article. http://libproxy.lib.ilstu.edu/login?url=https://search.ebscohost.com/login.aspx?direct=true $\& \mathrm{db}=$ eric $\& A N=E D 509940 \&$ site $=$ ehost-live $\&$ scope $=$ site

Avraamidou, L. (2019). Stories we live, identities we build: How are elementary teachers' science identities shaped by their lived experiences? Cultural Studies of Science Education, 14(1), 33-59.

Baker, C. (2001). Foundations of bilingual education and bilingualism (3rd ed.). Multilingual Matters.

Baker, C., \& Wright, W. (2017). Foundation of bilingual education and bilingualism (6th ed.). Multilingual Matters.

Banchefsky, S., Westfall, J., Park, B., \& Judd, C. M. (2016). But you don't look like a scientist! Women scientists with feminine appearance are deemed less likely to be scientists. Sex Roles, 75(3), 95-109. https://doi.org/10.1007/s11199-016-0586-1 
Barton, A. C. (1998). Teaching science with homeless children: Pedagogy, representation, and identity. Journal of Research in Science Teaching, 35(4), 379-394.

Bates, C. C., \& Morgan, D. N. (2018). Seven Elements of Effective Professional Development. Reading Teacher, 71(5), 623-626. https://doi.org/10.1002/trtr.1674

Batt, E. G. (2008). Teachers' perceptions of ELL education: Potential solutions to overcome the greatest challenges. Multicultural Education, 15(3), 39-43.

Beauchamp, C., \& Thomas, L. (2009). Understanding teacher identity: An overview of issues in the literature and implications for teacher education. Cambridge Journal of Education, 39(2), 175-189. https://doi.org/10.1080/03057640902902252

Beeman, K., \& Urow, C. (2013). Teaching for biliteracy: Strengthening bridges between languages. Caslon.

Beijaard, D., Meijer, P. C., \& Verloop, N. (2004). Reconsidering Research on Teachers' Professional Identity. Teaching \& Teacher Education: An International Journal of Research and Studies, 20(2), 107-128.

Besterman, K. R., Ernst, J., \& Williams, T. O. (2018). Developments in STEM educators' preparedness for English language learners in the United States. Contemporary Issues in Education Research, 11(4), 165-176.

Betz, D. E., \& Sekaquaptewa, D. (2012). My fair physicist? Feminine math and science role models demotivate young girls. Social Psychological and Personality Science, 3(6), 738 746. https://doi.org/10.1177/1948550612440735

Bishop, J. P. (2012). "She's always been the smart one. I've always been the dumb one": Identities in the mathematics classroom. Journal for Research in Mathematics Education, 43(1), 34-74. JSTOR. https://doi.org/10.5951/jresematheduc.43.1.0034 
Brickhouse, N. W., Lowery, P., \& Schultz, K. (2000). What kind of a girl does science? The construction of school science identities. Journal of Research in Science Teaching, 37(5), $441-458$.

Brickhouse, N. W., \& Potter, J. T. (2001). Young women's scientific identity formation in an urban context. Journal of Research in Science Teaching, 38(8), 965-980.

Brinegar, K., Harrison, L., \& Hurd, E. (2019). Equity and cultural responsiveness in the middle grades. Information Age Publishing.

Brinkmann, S., \& Kvale, S. (2015). Interviews: Learning the craft of qualitative research interviewing (3rd ed.). Sage Publications, Inc.

Brown, E. (2006). The place of race in teacher identity: Self-narratives and curricular intervention as a practice of freedom. Teacher Education and Practice, 19(2), 275-279.

Bueno Hernández, Y. A. (2012). Teaching science in English through cognitive strategies. GIST Education and Learning Research Journal, 6, 129-146.

Canagarajah, S. (2011). Codemeshing in academic writing: Identifying teachable strategies of translanguaging. The Modern Language Journal, 95(3), 401-417. https://doi.org/10.1111/j.1540-4781.2011.01207.x

Canals, L. (2017). Instruments for gathering data (pp. 390-401). https://doi.org/10.14705/rpnet.2017.emmd2016.637

Carlone, H. B., Haun-Frank, J., \& Webb, A. (2011). Assessing equity beyond knowledge- and skills-based outcomes: A comparative ethnography of two fourth-grade reform-based science classrooms. Journal of Research in Science Teaching, 48(5), 459-485. 
Cenoz, J., \& Gorter, D. (2017). Minority languages and sustainable translanguaging: Threat or opportunity? Journal of Multilingual and Multicultural Development, 38(10), 901-912. https://doi.org/10.1080/01434632.2017.1284855

Chamot, A. U. (2009). The calla handbook: Implementing the cognitive academic language learning approach (2nd ed.). Pearson-Longman.

Chamot, A. U., \& O’Malley, J. M. (1994). The Calla Handbook. Implementing the Cognitive Academic Language Learning Approach (Addison-Wesley Publishing Company, White Plains, NY). Generic.

http://libproxy.lib.ilstu.edu/login?url=https://search.ebscohost.com/login.aspx?direct=true $\& \mathrm{db}=$ eric $\& \mathrm{AN}=\mathrm{ED} 379927 \&$ site $=$ ehost-live $\&$ scope $=$ site

Chapin, S. H., O’Connor, C., O’Connor, M. C., \& Anderson, N. C. (2013). Classroom discussions in math: A teacher's guide for using talk moves to support the common core and more, grades $K-6$. Math Solutions.

Chen, J. L., \& Mensah, F. M. (2018). Teaching Contexts That Influence Elementary Preservice Teachers' Teacher and Science Teacher Identity Development. Journal of Science Teacher Education, 29(5), 420-439. https://doi.org/10.1080/1046560X.2018.1469187

Children who speak a language other than English at home | KIDS COUNT Data Center. (2020). https://datacenter.kidscount.org/data/tables/81-children-who-speak-a-languageother-than-english-at-home

Childs, K. (2017). Integrating multiculturalism in education for the 2020 classroom: Moving beyond the "melting pot" of festivals and recognition months. Journal for Multicultural Education, 11(1), 31-36. 
Cho, J., \& Trent, A. (2006). Validity in qualitative research revisited. Qualitative Research, 6(3), 319-340. https://doi.org/10.1177/1468794106065006

Christidou, V. (2011). Interest, attitudes and images related to science: Combining students' voices with the voices of school science, teachers, and popular science. International Journal of Environmental and Science Education, 6(2), 141-159.

Cochran-Smith, M., \& Lytle, S. (2009). Inquiry as stance: Practitioner research for the next generation. Teachers College Press.

Corbin, J., \& Strauss, A. (2015). Basics of qualitative research: Techniques and procedures for developing grounded theory (4th ed.). Sage Publications.

Corces-Zimmerman, C., \& Floramaria Guida, T. (2019). Toward a critical whiteness methodology: Challenging whiteness through qualitative research. In Theory and method in higher education research (Vol. 5, pp. 91-109). Emerald Publishing Limited. https://doi.org/10.1108/S2056-375220190000005007

Cosentino de Cohen, C., \& Clewell, B. C. (2007). Putting English language learners on the educational map the No Child Left Behind Act implemented: (722672011-001) [Data set]. American Psychological Association. https://doi.org/10.1037/e722672011-001

Council of the Great, C. S. (2016). A Framework for re-envisioning mathematics instruction for English language learners. Council of the Great City Schools, Generic. http://libproxy.lib.ilstu.edu/login?url=https://search.ebscohost.com/login.aspx?direct=true $\& \mathrm{db}=$ eric $\& A N=E D 580863 \&$ site $=$ ehost-live $\&$ scope $=$ site

Craig, D. V. (2009). Action Research Essentials. John Wiley \& Sons.

Crandall, J. (Jodi), \& Bailey, K. M. (2018). Global perspectives on language education policies. Routledge. 
Creese, A. (2006). Supporting talk? Partnership teachers in classroom interaction. International Journal of Bilingual Education and Bilingualism, 9(4), 434-453.

Creswell, J. W., \& Miller, D. L. (2000). Determining Validity in Qualitative Inquiry. Theory Into Practice, 39(3), 124-130. https://doi.org/10.1207/s15430421tip3903_2

Crosnoe, R. (2012). Family-school connections, early learning, and socioeconomic inequality in the US. REMIE : Multidisciplinary Journal of Educational Research, 2(1), 1-36.

Darling-Hammond, L., Hyler, M. E., \& Gardner, M. (2017). Effective teacher professional development. Palo Alto: Learning Policy Institute, 76.

Davison, C. (2006). Collaboration between ESL and content teachers: How do we know when we are doing it right? International Journal of Bilingual Education and Bilingualism, 9(4), 454-475.

DeCarlo, M. (2018). 6.2 Paradigms, theories, and how they shape a researcher's approach. https://scientificinquiryinsocialwork.pressbooks.com/chapter/6-2-paradigms-theoriesand-how-they-shape-a-researchers-approach/

Delgado, R., \& Stefancic, J. (Eds.). (2000). Critical race theory: The cutting edge. Temple University Press.

Denzin, N. K., \& Lincoln, Y. S. (2013). Collecting and interpreting qualitative materials (4th ed.). Sage.

DiAngelo, R. (2011). White fragility. International Journal of Critical Pedagogy, 3(3), 54-70.

Dove, M., \& Honigsfeld, A. (2010). ESL coteaching and collaboration: Opportunities to develop teacher leadership and enhance student learning. TESOL Journal, 1(1), 3-22. 
Ellerbrock, C., \& Vomvoridi-Ivanovic, E. (2019). A Framework for responsive middle level mathematics teaching. In K. Brinegar, L. Harrison, \& E. Hurd (Eds.), Equity and cultural responsiveness in the middle grades (pp. 45-65). Information Age Publishing.

Esteban-Guitart, M., Lalueza, J. L., Zhang-Yu, C., \& Llopart, M. (2019). Sustaining students' cultures and identities. A qualitative study based on the funds of knowledge and identity approaches. Sustainability, 11(12), 3400. https://doi.org/10.3390/su11123400

Esteban-Guitart, M., Subero, D., \& Brito-Rivera, L. F. (2015). La incorporación de los fondos de identidad en un centro abierto: El proyecto FICAB. REMIE : Multidisciplinary Journal of Educational Research, 5(1), 55-81.

Feldman, S., \& Malagon, V. F. (2017). Unlocking learning: Science as a lever for English learner equity. The Education Trust-West.

Fortuny, K., Hernandez, D. J., \& Chaudry, A. (2010). Young children of immigrants: The leading edge of america's future. In Urban Institute (NJ1) (3rd ed.). Urban Institute. https://eric.ed.gov/?id=ED511771

Foxen, P., \& Mather, M. (2016). Toward a more equitable future: The trends and challenges facing America's latino children. NCLR. http://publications.nclr.org/handle/123456789/1627

Framework. (2012). A Framework for K-12 Science Education. https://www.nextgenscience.org/framework-k-12-science-education Fullan, M. (2007). The new meaning of educational change (4th ed.). Teachers College, Columbia University. 
Gamoran, A., Anderson, C. W., Quiroz, P. A., Secada, W. G., Williams, T., \& Ashmann, S. (2003). Transforming teaching in math and science: How schools and districts can support change. Sociology of education series. Teachers College Press. http://libproxy.lib.ilstu.edu/login?url=https://search.ebscohost.com/login.aspx?direct=true $\& \mathrm{db}=$ eric $\& \mathrm{AN}=\mathrm{ED} 474437 \&$ site $=$ ehost-live $\&$ scope $=$ site

Gándara, P., \& Santibañez, L. (2016). The teachers our English language learners need. Educational Leadership, 73(5), 32-37.

García, O. (2009). Bilingual education in the 21st century: A global perspective. Wiley/Blackwell.

García, O., Johnson, S. I., \& Seltzer, K. (2017). The translanguaging classroom: Leveraging student bilingualism for learning. Caslon.

García, O., \& Lin, A. M. Y. (2017). Extending understandings of bilingual and multilingual education. In O. García, A. M. Y. Lin, \& S. May (Eds.), Bilingual and Multilingual Education (3rd ed., pp. 1-20). Springer.

García, O., \& Wei, L. (2014). Translanguaging. Palgrave Macmillan UK. https://doi.org/10.1057/9781137385765

Gay, G. (2002). Preparing for culturally responsive teaching. Journal of Educator Education, 53(2), 106-116.

Gay, G. (2010). Culturally responsive teaching: Theory, research, and practice (2nd edition). New York: Educators College. (2n ed.). Educators College.

Gee, J. P. (2000). Identity as an Analytic Lens for Research in Education. Review of Research in Education, 25, 99-125. https://doi.org/10.2307/1167322 
Gholson, M. L., \& Wilkes, C. E. (2017). (Mis)Taken identities: Reclaiming identities of the "Collective Black" in mathematics education research through an exercise in black specificity. Review of Research in Education, 41(1), 228-252.

https://doi.org/10.3102/0091732X16686950

Gillborn, D. (2016). Education policy as an act of white supremacy. In E. Taylor, D. Gillborn, \& G. Ladson-Billings (Eds.), Foundations of Critical Race Theory in Education (2nd ed., pp. 43-59). Routledge.

González Canché, M. S. (2019). Repurposing standardized testing for educational equity: Can geographical bias and adversity scores expand true college access? Policy Insights from the Behavioral and Brain Sciences, 6(2), 225-235.

https://doi.org/10.1177/2372732219861123

González, N., \& Moll, L. C. (2002). Cruzando el Puente: Building bridges to funds of knowledge. Educational Policy, 16(4), 623-641.

https://doi.org/10.1177/0895904802016004009

González, N., Moll, L. C., \& Amanti, C. (2005). Funds of knowledge: Theorizing practices in households, communities, and classrooms. Routledge.

Google slides. (n.d.). https://www.google.com/drive/

Graves, M. F., August, D., \& Mancilla-Martinez, J. (2012). Teaching vocabulary to English language learners. Teachers College Press.

Hanna, F., Oostdam, R., Severiens, S., \& Zijlstra, B. J. H. (2019). Domains of teacher identity: A review of quantitative measurement instruments. Education Research Review, 27, 15-27. https://doi.org/10.1016/J.EDUREV.2019.01.003 
Hansen-Thomas, H., Richins, L. G., Kakkar, K., \& Okeyo, C. (2016). I do not feel I am properly trained to help them! Rural teachers' perceptions of challenges and needs with Englishlanguage learners. Professional Development in Education, 42(2), 308-324. https://doi.org/10.1080/19415257.2014.973528

Hatt, B. (2007). Street smarts vs. Book smarts: The figured world of smartness in the lives of marginalized, urban youth. Urban Review: Issues and Ideas in Public Education, 39(2), 145-166.

Hatt, B. (2012). Smartness as a cultural practice in schools. American Educational Research Journal, 49(3), 438-460.

Hatt, B. (2016). Racializing smartness. Race Ethnicity and Education, 19(6), 1141-1148. https://doi.org/10.1080/13613324.2016.1168537

Hatt, B., \& Urrieta, L. (2020). Contesting the Alamo and smartness: Theorizing student identities, agency, and learning within the contentious practices of U.S. classrooms. Theory Into Practice, 59(2), 202-212. https://doi.org/10.1080/00405841.2019.1705108

Herr, K., \& Anderson, G. (2005). The action research dissertation: A guide for students and faculty. Sage Publications.

Herr, K., \& Anderson, G. (2015). The action research dissertation: A guide for students and faculty (2nd ed.). Sage Publications, Inc.

Herrera, S., Cabral, R., \& Murry, K. (2013). Assessment accommodations for classroom teachers of culturally and linguistically diverse students (2nd ed.). Pearson.

Hill, C., Corbett, C., \& St. Rose, A. (2010). Why so few? Women in science, technology, engineering, and mathematics. In American Association of University Women. American Association of University Women. https://eric.ed.gov/?id=ED509653 
Hogg, L. (2011). Funds of Knowledge: An investigation of coherence within the literature.

Teaching and Teacher Education, 27(3), 666-677.

https://doi.org/10.1016/j.tate.2010.11.005

Hornberger, N., \& Link, H. (2012). Translanguaging in today's classrooms: A biliteracy lens.

Theory Into Practice, 51(4), 239-247. https://doi.org/10.1080/00405841.2012.726051

Huerta, M., Garza, T., Jackson, J. K., \& Murukutla, M. (2019). Science teacher attitudes towards English learners. Teaching and Teacher Education, 77, 1-9.

https://doi.org/10.1016/j.tate.2018.09.007

Hurd, E., \& Weilbacher, G. (2017). "You want me to do what?" The benefits of co-teaching in the middle level. Middle Grades Review, 3(1). http://libproxy.lib.ilstu.edu/login?url=https://search.ebscohost.com/login.aspx?direct=true $\& \mathrm{db}=$ eric $\& A N=E J 1154829 \&$ site $=$ ehost-live $\&$ scope $=$ site

Hussar, W. J., \& Bailey, T. M. (n.d.). Projections of education statistics to 2018. 168.

Irby, B. J., Lara-Alecio, R., Tong, F., Guerrero, C., Sutton-Jones, K., \& Abdelrahman, N. (2018). Implementation of research-based ESL strategies with lower grade middle school ELLs in the science classroom: Findings from an experimental study. TESL-EJ, 22(1). http://libproxy.lib.ilstu.edu/login?url=https://search.ebscohost.com/login.aspx?direct=true $\& \mathrm{db}=$ eric $\& A N=E J 1178995 \&$ site $=$ ehost-live $\&$ scope $=$ site

Johnson, A. (2009). Action Research. Columbus, OH: Pearson Education, Inc. Pearson Education, Inc.

Johnson, E. J., \& Johnson, A. B. (2016). Enhancing academic investment through home-school connections and building on ELL students' scholastic funds of knowledge. Journal of Language and Literacy Education, 12(1), 104-121. 
Jordan, W. J. (2010). Defining equity: Multiple perspectives to analyzing the performance of diverse learners. Review of Research in Education, 34(1), 142-178.

Jovés, P., Siqués, C., \& Esteban-Guitart, M. (2015). The incorporation of funds of knowledge and funds of identity of students and their families into educational practice. A case study from Catalonia, Spain. Teaching and Teacher Education, 49, 68-77. https://doi.org/10.1016/j.tate.2015.03.001

Kang, H., Calabrese Barton, A., Tan, E., Simpkins, S., Rhee, H., \& Turner, C. (2019). How do middle school girls of color develop STEM identities? Middle school girls' participation in science activities and identification with STEM careers. Science Education, 103(2), $418-439$.

Kim, A. Y., Sinatra, G. M., \& Seyranian, V. (2018). Developing a STEM identity among young women: A social identity perspective: Review of Educational Research. https://doi.org/10.3102/0034654318779957

Kincheloe, J. L. (2013). Knowledge and critical pedagogy: An introduction. Routledge. Kincheloe, J. L., McLaren, P., \& Steinberg, S. (2011). Critical pedagogy and qualitative research: Moving to bricolage. In N.K. Denzin \& Y.S. Lincoln (Eds.), The Sage handbook of qualitative research (pp. 163-178). Sage.

Koh, N., Reddy, V., \& Chatterji, M. (2014). Understanding validity issues surrounding testbased accountability measures in the US. Quality Assurance in Education, 22(1), 42-52. https://doi.org/10.1108/QAE-12-2013-0051

Ladson-Billings, G. (2002). But that's just good teaching! The case for culturally relevant pedagogy. In Improving schools for African American students: A reader for educational leaders. (pp. 95-102). Charles C Thomas Publisher. 
Ladson-Billings, G. (2007). Pushing past the achievement gap: An essay on the language of deficit. Journal of Negro Education, 76(3), 316-323.

Ladson-Billings, G. (2016). Just what is critical race theory? In E. Taylor, D. Gillborn, \& G. Ladson-Billings (Eds.), Foundations of Critical Race Theory (2nd ed., pp. 15-30). Routledge.

Lat Crit. (n.d.). Retrieved June 24, 2020, from http://latcrit.org/content/about/

Lawrence, L., \& Nagashima, Y. (2020). The Intersectionality of Gender, Sexuality, Race, and Native-Speakerness: Investigating ELT Teacher Identity through Duoethnography. Journal of Language, Identity, and Education, 19(1), 42-55.

Laws, M. (2020, June 16). Why we capitalize 'Black' (and not 'white'). Columbia Journalism Review. https://www.cjr.org/analysis/capital-b-black-styleguide.php

Lee, O. (2005). Science education with English language learners: Synthesis and research agenda. Review of Educational Research, 75(4), 491-530.

Lee, O., \& Buxton, C. A. (2013a). Integrating science and English proficiency for English language learners. Theory Into Practice, 52(1), 36-42; 7.

Lee, O., \& Buxton, C. A. (2013b). Teacher professional development to improve science and literacy achievement of English language learners. Theory Into Practice, 52(2), 110-117.

Lee, O., Llosa, L., Jiang, F., Haas, A., O’Connor, C., \& Booven, C. D. V. (2016). Elementary teachers' science knowledge and instructional practices: Impact of an intervention focused on english language learners. Journal of Research in Science Teaching, 53(4), 579-597. https://doi.org/10.1002/tea.21314 
Lee, O., \& Luykx, A. (2007). Science education and student diversity: Race/ethnicity, language, culture, and socioeconomic status. In S. K. Abell \& N. G. Ledereman (Eds.), Handbook of Research in Science Education (2nd ed., pp. 171-197). Erlbaum.

Lee, O., Maerten-Rivera, J., Penfield, R. D., LeRoy, K., \& Secada, W. G. (2008). Science achievement of English language learners in urban elementary schools: Results of a firstyear professional development intervention. Journal of Research in Science Teaching, $45(1), 31-52$.

Lee, O., Quinn, H., \& Valdes, G. (2013). Science and language for English language learners in relation to next generation science standards and with implications for common core state standards for English language arts and mathematics. Educational Researcher, 42(4), $223-233$.

Leung, C., \& Creese, A. (2008). Professional issues in working with ethnolinguistic differences: Inclusive policy in practice. In D. E. Murray (Ed.), Planning change, changing plans: Innovations in second language teaching (pp. 155-173). University of Michigan Press.

Licona, M. M. (2013). Mexican and Mexican-American children's funds of knowledge as interventions into deficit thinking: Opportunities for praxis in science education. Cultural Studies of Science Education, 8(4), 859-872.

Lucas, T., Villegas, A. M., \& Freedson-Gonzalez, M. (2008). Linguistically responsive teacher education: Preparing classroom reachers to teach English language learners. Journal of Teacher Education, 59(4), 361-373.

Luehmann, A. L. (2007). Identity development as a lens to science teacher preparation. Science Education (Salem, Mass.), 91(5), 822-839. https://doi.org/10.1002/sce.20209 
Martinez, A., Rhodes, H., Copson, E., Tiano, M., DellaRocco, N., Donoghue, N., Marco, L., Abt Associates, I., \& Education Development Center, I. (2011). Math and science education with English language learners: Contributions of the DR K-12 program. Targeted study group working paper. Abt Associates, Generic.

http://libproxy.lib.ilstu.edu/login?url=https://search.ebscohost.com/login.aspx?direct=true $\& \mathrm{db}=$ eric $\& A N=E D 546121 \&$ site $=$ ehost-live $\&$ scope $=$ site

Matias, C. E., \& Mackey, J. (2016). Breakin’ Down Whiteness in Antiracist Teaching: Introducing Critical Whiteness Pedagogy. The Urban Review, 48(1), 32-50. https://doi.org/10.1007/s11256-015-0344-7

McClure, G., \& Cahnmann-Taylor, M. (2010). Pushing back against push-in: ESOL teacher resistance and the complexities of coteaching. TESOL Journal, 1(1), 101-129.

McIntyre, E., Kyle, D., Chen, C.-T., Munoz, M., \& Beldon, S. (2010). Teacher learning and ELL reading achievement in sheltered instruction classrooms: Linking professional development to student development. Literacy Research and Instruction, 49(4), 334-351.

McIntyre, J., \& Hobson, A. J. (2016). Supporting beginner teacher identity development:

External mentors and the third space. Research Papers in Education, 31(2), 133-158. https://doi.org/10.1080/02671522.2015.1015438

McKenzie, K. B., \& Scheurich, J. J. (2004). Equity Traps: A Useful Construct for Preparing Principals to Lead Schools That Are Successful With Racially Diverse Students. Educational Administration Quarterly, 40(5), 601-632. https://doi.org/10.1177/0013161X04268839 
McLaughlin, D. S., \& Barton, A. C. (2013). Preservice teachers' uptake and understanding of funds of knowledge in elementary science. Journal of Science Teacher Education, 24(1), $13-36$.

Merriam, S. B., \& Tisdell, E. J. (2016). Qualitative research: A guide to design and implementation (4th ed.). Jossey Bass.

Michaels, S., \& O'Connor, C. (2012). Talk science primer. TERC.

Miller, E., Januszyk, R., \& Lee, O. (2015). "NGSS" in action. Science and Children, 53(2), 64$70 ; 7$.

Moll, L. C. (2014). L. S. Vygotsky and education. Routledge.

Moll, L. C., Amanti, C., Neff, D., \& González, N. (1992). Funds of knowledge for teaching: Using a qualitative approach to connect homes and classrooms. Theory Into Practice, 31(2), 132.

Moschkovich, J. (2007). Beyond words to mathematical content: Assessing English learners in the mathematics classroom. In A. H. Schoenfeld (Ed.), Assessing Mathematical Proficiency (pp. 345-352). Cambridge University Press. https://doi.org/10.1017/CBO9780511755378.027

Moschkovich, J. N. (2015). Academic literacy in mathematics for English Learners. The Journal of Mathematical Behavior, 40(Generic), 43-62. https://doi.org/10.1016/j.jmathb.2015.01.005

Muñiz, J., \& America, N. (2019). Culturally responsive teaching: A 50-state survey of teaching standards. In New America. New America. http://libproxy.lib.ilstu.edu/login?url=https://search.ebscohost.com/login.aspx?direct=true $\& \mathrm{db}=$ eric $\& A N=E D 594599 \&$ site $=$ ehost-live $\&$ scope $=$ site 
Nieto, S. (2017). Becoming sociocultural mediators: What all educators can learn from bilingual and ESL teachers. Issues in Teacher Education, 26(2), 129-141.

Noonan, J. (2019). An Affinity for Learning: Teacher Identity and Powerful Professional Development. Journal of Teacher Education, 70(5), 526-537. https://doi.org/10.1177/0022487118788838

Osborne, J., Simon, S., \& Collins, S. (2003). Attitudes towards science: A review of the literature and its implications. International Journal of Science Education, 25(9), 1049-1079. https://doi.org/10.1080/0950069032000032199

Otheguy, R., García, O., \& Reid, W. (2015). Clarifying translanguaging and deconstructing named languages: A perspective from linguistics. Applied Linguistics Review, 6(3), 281307.

Özüdogru, F. (2018). The readiness of prospective teachers for culturally responsive teaching. Acta Didactica Napocensia, 11(3-4), 1-12.

Paris, D. (2017). On educating culturally sustaining teachers. Equity by design. In Equity Assistance Center Region III, Midwest and Plains Equity Assistance Center. Equity Assistance Center Region III, Midwest and Plains Equity Assistance Center. http://libproxy.lib.ilstu.edu/login?url=https://search.ebscohost.com/login.aspx?direct=true $\& \mathrm{db}=$ eric $\& A N=E D 580793 \&$ site $=$ ehost-live $\&$ scope $=$ site

Paris, D., \& Alim, H. S. (2014). What are we seeking to sustain through culturally sustaining pedagogy? A loving critique forward. Harvard Educational Review, 84(1), 85-100. 
Parker, L., \& Lynn, M. (2016). What's race got to do with it? Critical race theory's conflicts with and connections to qualitative research methodology and epistemology. In E. Taylor, D. Gillborn, \& G. Ladson-Billings (Eds.), Foundations of critical race theory in education (2nd ed., pp. 143-155). Routledge.

Parsons, S. A., Hutchison, A. C., Hall, L. A., Parsons, A. W., Ives, S. T., \& Leggett, A. B. (2019). U.S. teachers' perceptions of online professional development. Teaching and Teacher Education, 82, 33-42. https://doi.org/10.1016/j.tate.2019.03.006

Peralta, C., Caspary, M., \& Boothe, D. (2013). Success factors impacting latina/o persistence in higher education leading to STEM opportunities. Cultural Studies of Science Education, 8(4), 905-918.

Pica, T. (2008). Task-based instruction. In N. Van Deusen-Scholl \& N. H. Hornberger (Eds.), Encyclopedia of language and education (2nd ed., Vol. 4, pp. 71-820). Springer Science/Business Media.

Polly, D., \& Hannafin, M. J. (2010). Reexamining technology's role in learner-centered professional development. Educational Technology Research \& Development, 58(5), 557-571. https://doi.org/10.1007/s11423-009-9146-5

Probst, B., \& Berenson, L. (2014). The double arrow: How qualitative social work researchers use reflexivity. Qualitative Social Work, 13(6), 813-827. https://doi.org/10.1177/1473325013506248

Qualitative Data Analysis Software | NVivo. (n.d.). Retrieved June 4, 2021, from https://www.qsrinternational.com/nvivo-qualitative-data-analysis-software/home 
Radunzel, J., Mattern, K., \& Westrick, P. (2016). The role of academic preparation and interest on STEM success. ACT research report series. In ACT, Inc. ACT, Inc. https://eric.ed.gov/?id=ED581664

Richardson, L., \& St. Pierre, E. A. (2005). Writing: A method of inquiry. In The Sage handbook of qualitative research, 3rd ed (pp. 959-978). Sage Publications Ltd.

Riel, M. (2019). Understanding collaborative action research. http://cadres.pepperdine.edu/ccar/define.html

Rodesiler, L. (2017). For Teachers, by Teachers: An Exploration of Teacher-Generated Online Professional Development. Journal of Digital Learning in Teacher Education, 33(4), 138-147. https://doi.org/10.1080/21532974.2017.1347535

Saldaña, J. (2016). The Coding manual for qualitative researchers (3E ed.). SAGE Publications, Inc.

Samuels, A. J. (2018). Exploring culturally responsive pedagogy: Teachers' perspectives on fostering equitable and inclusive classrooms. SRATE Journal, 27(1), 22-30.

Saygin, P. O. (2019). Gender bias in standardized tests: Evidence from a centralized college admissions system. Empirical Economics. https://doi.org/10.1007/s00181-019-01662-z

says, J. K. (2019, October 28). Developing the math language routines. Achieve the Core Aligned Materials. https://achievethecore.org/aligned/developing-math-language-routines/

Schultz, K., \& Ravitch, S. M. (2013). Narratives of Learning to Teach: Taking on Professional Identities. Journal of Teacher Education, 64(1), 35-46. https://doi.org/10.1177/0022487112458801 
Scott, K. M., Baur, L., \& Barrett, J. (2017). Evidence-Based Principles for Using TechnologyEnhanced Learning in the Continuing Professional Development of Health Professionals: Journal of Continuing Education in the Health Professions, 37(1), 61-66. https://doi.org/10.1097/CEH.0000000000000146

Screencast-o-matic. (n.d.). https://screencast-o-matic.com/

Sheng, Z., Sheng, Y., \& Anderson, C. J. (2011). Dropping out of school among ELL students: Implications to schools and teacher education. Clearing House: A Journal of Educational Strategies, Issues and Ideas, 84(3), 98-103.

Short, D. J., Vogt, M., \& Echavarría, J. (2011). The SIOP model for teaching science to English learners. Pearson Education.

Silva, C., Weinburgh, M., Malloy, R., Smith, K. H., \& Marshall, J. N. (2012). Toward integration: An instructional model of science and academic language. Childhood Education, 88(2), 91-95.

Singh, K., Granville, M., \& Dika, S. (2002). Mathematics and science achievement: Effects of motivation, interest, and academic engagement. The Journal of Educational Research, 95(6), 323-332. https://doi.org/10.1080/00220670209596607

Sleeter, C. E. (2017). Critical Race Theory and the Whiteness of Teacher Education. Urban Education, 52(2), 155-169.

Snyder, T. D., de Brey, C., \& Dillow, S. A. (2019). Digest of Education Statistics 2017. In National Center for Education Statistics (53rd ed.). National Center for Education Statistics. https://eric.ed.gov/?id=ED592104 
Solórzano, D., \& Yosso, T. (2016). Critical race methodology. In E. Taylor, D. Gillborn, \& G. Ladson-Billings (Eds.), Foundations of Critical Race Theory in Education (2nd ed.). Routledge.

Spycher, P., \& Haynes, E. (2019). Culturally and linguistically diverse learners and STEAM: Teachers and researchers working in partnership to build a better tomorrow. Information Age Publishing.

*State report card. (2019). Information pulled from the state's school report card but listing it would cause identification of the state

Subero, D., Vujasinovic, E., \& Esteban-Guitart, M. (2017). Mobilising funds of identity in and out of school. Cambridge Journal of Education, 47(2), 247-263.

Trotter, Y. D. (2006). Adult Learning Theories: Impacting Professional Development Programs. Delta Kappa Gamma Bulletin, 72(2), 8-13.

Turner, E., Dominguez, H., Maldonado, L., \& Empson, S. (2013). English learners' participation in mathematical discussion: Shifting positionings and dynamic identities. Journal for Research in Mathematics Education, 44(1), 199-234.

Valdez, T. M., \& Lugg, C. (2010). Community cultural wealth and chicano/latino students. Journal of School Public Relations, 31(3), 224-237.

Vidal-Ortiz, S., \& Martínez, J. (2018). Latinx thoughts: Latinidad with an X. Latino Studies, 16(3), 384-395. https://doi.org/10.1057/s41276-018-0137-8

Villa, R., Thousand, J., \& Nevin, A. (2008). A Guide to co-teaching (2nd ed.). Corwin.

Villegas, A. M., \& Lucas, T. (2007). The culturally responsive teacher. Educational Leadership, 64(6), 28-33. 
Watson, D., Charner-Laird, M., Kirkpatrick, C. L., Szczesiul, S. A., \& Gordon, P. J. (2006). Effective teaching/effective urban teaching. Journal of Teacher Education, 57(4), 395409.

Weinburgh, M., Silva, C., Smith, K. H., Groulx, J., \& Nettles, J. (2014). The intersection of inquiry-based science and language: Preparing teachers for ELL classrooms. Journal of Science Teacher Education, 25(5), 519-541.

White, G. W., Stepney, C. T., Hatchimonji, D. R., Moceri, D. C., Linsky, A. V., Reyes-Portillo, J. A., \& Elias, M. J. (2016). The increasing impact of socioeconomics and race on standardized academic test scores across elementary, middle, and high school. American Journal of Orthopsychiatry, 86(1), 10-23. https://doi.org/10.1037/ort0000122

WIDA. (n.d.). Retrieved July 27, 2020, from https://wida.wisc.edu/

Wilson, S. (2008). Research is ceremony: Indigenous research methods. Fernwood Publishing.

Wynants, S., \& Dennis, J. (2018). Professional development in an online context: Opportunities and challenges from the voices of college faculty. The Journal of Educators Online, 15(1).

Wynter-Hoyte, K., Braden, E. G., Rodriguez, S., \& Thornton, N. (2019). Disrupting the status quo: Exploring culturally relevant and sustaining pedagogies for young diverse learners. Race, Ethnicity and Education, 22(3), 428-447.

Yip, J., \& García, O. (2015). Translanguaging: Practice briefs for educators. Theory, Research, and Action in Urban Education, 4(1). 
Yoon, B., \& Uliassi, C. (2019). Educators' practice for English language learners' critical consciousness: From marginalized identities to active agents. In K. Brinegar, L. Harrison, \& E. Hurd (Eds.), Equity and cultural responsiveness in the middle grades (pp. 239-253). Information Age Publishing.

Yosso, T. J. (2005). Whose culture has capital? A critical race theory discussion of community cultural wealth. Race, Ethnicity and Education, 8(1), 69-91.

YouTube. (n.d.). Retrieved July 20, 2021, from https://www.youtube.com/

Zeigler, K., \& Camarota, S. (2019). 67.3 Million in the United States spoke a foreign language at home in 2018. CIS.Org. https://cis.org/Report/673-Million-United-States-Spoke-ForeignLanguage-Home-2018

Zoom. (n.d.). Zoom Video. Retrieved June 11, 2021, from https://zoom.us/ 


\title{
APPENDIX A: PRE-INTERVIEW QUESTIONS
}

\author{
Study Pre-Observation Interview
}

1. What is your name?

2. What is your position?

3. How long have you been teaching?

4. How long have you been teaching in your current position?

5. How long have you been working with English learners?

\section{"The goal of this study is to provide professional development for math and science \\ teachers who work with multilingual students."}

6. How would you describe a multilingual student?

7. What are some of the assets and challenges that multilingual students have/face?

8. Would you please describe the training you received for working with English learners in your teacher preparation program?

9. Have you had opportunities to take part in professional development directly connected to teaching English learners?

a. If no, move onto question 11 .

b. If yes, move onto question 9 .

10. Can you describe the professional development?

11. Did you feel that you could layer the professional development into your instruction, why or why not?

12. What do you think have been some of the strengths of your preparation to work with English learners?

13. What do you think are areas in which you would like to improve your training for working with English learners?

14. What do you find rewarding about working with English learners?

15. What are the challenges that you have found while working with English learners?

16. Why do you think that specific professional development for working with multilingual students needs to be provided to general education teachers?

"Part of this professional development focuses on identity."

17. How would you describe your identity?

18. Why did you become a teacher?

19. How would you describe what a "teacher identity" is? Do you think it is the same as identity?

20. If someone asked you what your teacher identity was, how would you describe yourself as a teacher?

21. How do you think your teacher identity was influenced by your own experiences in school and growing up?

22. Can you think of a time that you changed as a teacher?

23. What was it that caused that change?

24. How does your identity influence you in your classroom?

25. What role do you think identity plays in education?

"Thank you for being willing to be a part of this study." 


\section{APPENDIX B: QUESTIONNAIRE - PRIOR TO EACH MODULE}

1. Describe your previous training connected to (module content topic). It is fine to say, "I have not had any training on the topic."
a. Working with English learners in general
b. Lesson planning for English learners
c. Science teaching with English learners
d. Math teaching with English learners
e. Equity frameworks
f. Funds of Knowledge/Identity
g. Co-teaching with English learners

2. Describe what you know about (module content topic)
a. Working with English learners in general
b. Lesson planning for English learners
c. Science teaching with English learners
d. Math teaching with English learners
e. Equity frameworks
f. Funds of Knowledge/Identity
g. Co-teaching with English learners

3. What do you hope to learn about (module content topic)?
a. Working with English learners in general
b. Lesson planning for English learners
c. Science teaching with English learners
d. Math teaching with English learners
e. Equity frameworks
f. Funds of Knowledge/Identity
g. Co-teaching with English learners

4. Why do you think (module content topic) was included in this study?
a. Working with English learners in general
b. Lesson planning for English learners
c. Science teaching with English learners
d. Math teaching with English learners
e. Equity frameworks
f. Funds of Knowledge/Identity
g. Co-teaching with English learners 


\section{APPENDIX C: QUESTIONNAIRE- FOLLOWING EACH MODULE}

1. What were some of your take-aways about (module content topic) following this module?
a. Working with English learners in general
b. Lesson planning for English learners
c. Science teaching with English learners
d. Math teaching with English learners
e. Equity frameworks
f. Funds of Knowledge/Identity
g. Co-teaching with English learners

2. How would knowing the content about (module content topic) help teachers when working with English learners?
a. Working with English learners in general
b. Lesson planning for English learners
c. Science teaching with English learners
d. Math teaching with English learners
e. Equity frameworks
f. Funds of Knowledge/Identity
g. Co-teaching with English learners

3. What further questions do you have about (module content topic)?
a. Working with English learners in general
b. Lesson planning for English learners
c. Science teaching with English learners
d. Math teaching with English learners
e. Equity frameworks
f. Funds of Knowledge/Identity
g. Co-teaching with English learners

4. How could you layer an element from this module into your teaching practices?
a. Working with English learners in general
b. Lesson planning for English learners
c. Science teaching with English learners
d. Math teaching with English learners
e. Equity frameworks
f. Funds of Knowledge/Identity
g. Co-teaching with English learners 


\section{APPENDIX D: FOCUS GROUP QUESTIONS}

1. What was one take-away from the module about (name of the module)?

a. Did anyone else have that take-away?

2. Was the content about (name of module) new to you? Why or why not?

3. How do you think you have seen elements of this (name of module) possibly affect your classroom or your teaching experience?

4. Do you feel you need further training focusing on (name of module)?

5. Why do you think this module was included in this study?

These are in addition to the end of module thinking questions and will be used to bridge into those questions. 


\section{APPENDIX E: POST-STUDY INTERVIEW}

\section{Post Study Interview}

1. How would you describe a CLD student?

2. What are some of the assets and challenges that CLD learners have/face?

3. What do you find rewarding about working with CLD students-if not answered in 2?

4. What are the challenges that you have found while working with CLD learners- if not answered in 2 ?

5. Why do you think that specific professional development for working with CLD learners needs to be provided to general education teachers?

6. What types of professional development should be included for general education teachers who work with CLD learners?

Throughout these modules, we talked a lot about identity and who CLD learners are.

7. How would you describe your teacher identity?

8. As teachers, we all have a teacher identity; how is your teacher identity shaped by your own experiences?

9. How do you envision yourself as a CLD math or CLD science teacher?

10. How does your identity influence or not influence your classroom and your teacher identity?

11. Do you think a teacher's identity can change? Identity vs teacher identity?

12. What experience do you want your CLD students to have in your classroom?

13. How do you envision getting there?

14. What further professional development or resources are you interested in focusing on multilingual students following these modules? 
IRB \#: IRB-2020-157

Title: The Effect of Math and Science CLD Training Modules on the Pedagogical Views and Practices of Middle School Math and Science Teachers

Creation Date: $3-25-2020$

\section{End Date:}

Status: Approved

Principal Investigator: Ellis Hurd

Review Board: Illinois State University IRB

Sponsor:

\section{Study History}

\begin{tabular}{lll}
\hline Submission Type Initial & Review Type Expedited & Decision Approved \\
\hline Submission Type Modification & Review Type Expedited & Decision Approved \\
\hline
\end{tabular}

\section{Key Study Contacts}

\begin{tabular}{lll}
\hline Member Helen Brandon & Role Co-Principal Investigator & Contact hdbrand@ilstu.edu \\
\hline Member Ellis Hurd & Role Principal Investigator & Contact ehurd@ilstu.edu \\
\hline Member Ellis Hurd & Role Primary Contact & Contact ehurd@ilstu.edu \\
\hline
\end{tabular}

